\title{
Alterações no perfil metabólico em resposta a isquemia/reperfusão renal em modelo suíno de lesão renal aguda
}

\author{
Dissertação apresentada à Faculdade de Medicina da \\ Universidade de São Paulo para obtenção do título de \\ Mestre em Ciências.
}

Programa de Ciências Médicas

Área de concentração: Distúrbios Genéticos de Desenvolvimento e Metabolismo

Orientador: Prof. Dr. Alexandre da Costa Pereira

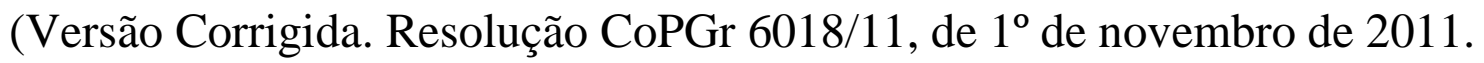
A versão original está disponível na biblioteca da FMUSP).

\section{SÃO PAULO}


Dados Internacionais de Catalogação na Publicação (CIP)

Preparada pela Biblioteca da

Faculdade de Medicina da Universidade de São Paulo

Creprodução autorizada pelo autor

\section{Malagrino, Pamella Araujo}

Alterações no perfil metabólico em resposta a isquemia/reperfusão renal em modelo suíno de lesão renal aguda / Pamella Araujo Malagrino. -- São Paulo, 2014.

Dissertação(mestrado)--Faculdade de Medicina da Universidade de São Paulo.

Programa de Ciências Médicas. Área de concetração: Distúrbios Genéticos de Desenvolvimento e Metabolismo.

Orientador: Alexandre da Costa Pereira.

Descritores: 1.Isquemia 2.Oclusão com balão 3.Lesão renal aguda 4.Necrose tubular aguda 5.Rim/irrigação sanguínea 6.Traumatismo por reperfusão 7.Marcadores biológicos 8 .Metabolômica 9.Espectroscopia de ressonância magnética 10. Suínos

USP/FM/DBD-275/14 
Dedico esta dissertação às minhas amigas e companheiras de trabalho (Gabriela, Patrícia, Ana Paula, Kallyandra, Bianca e Tamiris) que colaboraram não só com as experimentações, mas em tornar meus dias de trabalhos muito mais prazerosos. 



\section{Agradecimentos}

Agradeço primeiramente a Deus que me guiou até este trabalho e a Nossa Senhora que sempre intercedeu por mim, antes, durante e após cada decisão da minha vida, incluindo cada experimento para que eu o conduzisse da melhor forma possível e com toda a paciência do mundo.

À minha família que eu amo muito mãe (Marilene Malagrino), pai (João A. T. Malagrino), irmãs (Pollyana Araujo Malagrino e Laura da Silva Fagundes), tias e tios (Tai, Susu e Gonçalvez) a que eu devo a minha vida e tudo que sou. Minha família é a maior responsável por meu sustento, não só financeiro, mas também emocional para que eu possa me dedicar de corpo e alma ao meu trabalho, sem nunca desistir. A tia Adir que me abrigou com amor 3 meses em sua casa e me deu todo o apoio e carinho pra eu continuar essa jornada.

Agradeço também a meu namorado Rodrigo D Esposti, por todo o companheirismo, amor e compreensão com as horas dedicadas ao meu trabalho e ao estresse que todo trabalho proporciona.

Aos meus professores da Unesp e iniciação cientifica (Angelina Zanesco), pelo preparo par o ingresso no mestrado.

A amiga Carol Parga que me incentivou a vir a São Paulo e ao amigo Victor Mescolotti pelo abrigo inicial em sua moradia.

Agradeço a todos do grupo de genética que me ajudaram sempre que eu precisei, com material, dúvidas e conselhos em nossas reuniões. Em especial a Dra. Julia Masiglia, que foi a primeira a me receber bem no laboratório. A primeira impressão é a que fica.

Aos colegas do Laboraório de Pneumologia (Milena, Vanessa, Carlos) que me ajudaram com os equipamentos e dúvidas sobre ELISA e aos técnicos dos laboratórios de Biologia Vascular, Imunologia e Lípides (Vitor Debbas, Andrea Kuramoto e Débora, respectivamente), que me ajudaram tirando dúvidas e disponibilizando equipamentos quando necessário.

Agradeço a Ana Lucia Garippo, técnica responsável pelo uso do confocal, pelo trabalho, paciência e incentivo. Ao Dr. Francisco Rafael Laurindo, Dr. Paulo Guttierre, 
Dr. Roberto Zatz, Dr. Luis Yu, Dra. Etiene, Dr. Burdman pelas dúvidas esclarecidas em aula e fora delas.

À patologista Dra. Denise Malheiros pelas análises das lâminas dos rins e ajuda na compreensão dos resultados. E ao seu aluno Rodrigo Ramalho que me ensinou a cultivar células glomerulares.

Ao Alexandre do centro cirúrgico do Hospital das Cínicas FMUSP que me ajudou com cortes no criostato.

À Dra. Adriana Girardi pelas ajudas nas compreensões dos resultados e sugestões de experimentos na área de fisiologia renal. E também aos alunos do grupo dela (Gabriela Aragão, Bianca Paiotti, Renato Crajoinhas, Carla, Daniel, Tiago Sales) pelas ajudas diretas e indiretas com os experimentos.

Ao Alexandre Favaro com quem eu tirei varias dúvidas no inicio do mestrado.

Ao Dr. Joaquim Motta Leal Filho pelo desenvolvimento do método e cirurgia de isquemia/reperfusão renal, além de explicações técnicas sobre o mesmo. Ao Dr. Celso Kimura pela ajuda cirúrgica com o animal. E à equipe da Divisão de Experimentação do InCor, Edna, Nelson, Richard, Pedro, Mônica, sempre atenciosa aos nossos animais.

Ao amigo Rafael Darioli que participou de todos os experimentos com coletas sanguíneas e urinárias dos animais em $24 \mathrm{~h}$ e também por ajudar com as discussões dos resultados apresentados. Aos amigos Marcos Vinícius e Camila Zogbi por suas ajudas nas coletas sanguíneas. Aos colegas do laboratório geral que sempre me incentivaram e ajudaram tirando duvidas e alegrando meu dia.

Ao pessoal do apoio do laboratório: secretárias (Maúde, Silvana, Luciana, Sileide, Felicia, Cristina, Lúcia e Ana) pelas ajudas com a parte burocrática; setor de limpeza (Andréa, Arruda e Breno).

Ao técnico de histologia Márcio Chaves que fez minhas lâminas histológicas e me ensinou a técnica.

A Dra. Rosa pelo incentivo durante a qualificação e a sua aluna Aline Baptista que me ajudou com dúvidas clínicas.

A Dra. Ana Zeri que nos emprestou o Laboratório de Ressonância Magnética Nuclear do CNPEN para o desenvolvimento da metabolômica. E ao técnico Mauricio Sforça e aluno Rafael Canevarolo que me ajudaram com as análises. Agradeço também, à Dra. Adriana Paes Leme e sua técnica Romenia que me ajudaram com análises proteômicas em espectrômetro de massas. 
Ao grupo Fleury pelo apoio técnico e financeiro. Em especial a seus pesquisadores Dra. Karina Cardozo e Dr. Valdemir Carvalho que me orientaram junto aos seus equipamentos de forma muito amável.

Ao meu grupo Gabriela Venturini, Patrícia Schneider, Bianca Kiers, Tamiris Gois, Kallyandra Padilha e Ana Paula Carneiro, por toda a grande ajuda no desenvolvimento completo desta dissertação e ainda mais importante, pela amizade adquirida que não tem preço. Em especial gostaria de agradecer Gabriela Venturini que me inspirou a trabalhar com biomarcadores, demostrando uma enorme paixão pelo faz, e que me co-orientou com paciência e dedicação a todo momento, desenvolvendo lado a lado este trabalho comigo.

E obviamente, gostaria de agradecer ao Dr. José Eduardo Krieger que me forneceu o laboratório apropriado as analises e ao Dr. Alexandre da Costa Pereira pela orientação, confiança, amizade e carinho com que tem me tratado todos esses anos e com que trata todos os seus projetos. É muito bom fazer parte do seu grupo!

Esse trabalho foi elaborado com apoio financeiro do grupo Fleury e da Fundação de Amaparo a Pesquisa do Estado de São Paulo (Fapesp). 
Esta dissertação está de acordo com as seguintes normas, em vigor no momento desta publicação:

Referências: adaptado de International Committee of Medical Journals Editors (Vancouver)

Universidade de São Paulo. Faculdade de Medicina. Serviço de Biblioteca e Documentação. Guia de apresentação de dissertações, teses e monografias. Elaborado por Anneliese Carneiro da Cunha, Maria Julia de A. L. Freddi, Maria F. Crestana, Marinalva de Souza Aragão, Suely Campos Cardoso, Valéria Vilhena. 3a ed. São Paulo: Serviço de Biblioteca e Documentação; 2011.

Abreviaturas dos títulos dos periódicos de acordo com List of Journals Indexed in Index Medicus. 
"A única maneira de fazer um bom trabalho,é amar o que faz" (Steve Jobs). 



\section{SUMÁRIO}

Lista de Siglas

Lista de Símbolos.

Lista de Tabelas.

Lista de Figuras.

RESUMO

ABSTRACT.

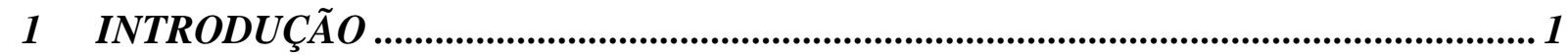

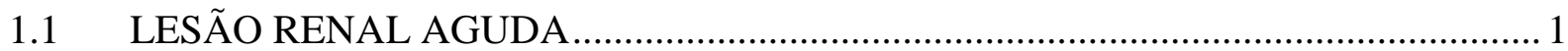

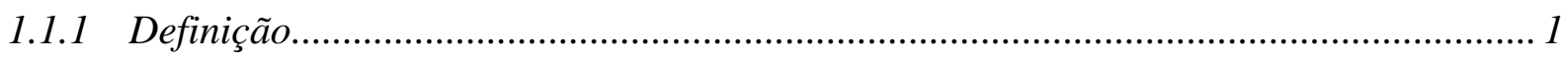

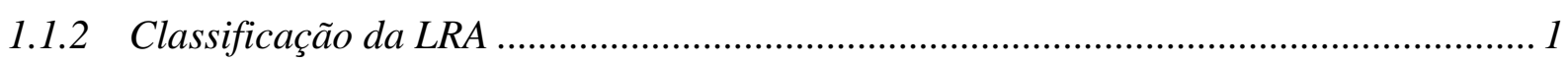

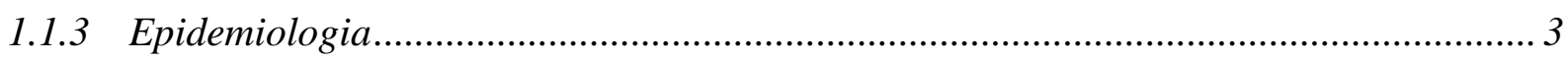

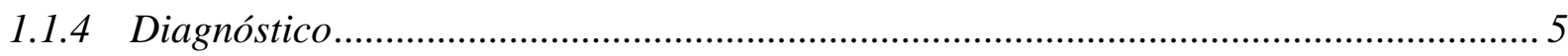

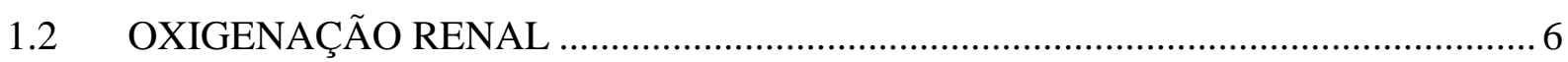

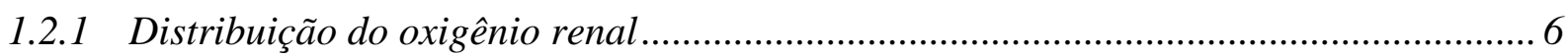

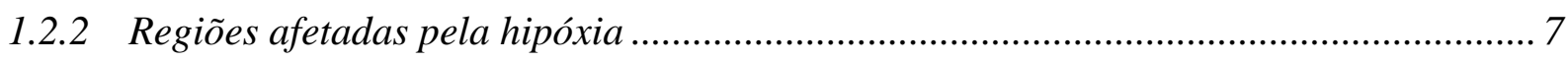

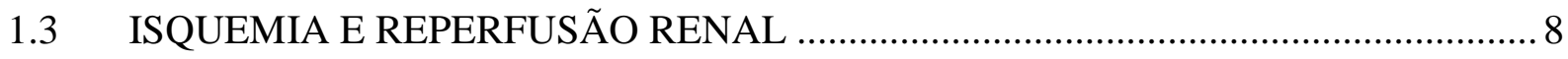

1.3.1 Definição e principais causas.............................................................................. 8

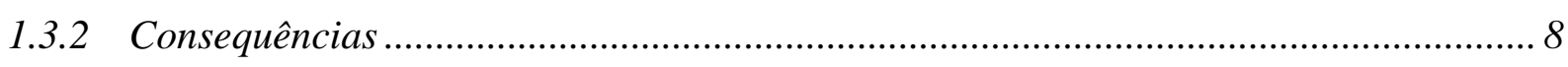

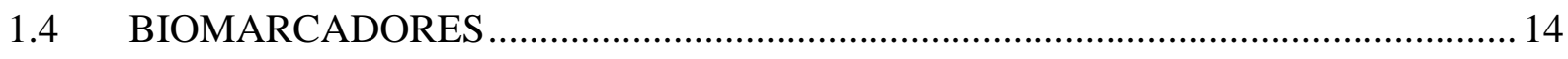

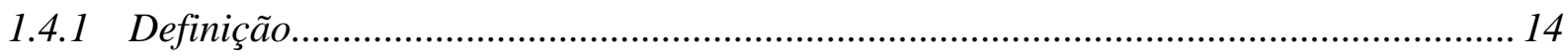

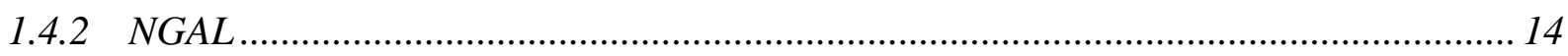

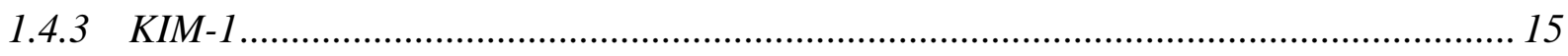

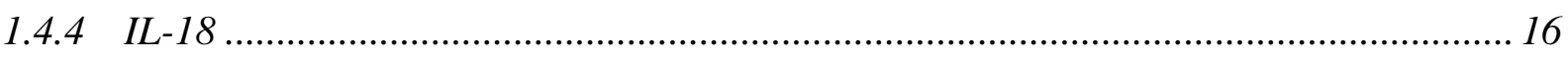

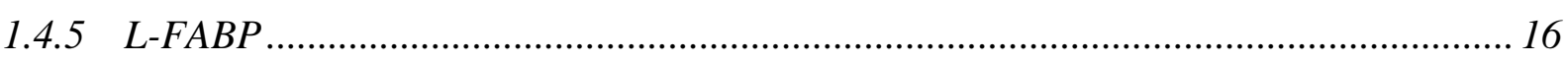

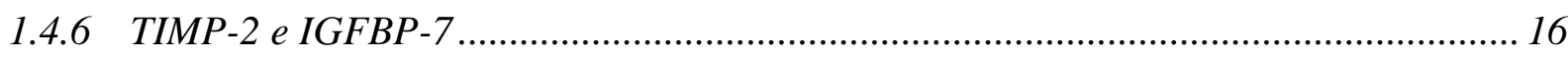

1.4.7 Normalização da concentração urinária................................................................ 18 
1.5 MODELO DE ISQUEMIA/REPERFUSÃO RENAL ........................................... 18

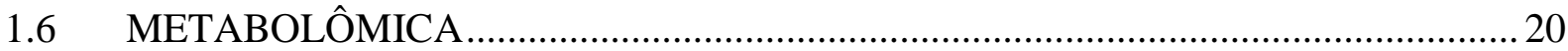

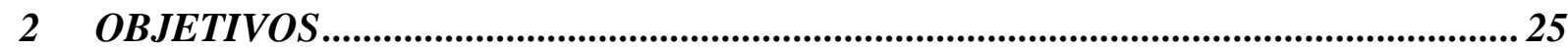

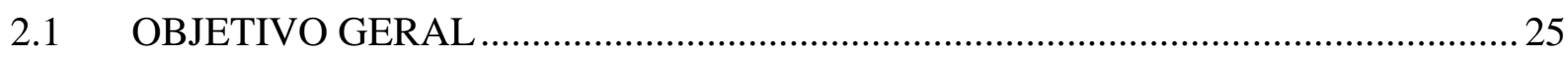

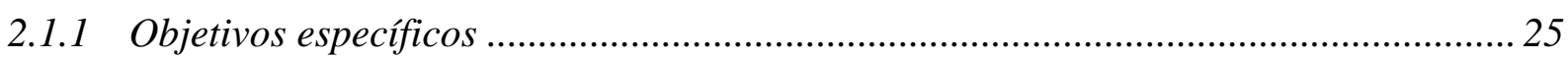

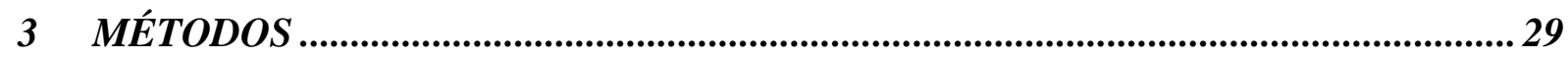

3.1 MODELO ANIMAL DE ISQUEMIA/REPERFUSÃO RENAL AGUDA ................. 29

3.1.1 Indução percutânea de isquemia renal aguda.............................................................. 30

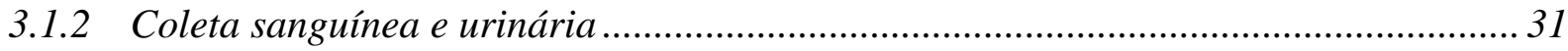

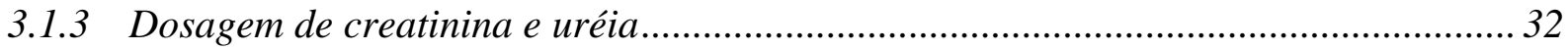

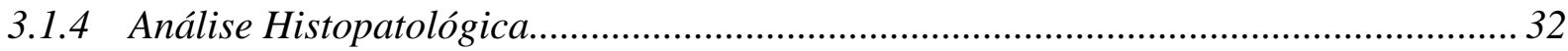

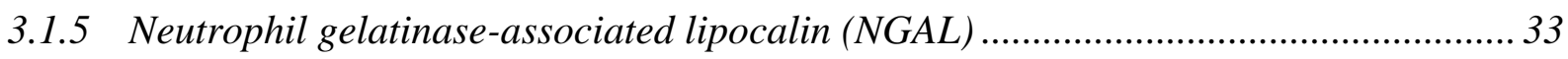

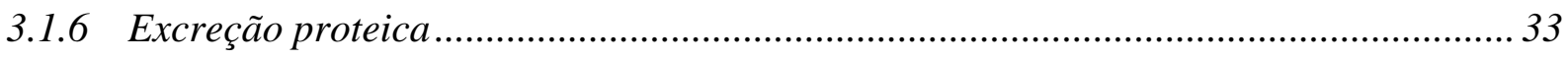

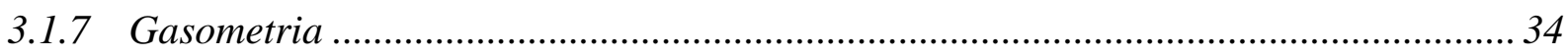

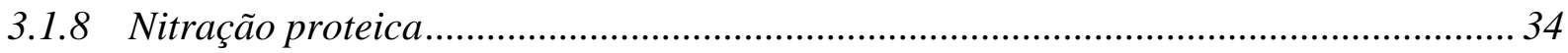

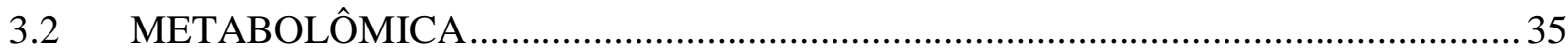

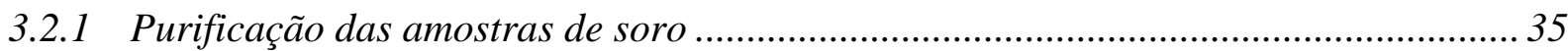

3.2.2 Preparo das amostras para a análise na Ressonância Magnética Nuclear de

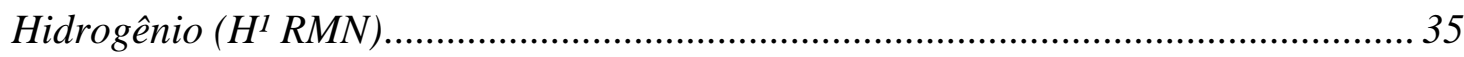

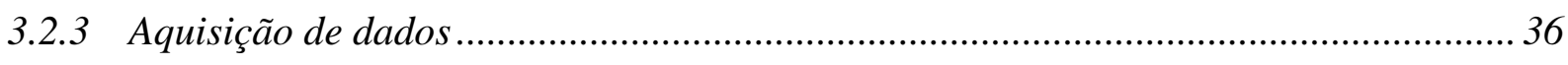

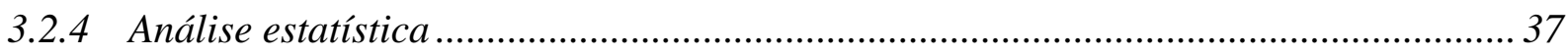

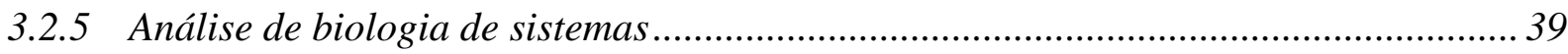

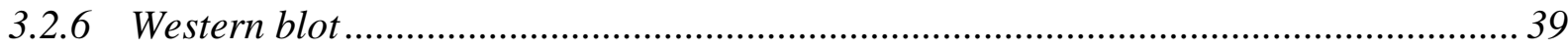

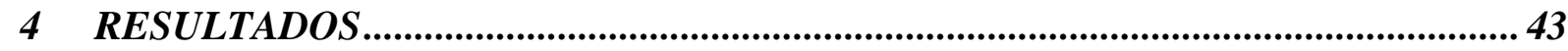

4.1 CARACTERIZAÇÃO DO MODELO DE I/R RENAL …....................................... 43

4.1.1 Avaliação do procedimento de isquemia/reperfusão renal ......................................... 43

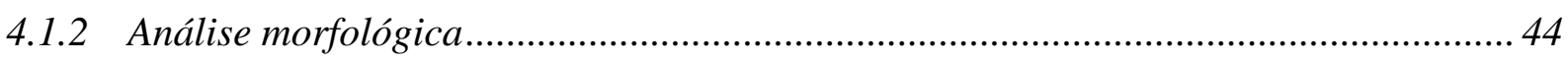

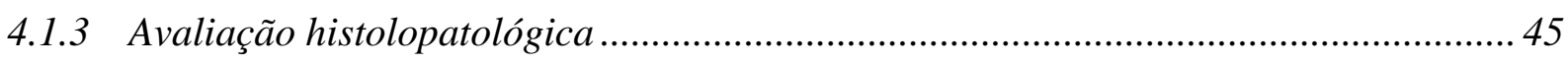

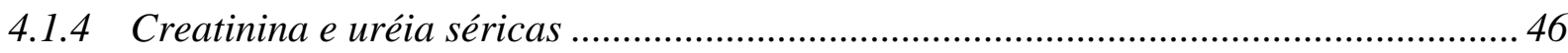

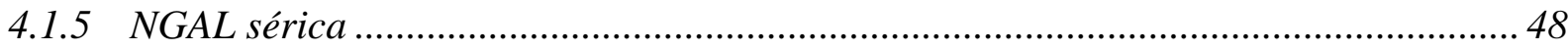

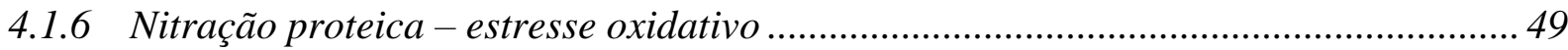




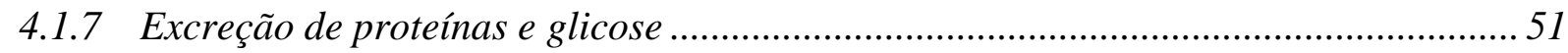

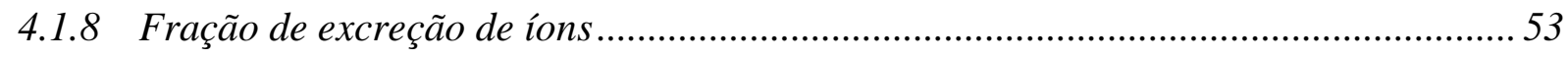

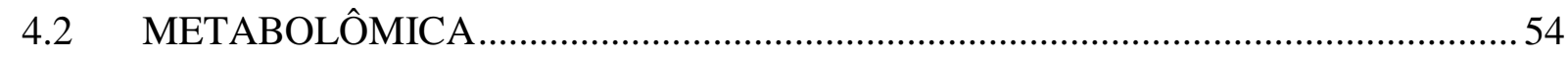

4.2.1 Identificação e seleção de metabólitos alterados pela I/R renal................................ 54

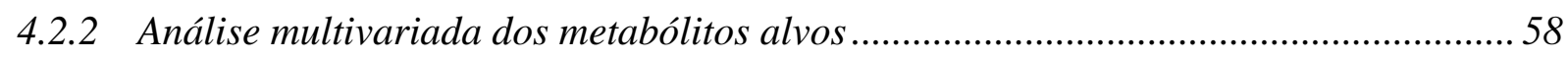

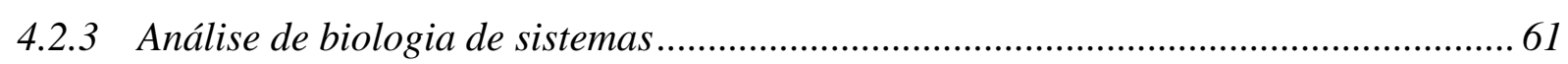

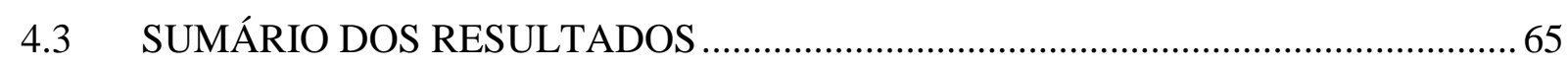

4.3.1 Avaliação do procedimento de isquemia/reperfusão renal .......................................... 65

4.3.2 Identificação e seleção de metabólitos alterados pela I/R renal................................. 65

5 DISCUSSÃ

5.1 DESENVOLVIMENTO E CARACTERIZAÇÃO DO MODELO SUÍNO DE

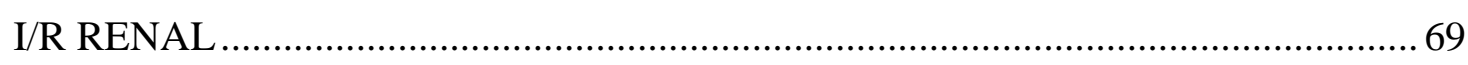

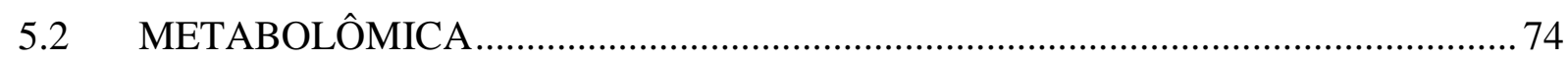

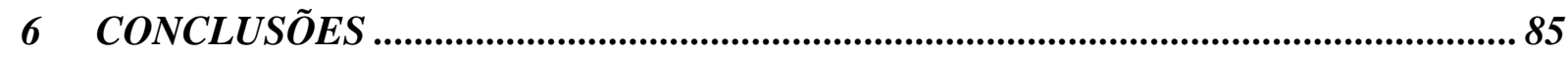

$7 \quad$ ANEXO

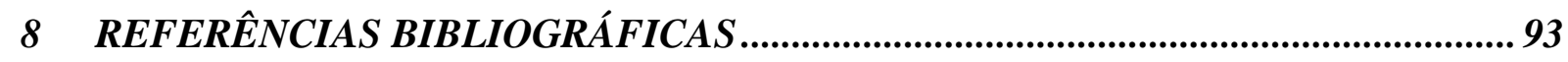



1D

2D

3D

ADMA

AKIN

ANOVA

ATP

BSA

CAPPesq

CNPEN

DNA

DRC

DTPA

ELISA

ERNs

EROs

EUA

$\mathrm{Fe}^{++}$

$\mathrm{FeCl}^{-}$

$\mathrm{FeK}^{+}$
Uma dimensão

Duas dimensões

Três dimensões

do inglês asymmetric dimethylarginine

do inglês Acute Kidney Injury Network

Análise de variância

Adenosina trifosfato

Albumina de soro bovino

Comissão de ética para análise de projetos de pesquisa

Centro Nacional de Pesquisa em Energia e Materiais

do inglês Deoxyribonucleic acid

Doença renal crônica

do inglês Diethylenetriaminepenta-acetic acid

do inglês Enzyme-linked immunosorbent assay

Espécies reativas de nitrogênio

Espécies reativas de oxigênio

Estados Unidos da América

Ferro

Fração de excreção de cloreto

Fração de excreção de potássio 


\begin{tabular}{|c|c|}
\hline $\mathrm{FeNa}^{+}$ & Fração de excreção de sódio \\
\hline FIDs & do ingles free induction decays \\
\hline $\mathrm{H}_{2} \mathrm{CO}_{3}$ & Bicarbonato \\
\hline $\mathrm{HCO}_{3}^{-}$ & Carbonato \\
\hline HMDB & do inglês Human Metabolome Database \\
\hline HTT & Huntingtina \\
\hline $\mathrm{I} / \mathrm{R}$ & Isquemia e reperfusão \\
\hline IGFBP7 & do inglês Insulin growth factor-binding protein 7 \\
\hline $\operatorname{IgG}$ & Imunoglobilina $\mathrm{G}$ \\
\hline IL-18 & Interleucina 18 \\
\hline InCor & Instituto do Coração \\
\hline iNOS & do inglês Inducible nitric oxide synthase \\
\hline $\mathrm{KCl}$, & Cloreto de potásio \\
\hline $\mathrm{kDa}$ & Kilodaltons \\
\hline $\mathrm{KH}_{2} \mathrm{PO}_{4}$ & Fosfato de potásio monobásico \\
\hline KDIGO & do inglês kidney disease improving global outcomes \\
\hline KIM-1 & do inglês Kidney injury molecule 1 \\
\hline L-FABP & do inglês Liver fatty acid binding proteins \\
\hline LOOCV & do inglês Leave one out cross validation \\
\hline LRA & Lesão renal aguda \\
\hline $\mathrm{Na}^{+} \mathrm{K}^{+}$ATPase & Sódio potássio adenosina trifosfatase \\
\hline $\mathrm{Na}_{2} \mathrm{HPO}_{4}$ & Fosfato de sódio \\
\hline
\end{tabular}




\begin{tabular}{|c|c|}
\hline $\mathrm{NaCl}$ & Cloreto de sódio \\
\hline $\mathrm{NaH}_{2} \mathrm{PO}_{4}$ & Fosfato monossódico \\
\hline $\mathrm{NaHCO}_{3}$ & Bicarbonato de sódio \\
\hline $\mathrm{NF} \kappa \mathrm{B}$ & do ingês Nuclear Factor-KappaB \\
\hline NGAL & do inglês Neutrophil gelatinase-associated lipocalin \\
\hline NO & Óxido nitrico \\
\hline NTA & Necrose tubular aguda \\
\hline $\mathrm{ONOO}^{-}$ & Peroxinitrito \\
\hline PBS & Tampão fosfato de sódio \\
\hline PBST & Tampão fosfato de sódio com Tween 20 \\
\hline PCA & do inglês Principal component analysis \\
\hline $\mathrm{pCO}_{2}$ & Pressão parcial de dióxido de carbono \\
\hline PFA & Paraformaldeído \\
\hline $\mathrm{pH}$ & Potêncial hidrogeniônico \\
\hline PLS-DA & do inglês Partial Least Squares Discriminant Analysis \\
\hline PVA & do inglês polyvinyl alcohol \\
\hline$Q^{2}$ & Validação \\
\hline $\mathrm{R}^{2}$ & Calibração \\
\hline RIFLE & $\begin{array}{l}\text { do inglês Risk, Injury, Failure, Loss and End-stage } \\
\text { kidney disease }\end{array}$ \\
\hline $\mathrm{RMN}$ & Ressonância nuclear magnética \\
\hline SDS-PAGE & $\begin{array}{l}\text { Eletroforese de gel de poliacrilamida com } \\
\text { dodecilsulfato de sódio }\end{array}$ \\
\hline
\end{tabular}


TFG

TIMP-2

TMAO

TNF- $\alpha$

TSP

Tween 20

USP

UTI

VIP
Taxa de filtração glomerular

do inglês Tissue inhibitor of metalloproteinases 2

do inglês Trimetilamina- $N$-oxide

do inglês Tumor necrosis factor-alpha

do inglês Trimetilsilil Propionato

Polioxietileno-20-sorbitan monolaureato

Universidade de São Paulo

Unidade de terapia intensiva

do inglês Variable importance in the projection 
Lista de Símbolos

\begin{tabular}{|c|c|}
\hline$\%$ & Porcentagem \\
\hline$<$ & Menor \\
\hline$>$ & Maior \\
\hline${ }^{\circ} \mathrm{C}$ & Graus Celsius \\
\hline$\mu \mathrm{g}$ & Micrograma \\
\hline$\mu \mathrm{L}$ & Microlitro \\
\hline$\mu \mathrm{m}$ & Micrômetro \\
\hline $\mathrm{Cl}^{-}$ & Cloreto \\
\hline $\mathrm{cm}$ & Centímetro \\
\hline $\mathrm{cm}^{2}$ & Centímetro quadrado \\
\hline $\mathrm{dL}$ & Decilitro \\
\hline $\mathrm{F}$ & French \\
\hline G & Força $\mathrm{G}$ \\
\hline $\mathrm{h}$ & Horas \\
\hline $\mathrm{Hz}$ & Hertz \\
\hline $\mathrm{K}^{+}$ & Potássio \\
\hline $\mathrm{KDa}$ & Quilodalton \\
\hline $\mathrm{kg}$ & Quilograma \\
\hline M & Molar \\
\hline $\mathrm{mg}$ & Miligrama \\
\hline $\mathrm{MHz}$ & Mega Hertz \\
\hline
\end{tabular}




$\begin{array}{ll}\mathrm{min} & \text { minutos } \\ \mathrm{mL} & \text { Mililitro } \\ \mathrm{mm} & \text { Milímetro } \\ \mathrm{mM} & \text { Milimolar } \\ \mathrm{mm}^{3} & \text { Milímetro cúbico } \\ \mathrm{Na}^{+} & \text {Sódio } \\ \mathrm{nM} & \text { Nanomolar } \\ \mathrm{pg} & \text { Picograma } \\ \mathrm{s} & \text { Segundos }\end{array}$




\section{Lista de tabela}

Tabela 1. Sistema de classificação para lesão renal aguda dado pelo AKIN............... 2 



\section{Lista de figuras}

Figura 1 - O rim recebe uma quantidade de oxigênio muito superior à necessária, porém a região medular externa consome mais de $80 \%$ do aporte de oxigênio, superando cérebro e miocárdio. A porção azul da barra representa o consumo de oxigênio, enquanto a altura total da mesma representa o aporte total de oxigênio ao tecido (Zatz 2011).

Figura 2 - Lesão e reparo tubular na lesão renal aguda. Após a isquemia/reperfusão ocorre perda da borda em escova dos túbulos proximais, perda de polaridade e redistribuição de integrinas e Na+K+ATPase para a superfície apical com perda do formato tubular. Cálcio e espécies reativas de oxigênio atuam nestas alterações com subsequente morte celular por necrose e/ou apoptose. Células viáveis e inviáveis descamam e seguem para o lúmen obstruindo-o e reduzindo a taxa de filtração glomerular. $\mathrm{O}$ rim pode se restaurar completamente espalhando e desdiferenciando células viáveis para substituir as lesionadas. Diversos fatores de crescimento ajudam na restauração dos epitélios tubulares. Esquema modificado de Thadhani et.al, 1996. 11

Figura 3 - Alterações no metabolismo das células dos túbulos após LRA isquêmica. A fase inicial da isquemia é caracterizada pela depleção de ATP, que através da ativação de caspases, fosfolipases e aumento de $\mathrm{Ca}^{++}$intracelular levam a morte celular. A isquemia prolongada seguida de reperfusão reduz a ativação de morte celular por necrose, mas causa lesão oxidativa e modificações proteicas, principalmente pela via da hipoxantina. Modificado de (Devarajan 2006). 13

Figura 4 - Comparação morfológica entre os rins de humano, porco e rato. Os rins de suínos são mais similares aos humanos por apresentarem anatomia multilobular e arquitetura multipapilar, diferente dos rins de rato e também dos cachorros e coelhos que apresentam anatomia unilobular e arquitetura unipapilar 19

Figura 5 - Períodos das coletas sanguíneas e urinárias. Foram feitas coletas antes do procedimento de indução de isquemia (0 minutos), durante a isquemia $(15,30$, 60, 90 e 120 minutos) e após o início da reperfusão (135, 150 e 180 minutos e em intervalos de 60 minutos até completar 24 horas após o início de reperfusão). Os rins foram explantados após as $24 \mathrm{~h}$ de reperfusão. Os tempos representativos da resposta a isquemia/reperfusão, baseados no perfil de creatinina sérica estão representados pelas setas cinzas. Estes tempos foram selecionados para as análises de metabolômica sérica e dosagens bioquímicas urinárias. 31

Figura 6 - Fluxograma da análise estatística por quintil. Os valores séricos em milli Molar ( $\mathrm{mM}$ ), por exemplo da creatinina, foram normalizados dentro dos valores apresentados pelo próprio animal nos diversos tempos (0,60, 150, 480, 780 minutos). Foi feita a subtração da média para cada valor, seguida pela divisão pelo desvio padrão. Os valores normalizados obtidos foram colocados em ordem 
crescente e feita a divisão por quintil. Cada quintil recebeu um score (1 a 5) e a média destes scores foram usadas para a ilustração por mapa de calor. Esta análise foi feita para cada metabólito identificado na análise por RMN. 38

Figura 7 - Imagens angiográficas do sistema renal direito suíno obtidas durante procedimento de isquemia/reperfusão. A) Angiografia da artéria renal direita préisquemia demonstrando total vascularização do órgão. B) Angiografia da artéria renal direita pré-isquemia com total vascularização parenquimal do rim. C) Uma corda-guia de 0,014" foi introduzida dentro da artéria renal direita,. D) Um catetebalão $5 \times 20 \mathrm{~mm}$ foi inflado na porção proximal da artéria renal direita para total oclusão do fluxo renal por 120 minutos. E) Angiografia da aorta abdominal confirmando a isquemia, com completa ocusão da artéria renal, sem vascularização.F) Angiografia final da aorta abdominal e artérias renais, mostrando a reperfusão renal com um pequeno espasmo na porção distal da artéria após a retirada do balão (seta branca), mas sem interferência na reperfusão. Note em todas as imagens um cateter localizado dentro da veia cava inferior acima das veias renais

Figura 8 - Morfologia dos rins dos animais que sofreram I/R. A) Animal 1; B) Animal 2; C) Animal 3; D)Animal 4; E) Animal 5. Os rins do lado esquerdo são os que sofreram isquêmia e os do lado direito, os contralaterais. Exceto para o animal 1 , apresentaram necrose na parte inferior ou medial em diferentes graus. Já os rins contralaterais apresentaram o mesmo tamanho dos rins isquêmicos, exceto para os animais 4 e 5 .

Figura 9 - Avaliação histopatológica dos córtices renais. Gráfico indicando a porcentagem de área de córtices renais analisados com NTA. A) Rim contralateral sem o insulto isquêmico e sem NTA. B) NTA em 10-25\% do córtex renal isquêmico do animal 1. C) Necrose branca e NTA em mais de $51 \%$ do córtex renal. Representativo dos animais P2,P3,P4 e P5. Coloração por ácido periódico de Schiff (PAS), magnitude de 50X. D) Caracterização de NTA em maior aumento. Note as alterações tubulares como restos celulares intratubulares $(*)$ e perda da borda em escova ( $($ ). Coloração por hematoxilina-eosina, magnitude de 200X. E) Quantificação da porcentagem de NTA em rins isquêmicos de diferentes animais (P1, P2, P3, P4, P5). Necrose tubular aguda (NTA). 46

Figura 10 - Valores das concentrações de uréia e creatinina séricas dos animais antes e após indução de isquemia/reperfusão. A uréia e a creatinina foram dosadas em todos os momentos: pré-isquemia (0), durante a isquemia (1 a $120 \mathrm{~min}$ ) e durante a reperfusão (135 a 1560min). A concentração de ambas aumentaram significamente comparadas ao tempo pré-isquemia. A) Valores de uréia sérica plotados individualmente $(\mathrm{mg} / \mathrm{dL})$ durante todo o experimento; B) Valores de creatinina sérica plotados individualmente $(\mathrm{mg} / \mathrm{dL})$ durante todo o experimento ( $\mathrm{mg} / \mathrm{dL})$; C) Médiaterro padrão da média dos valores de uréia sérica para todos os animais (mg/dL); D) Médiaterro padrão da média dos valores de 
creatinina sérica para todos os animais $(\mathrm{mg} / \mathrm{dL})$. Análise para medidas repetidas (ANOVA) com * $p<0,05(n=5)$ em relação ao valor basal.

Figura 11 - Análise percentual do aumento na creatinina sérica em relação ao valor basal, independente do tempo de coleta. A linha sob a sigla LRA indica o valor limite do aumento de creatina em $48 \mathrm{~h}$ para uma função renal normal. Acima deste valor ( $150 \%$ em relação ao valor basal) o indivíduo é diagnosticado como tendo lesão renal aguda (LRA) segundo AKIN (Mehta et al. 2007). Note que apenas os animais 3 e 4 apresentaram creatinina sérica acima de $150 \%$, sendo classificados com LRA.

Figura 12 - Concentração sérica de Neutrophil gelatinase-associated lipocalin (NGAL) no soro dos animais ao longo do tempo de isquemia e reperfusão. A) Valores de concentração da NGAL $(\mathrm{ng} / \mathrm{mL})$ ao longo do tempo de coleta. B) Diferença da concentração dos valores pós isquemia em relação ao basal (préisquemia), destacando a redução estatisticamente significativa da NGAL durante a isquemia e o aumento após a reperfusão. Os valores foram apresentados em média \pm rro padrão da média. Análise para medidas repetidas (ANOVA) * $p<0,05$ para comparação com o valor basal e \# $p<0,05$ para comparação com os valores durante $a$ isquemia $(n=5)$. 48

Figura 13 - Análise de estresse oxidativo através de quantificação de concentração de proteínas nitradas séricas e urinárias durante a isquemia e reperfusão. A) Concentração de proteínas nitradas totais no soro (nM) demonstrando o aumento após reperfusão. B) Diferença entre os tempos pós isquemia e basal (préisquemia), destacando o aumento pós reperfusão. C) Aumento do estresse oxidativo renal durante a isquemia caracterizado pelo aumento na excreção de proteínas nitradas normalizada pela concentração de creatinina urinária $(n=4)$. Todos os valores foram apresentados como média‡erro padrão da média com aumentos estatisticamente significativos. Análise para medidas repetidas (ANOVA) $p<0,05$, sendo * comparado ao valor basal. 50

Figura 14 - Análise da excreção urinária de proteínas e glicose. A) Razão da concentração de proteinas por creatinina $(n=5)$ observando um aumento da excreção de proteínas em 360 minutos B) Padrão de proteínas urinárias em SDSPAGE. As bandas mais escuras são bandas de albumina (69KDa), observação confirmada pelo uso do padrão BSA, (bovine serum albumin, $2 \mu \mathrm{g}$ ). Nota-se uma alteração do perfil de tamanho das proteínas excretadas após isquemia/reperfusão. C) Razão entre concentrações de glicose e creatinina $(n=4)$. As excreções de proteínas e glicose aumentaram significativamente com a isquemia. Os valores foram apresentados como média terro padrão da média.

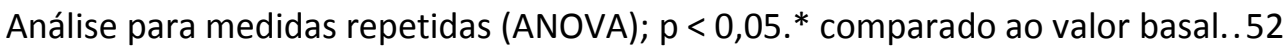

Figura 15 - Análise bioquímica da excreção de íons durante a isquemia e reperfusão. A) Fração de excreção de sódio $\left(\mathrm{FeNa}^{+}\right)$com um evidente aumento após isquemia e retorno dos valores basais na reperfusão. B) Fração de excreção 
de potassio (FeK ${ }^{+}$com aumento tardio após isquemia/reperfusão. C) Fração de excreção de cloreto $\left(\mathrm{FeCl}^{-}\right)$apresentando o mesmo perfil identificado na fração de excreção de $\mathrm{Na}^{+}$. D) Excreção de bicarbonato $\left(\mathrm{HCO}_{3}^{-}\right)$normalizado por creatinina, ainda mantendo o mesmo padrão dos demais íons. E) Medida de $\mathrm{pH}$ urinário, com um leve aumento durante a isquemia. Todas as análises apresentaram diferença estatisticamente significativa. Os valores foram apresentados como médiaterro padrão da média. Análise para medidas repetidas (ANOVA); $p<0,05(n=5)$. * comparado ao valor basal.

Figura 16 - Representação de espectros de $600 \mathrm{MHz}$ H1 RMN com o perfil de metabólitos típicos encontrados nas amostras de soro dos animais. Nota-se a diferença das concentrações de alguns metabólitos (seta em azul) no decorrer do processo de isquemia/reperfusão. A) Espectro de metabólitos pré-isquemia. B) Espectro com metabólitos durante a isquemia. C) Espectro com metabólitos após 11 horas de reperfusão. 54

Figura 17 - Representação por mapa de calor dos 55 metabólitos encontrados no modelo de isquemia/reperfusão renal. 0 retângulo azul destaca os metabólitos que aumentaram a concentração (valores de cada animal normalizados) após 60 minutos da isquemia. Os valores de concentração variam em uma escala de menor concentração, em verde, até os metabólitos mais concentrados, em vermelho. 55

Figura 18 - Representação por mapa de calor dos 55 metabólitos encontrados no modelo de isquemia/reperfusão renal (I/R) após a divisão por quintil. Os metabólitos em letras maiúsculas vermelhas destacam os metabólitos escolhidos como candidatos a biomarcadores de $\mathrm{I} / \mathrm{R}$ devido ao aumento rápido da concentração destes durante a isquemia com posterior queda após a reperfusão (L-glutamato, L-serina, N-isovaleroilglicina, L-metionina, L-prolina, 2aminobutirato e colina). A creatinina também foi selecionada para futuras comparações em painel metabólico. Os valores de concentração variam dos menos concentrados, em verde, até os mais concentrados, em vermelho. 56

Figura 19 - Mapa de calor dos 8 metabólitos selecionados devido a diferenças nas concentrações metabólicas dos momentos pré isquemia, isquemia e reperfusão. Os valores de concentração variam dos menos concentrados, em verde, até os mais concentrados, em vermelho.

Figura 20 - Representação 2D e 3D da análise de PLS-DA. Os momentos préisquemia (Prelschemia) e isquemia (Ischemia) puderam ser separados através de 2 ou 3 componentes, respectivamente. Pré-isquemia (verde) e isquemia (vermelho).

Figura 21 - Representação 2D e 3D da análise de PLS-DA. Os momentos isquemia (Isquemia) e pós reperfusão $11 \mathrm{~h}$ (Rep $11 \mathrm{~h}$ ) puderam ser separados através de 2 
ou 3 componentes, respectivamente. Isquemia (vermelho) e pós reperfusão $11 \mathrm{~h}$ (verde)......

Figura 22 - Perfil de metabólitos estatisticamente capazes de distinguir momentos pré-isquemia, isquemia e pós reperfusão (11h). Média \pm erro padrão da média.. 60

Figura 23 - Representação da importância da variável na projeção (VIP) listando em ordem decrescente de importância os metabólitos capazes de distinguir os momentos pré-isquemia da isquemia. As cores dos quadrados indicam se a concentração do metabólito está mais alta (vermelha) ou mais baixa que o outro momento (verde). L-glutamato, L-serina, $\mathrm{N}$-isovaleroilglicina, L-metionina, Lprolina, 2-aminobutirato, colina e creatinina seguiram em sua ordem de importância para o modelo. 61

Figura 24 - Principais vias associadas aos metabólitos candidatos identificadas através de uma análise de enriquecimento do programa MetaCore. 62

Figura 25 - Rede relacionada aos metabólitos candidatos a biomarcadores (MetaCore). L-glutamato (glutamic acid), L-Serina, L-metionina, L-prolina, 2aminobutirato (L-alpha-Aminobutyric acid), colina e creatinina. O glutamato apresentou uma via única, não demostrada, e o $\mathrm{N}$-isovaleroilglicina não foi encontrado no MetaCore. Todos estes metabólitos foram associados com transportadores de hidrogênio $\left(\mathrm{H}^{+}\right)$, sódio $\left(\mathrm{Na}^{+}\right)$e cloreto $\left(\mathrm{Cl}^{-}\right)$.

Figura 26 - Conecções dos metabolitos candidatos (vermelho) a proteinas, fatores de transcrição e outros metabótitos através do programa Ingenuity. Nesta rede, destacam-se o fator nuclear kappaB (NFKB), huntingtina (HTT) e proinsulina. Glutamato (L-glutamic acid), L-Serina (L-serine), L-metionina (L-methionine), Lprolina (L-proline), colina (choline) e creatinina (creatinine).

Figura 27 - Análise do fragmento N-terminal da proteína huntingtina no rim. A) Western blot da fração nuclear de córtex renal com uso do anticorpo monoclonal para região $\mathrm{N}$-terminal da huntingtina (HTT). $\mathrm{O}$ anticorpo da $\mathrm{HTT}$ reconheceu duas bandas no extrato renal: $65 \mathrm{KDa}$ e $55 \mathrm{KDa}$ e o GAPDH foi utilizado como normalizador. As bandas foram quantificadas por densitrometria. A) Densitometria da banda de $65 \mathrm{KDa} / \mathrm{GAPDH}$, apresentando uma maior intensidade no individuo isquêmico. B) Densitometria da banda de $55 \mathrm{KDa} / \mathrm{GAPDH}$, demostrando uma redução significativa do fragmento de HTT no extrato de rim isquêmico. A coluna branca no gráfico indica o rim contralateral à isquemia e a preta indica o rim isquêmico. Os valores foram apresentados como médiaterro padrão da média. Teste ' $t$ ' de Student pareado com ${ }^{*} p<0,05 \quad(n=5)$. $M=$ Marcador, $\mathrm{CL}=$ rim contralateral, Isq= rim isquêmico, NS = não específica 

Malagrino, PA. Alterações no perfil metabólico em resposta a isquemia/reperfusão renal em modelo suíno de lesão renal aguda. [dissertação]. São Paulo: "Faculdade de Medicina, Universidade de São Paulo"; 2014.

\section{RESUMO}

A lesão renal aguda (LRA) é uma séria complicação dos pacientes hospitalizados, causada principalmente pela isquemia/reperfusão (I/R). Ela é definida como um abrupto declínio da função renal baseada em alterações agudas da creatinina sérica e débito urinário. Porém, alterações na creatinina sérica são tardias e variam com o gênero, idade, massa muscular, metabolismo e hidratação do indivíduo. Novos biomarcadores para um diagnóstico mais preciso e precoce da doença são necessários. No entanto, devido em humanos a LRA ser uma doença, em sua maioria, secundária a outras doenças, o desenvolvimento de modelos animais com resposta similar aos humanos é de extrema importância. Assim, o presente estudo tem como objetivo o desenvolvimento e caracterização de um modelo suíno de I/R renal, seguido da identificação de alterações nos perfis metabólicos séricos durante à $\mathrm{I} / \mathrm{R}$ renal aguda. Além de colaborar com o melhor entendimento da fisiopatologia da doença, pode prover novos biomarcadores com potencial uso no diagnóstico e prognóstico através do monitoramento dos pacientes hospitalizados. Primeiramente, foi desenvolvido um modelo controlado e percutâneo, com único insulto de I/R renal, sem nefrectomia contralateral usando suínos como modelo. A isquemia foi induzida por um cateter-balão inflado por $120 \mathrm{~min}$ na artéria renal direita seguida de 24 horas de reperfusão. Amostras seriadas de soro e urina foram coletadas. A caracterização do modelo foi feita por análises histológicas e bioquímicas, e a identificação de novos biomarcadores, através da ressonância magnética nuclear $(600 \mathrm{MHz})$ seguida da análise por PLS-DA e biologia de sistemas. A necrose tubular aguda foi identificada em todos os animais, porém apenas dois deles apresentaram níveis de creatinina sérica acima de $150 \%$ dos seus valores basais. Como esperado, a I/R elevou os níveis de uréia e creatinina e ainda modulou a excreção de $\mathrm{Na}^{+}, \mathrm{K}^{+}, \mathrm{Cl}^{-}$, bicarbonato e glicose. A NGAL e as proteínas nitradas séricas apresentaram 
dois perfis: diminuíram com a isquemia e aumentaram com a reperfusão. Este declínio foi associado com o aumento da excreção de proteínas durante a isquemia e início da reperfusão. A partir deste modelo de I/R renal desenvolvido, selecionamos 8 marcadores metabólicos: L-glutamato, Lserina, N-isovaleroilglicina, L-metionina, L-prolina, 2-aminobutirato, colina e creatinina. Estes metabólitos foram capazes de distinguir indivíduos saudáveis e isquêmicos, restaurando seus valores após 11 horas da reperfusão. Através da análise de biologia de sistemas, estes metabólitos se mostraram altamente representativos da via dos aminoácidos, se relacionaram com alterações no transporte iônico e foram associados às vias do fator nuclear kappa B (NFkB), huntingtina (HTT) e pró-insulina. Assim, foi possível desenvolver um modelo de I/R renal percutâneo em modelo suíno, capaz de permitir o desenvolvimento de estudos para explorar respostas fisiopatológicas e novos biomarcadores isquêmicos renais. A partir dele, com ferramentas metabolômicas, foi possível elaborar um painel metabólico que contribui para o estudo da fisiopatologia da isquemia e pode tornar-se uma ferramenta promissora para a identificação precoce de pacientes com LRA geradas pela I/R renal.

Descritores: Isquemia. Oclusão com balão. Lesão renal aguda. Necrose tubular aguda. Rim/irrigação sanguínea. Traumatismo por reperfusão. Marcadores biológicos. Metabolômica. Espectroscopia de ressonância magnética. Suínos. 
Malagrino, PA. Changes in the metabolic profile in response to ischemia/reperfusion in a swine model of acute kidney injury. [dissertation]. São Paulo: "Faculdade de Medicina, Universidade de São Paulo"; 2014.

\begin{abstract}
Acute kidney injury (AKI) is a serious complication in hospitalized patients mainly caused by ischemia/reperfusion. AKI is defined as the abrupt decrease in kidney function based on acute alterations in serum creatinine or urine output. Nevertheless, changes in serum creatinine are late and vary with muscular mass, age, gender, metabolism and hydration of individuals. In this sense, new biomarkers for the accurate and early diagnosis are needed. In humans LRA is a secondary disease, related to the progress of other diseases. Thus, the development of animal models with similar response to humans is extremely important. This study aimed to develop and characterize a swine model of renal ischemia/reperfusion (I/R), followed by the identification of changes in serum metabolic profiles during acute renal $\mathrm{I} / \mathrm{R}$. In addition to collaborating with a better understanding of the physiopathology of the disease, these findings may provide new biomarkers with potential use in diagnosis and prognosis through the monitoring hospitalized patients. Here we report the development of a controlled, single-insult model of unilateral renal I/R without contralateral nephrectomy, using a suitable model, the pig. Animals underwent renal ischemia by balloon catheter placed and inflated into the right renal artery for 120 minutes and reperfusion over 24 hours. Serial serum and urine were sampled. The characterization of the renal $\mathrm{I} / \mathrm{R}$ model was made by histological and biochemical analyzes. Identification of new biomarkers was performed by nuclear magnetic resonance $(600 \mathrm{MHz})$ followed by PLSDA analysis and systems biology. Acute tubular necrosis (ATN) was identified in every animal, but only two animals showed levels of serum creatinine above $150 \%$ of baseline values. As expected, I/R increased serum creatinine and BUN. Fractional sodium, potassium, chloride, bicarbonate and glucose excretion were modulated during ischemia. Serum nitrated proteins and NGAL presented two profiles: decreased with ischemia and increased after reperfusion. This decline was associated with increased
\end{abstract}


protein excretion during ischemia and early reperfusion. From this renal I/R model developed, eight metabolites were selected: L-glutamate, L-serine, $\mathrm{N}$-isovaleroylglicine, L-methionine, L-proline, 2-aminobutyrated, choline and creatinine. PLS-DA analysis for these metabolites resulted in an accurate separation between pre ischemia and ischemia groups.

All selected metabolites recovered to baseline conditions after 11 hours of reperfusion. Through network analysis we found changes in $\mathrm{H}^{+}, \mathrm{Na}^{+}$and $\mathrm{Cl}^{-}$ion transport pathways and association with Nuclear Factor-KappaB (NFkB), Huntingtin (HTT) and proinsulin (insulin) pathways. Thus, it was possible to develop a percutaneous model of renal $\mathrm{I} / \mathrm{R}$ in swine model, allowing the development of studies to explore physiopathology responses and new renal ischemic biomarkers. With this model and metabolomic tools, it was possible to develop a metabolic panel that contributes to the study of ischemia physiopathology and may become a promising tool for the early identification of patients with AKI generated by renal I/R.

Descriptors: Ischemia. Balloon occlusion. Acute kidney injury. Acute tubular necrosis. Kidney/blood supply. Reperfusion injury. Biological markers. Metabolomics. Magnetic resonance spectroscopy. Swine. 


\section{INTRODUCÃO}







\section{INTRODUÇÃO}

\subsection{LESÃO RENAL AGUDA}

\subsubsection{Definição}

Os rins são responsáveis pela conservação da homeostase do organismo através da manutenção do equilíbrio ácido-base, pressão arterial e excreção de substâncias tóxicas. Além de participarem da produção de hormônios, como a eritropoetina e renina, e da síntese de vitamina D ativa. Alterações renais podem ocorrer independentemente ou secundáriamente a outras doenças, ambas causando graves danos ao organismo. A redução da função renal pode ocorrer de forma lenta (com perda progressiva dos néfrons) conhecida como doença renal crônica (DRC) ou de forma abrupta, denominada lesão renal aguda (LRA) (Zatz, 2011).

O termo LRA foi criado recentemente pelo grupo Acute Kidney Injury Network (AKIN, 2007) em substituição à denominação insuficiência renal aguda (IRA). Isso ocorreu devido à utilização do termo "lesão" englobar todo o espectro da IRA, reconhecendo que um rápido declínio da função renal é frequentemente secundário a uma lesão que já alterou a função ou estrutura dos rins. A LRA é caracterizada por uma redução da função renal baseado nos níveis de creatinina sérica e diurese durante $48 \mathrm{~h}$.

\subsubsection{Classificação da LRA}

A antiga classificação de LRA era estabelecida de acordo com os critérios do RIFLE (do inglês Risk, Injury, Failure, Loss and End-stage kidney disease) baseada no aumento de creatinina sérica em até 7 dias e 5 estágios (risco, lesão, falência, perda e estágio final da doença). Atualmente, essa classificação foi alterada pelo AKIN para 3 estágios com observação da elevação da creatinina sérica comparada ao valor basal ou aumento mínimo de $0,3 \mathrm{mg} / \mathrm{dL}$ em $48 \mathrm{~h}$ (Mehta et al. 2007), como representado na tabela 1. 
Tabela 1. Sistema de classificação para lesão renal aguda dado pelo AKIN.

\begin{tabular}{ccc}
\hline Estágio & Creatinina sérica & Débito urinário \\
\hline $\mathbf{1}$ & Aumento $\geq 0,3 \mathrm{mg} / \mathrm{dL}(26,4 \mu \mathrm{mol})$ ou & $<0,5 \mathrm{ml} / \mathrm{kg} / \mathrm{h}$ por mais \\
& aumento $\geq 150-200 \%$ do basal. & de $6 \mathrm{~h}$ \\
$\mathbf{2}$ & Aumento $>200-300 \%$ do basal. & $<0,5 \mathrm{ml} / \mathrm{kg} / \mathrm{h}$ por mais \\
& & de $12 \mathrm{~h}$ \\
$\mathbf{3}$ & Aumento $>300 \%$ do basal ou & $<0,3 \mathrm{ml} / \mathrm{kg} / \mathrm{h}$ por $24 \mathrm{~h}$ ou \\
& $\geq 4,0 \mathrm{mg} / \mathrm{dL}$ com aumento agudo de no & anúria por 12 horas ou \\
& mínimo $0,5 \mathrm{mg} / \mathrm{dL}$ ou precisa de terapia & precisa de terapia de \\
& de substituição renal & substituição renal \\
\hline
\end{tabular}

Em 2012, o grupo KDIGO (do inglês kidney disease improving global outcomes) publicou uma diretriz com orientações para o manejo clínico dos pacientes com LRA. Além disso, acrescentaram à tabela do AKIN a observação do aumento de creatinina por 7 dias quando não se tem o valor basal de creatinina do paciente (KDIGO, 2012). Para nosso estudo com abordagem aguda, usamos o AKIN como referência de LRA.

Baseado nos mecanismos que conduzem à lesão renal, a LRA pode ser classificada sob três formas (Thadhani et al. 1996):

LRA pré-renal - causada apenas por alterações hemodinâmicas (redução do fluxo sanguíneo renal, devido a uma queda da pressão de perfusão renal e um aumento da resistência vascular renal) sem que haja lesões renais. Com o restabelecimento hemodinâmico rápido, o rim volta ao seu funcionamento normal. Caso contrário, o rim é lesionado e o indivíduo passa para a próxima classificação.

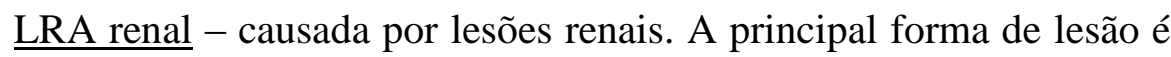
a necrose tubular aguda (NTA) que acomete entre 70 a $90 \%$ dos pacientes com LRA renal, sendo a causa mais comum em pacientes hospitalizados (Devarajan 2006). Ela é decorrente de hipoperfusão renal, hipóxia e em alguns casos de toxicidade, é acompanhada de obstrução tubular e vazamento do filtrado glomerular para o interstício renal. Em 50\% dos casos os indivíduos precisam de tratamento dialítico e internação por mais de 15 
dias para restaurar a função, levando a significativo aumento de gastos hospitalares.

LRA pós renal - causada por obstrução mecânica das vias urinárias, como cálculos ou processo tumoral. É revertida, caso a via seja rapidamente desobstruída, senão pode evoluir para uma perda da função renal permanente.

\subsubsection{Epidemiologia}

A incidência de LRA tem aumentado atualmente devido ao concomitante aumento da expectativa de vida da população, das doenças crônicas, das internações hospitalares, do uso de contrastes iodados e do uso de medicamentos nefrotóxicos (imunossupressores, anti-inflamatórios não hormonais, antibióticos, antifúngicos e agentes antivirais). Além disso, o consenso na definição de LRA e o aumento da sensibilidade do diagnóstico decorrente desta nova definição, têm aumentado também o número de diagnósticos. (Rewa and Bagshaw 2014).

A LRA é uma séria complicação que acomete principalmente pacientes hospitalizados em Unidade de Tratamento Intensivo (UTI), devido a medicamentos e contraste radiográfico, e pacientes pós-cirurgia cardíaca (Nash et al. 2002). Isto porque uma das principais causas da LRA é a isquemia, comum nas cirurgias cardíacas através da redução da demanda de oxigênio no intra-operatório, hipotensão, hipovolemia e redução no débito cardíaco (Mangano et al. 1998).

Os dados epidemiológicos antes da nova classificação de LRA (Mehta et al. 2007) eram muito heterogêneos, não podendo ser comparados devido a diferentes denominações de LRA. As novas classificações, seja do RIFLE, do AKIN ou do KDIGO, permitem uma melhor homogeinidade e possível comparação entre os estudos. No entanto, devido à recente reclassificação, dados epidemiológicos ainda são escassos (Hoyert et al. 2012).

Classificando pacientes de UTI apenas pelos níveis de creatinina sérica e não pelo débito urinário do RIFLE, uma incidência de LRA de $36,1 \%$, aumento de 3,29 vezes na taxa de mortalidade (Risco $17.9 \%$, Lesão 
$27.7 \%$ e Falência $33.2 \%$ ) e prolongamento da internação por quase dois dias nos casos mais graves foi descrita (Bagshaw et al. 2008). Incluindo a classificação de LRA por débito urinário do RIFLE, esses pacientes apresentaram uma incidência similar de 35,8\% e taxa de mortalidade maior que a do estudo anterior (Risco $20.9 \%$, Lesão 45,6\% e Falência 56,8\%) e do que os pacientes de UTI sem LRA, 8,4\% (Ostermann and Chang 2007). Com a nova classificação de AKIN e KDIGO, a incidência de LRA e a mortalidade se mantiveram próximas a esses valores com incidência de $39,3 \%$ (83\% deles desenvolveram LRA nos dois primeiros dias) e taxa de mortalidade em 90 dias de 33,7\% (29\% estágio 1, 34\% estágio 2 e 39\% estágio 3) (Nisula et al. 2013). Esses dados sugerem que aproximadamente, a cada nove pessoas que entram na UTI, três desenvolvem LRA e uma morre.

Já em pacientes que sofreram cirurgia cardíaca a incidência de LRA varia, pois é influenciada pelo tipo de operação (Chertow et al. 1997), e pode chegar a $30 \%$ em uma cirurgia mais delicada como as que envolvem o arco aórtico (Arnaoutakis et al. 2007). Pacientes que desenvolvem LRA pós-cirurgia cardíaca aumentam em 1,28 a taxa de mortalidade (Hobson et al. 2009) comparado àqueles que não apresentam lesão renal. A NTA aparece como o tipo de lesão mais frequente nesses pacientes (Sutton et al. 2002).

Apesar da LRA ser mais presente em pacientes em UTI e póscirurgia cardíaca, esta não pode ser considerada apenas como uma complicação desses tratamentos, (Levy et al. 1996), sendo imprecindível a sua prevenção num cenário médico mais amplo (Poch 2013).

Em indivíduos saudáveis, a incidência de LRA é maior em pacientes com mais de 55 anos, homens e negros (United States renal data system, 2012), sendo a isquemia a principal causa da LRA em pacientes idosos (Gong et al. 2012).

No Brasil cerca de 10 milhões de pessoas são vítimas de complicações renais, sendo que desse total, 2 milhões sofrem com doenças renais crônicas e $60 \%$ não sabem que têm problemas, podendo levar a complicações, vindo a perder o órgão ou mesmo a falecer (SBN, 2009). 


\subsubsection{Diagnóstico}

As manifestações clínicas iniciais das lesões renais são: presença de fadiga, letargia, fraqueza geral, anorexia, náuseas e vômitos e insônia (Smeltzer et al. 2010). Já nos casos mais graves inclui a retenção de líquido com edemas e anemia (Riella 1996). Sintomas estes que se assemelham aos de diversas outras doenças e se desenvolvem lentamente, dificultando a identificação precoce da doença.

O padrão ouro para a medida da taxa de filtração glomerular são os ensaios com substâncias exógenas como a inulina, iohexol, iotalamato ou o radiofármaco DTPA, pois são completamente filtradas, e secretadas, ou seja, não reabsorvidas ou metabolizadas pelos túbulos renais (Levey 1990). É uma técnica que consiste em uma infusão venosa constante e individualizada, com coleta urinária periódica para contabilizar a depuração dos metabólitos. No entanto, esta técnica é inviável na rotina clínica, visto que além do alto custo e uso de reagentes radioativos (inulina e DTPA), também é necessária a hospitalização do paciente (Macedo 2011).

Assim, na clínica, a avaliação renal tem sido realizada principalmente pelos ensaios sanguíneos de uréia e creatinina, podendo também serem utilizados dados provenientes de exames urinários de proteinúria, excreção de íons e uma análise descritiva da urina. A uréia sérica, apesar de utilizada para avaliar a função renal, não varia só com a taxa de filtração glomerular (TFG), mas também com a ingestão proteica, hemorragias, desidratação e medicamentos como corticoides. Além disso, ela subestima a TFG, pois é parte reabsorvida nos túbulos renais (Macedo 2011).

Atualmente, o melhor teste para o diagnóstico de LRA é o da creatinina sérica. No entanto, este também apresenta alguns problemas. A creatinina sérica ou plasmática é pouco sensível e só se encontra alterada com uma redução de ao menos $50 \%$ na ultrafiltração glomerular (Shemesh et al. 1985), podendo variar com a massa muscular, idade, gênero, metabolismo e hidratação do indivíduo. Além disso, a creatinina sérica pode superestimar a função renal através da sua secreção tubular, quando há redução da TFG, ou mesmo, demorar a alcançar o equilíbrio necessário para 
a acurácia da medida, podendo levar dias para se estabilizar, dificultando assim, o diagnóstico precoce e a condução clínica de pacientes.

Exames que avaliam a proteinúria e albuminúria não representam alta contribuição para o diagnóstico de LRA, devido essas alterações estarem mais presentes em glomerulopatias; podem ser úteis no diagnóstico e tratamento de lesão tubular comparado às lesões glomerulares, pois em lesões tubulares, a maioria das proteínas detectadas são menores que a albumina (Hofmann and Guder 1989).

\subsection{OXIGENAÇÃO RENAL}

\subsubsection{Distribuição do oxigênio renal}

A oxigenação de um órgão é dada pela razão percentual entre o oxigênio consumido e o oxigênio fornecido ao órgão pelo sangue. $\mathrm{O}$ aporte de oxigênio renal é alto comparado ao seu consumo, que só não é maior que o coração, consumindo 10L/min e $15 \mathrm{~mL} / \mathrm{min}$, respectivamente (Zäll et al. 1991) (Redfors et al. 2010). No entanto, a distribuição deste oxigênio intrarenal é heterogênea suportanto a necessidade de consumo de cada região. O maior fluxo sanguíneo é direcionado ao córtex renal para a filtração glomerular, permitindo que menos de $50 \%$ desse fluxo chegue até a região externa da medula. Esta região, formada principalmente pelos túbulos proximais e distais, tem que ter uma baixa concentração de oxigênio para a preservação da osmolaridade e concentração de urina. Ela deve, porém, ser o suficiente para síntese de ATP necessária para o transporte ativo de íons, glicose e aminoácidos. Ao atingir a medula, formada pela porção fina da alça de Henle e final do ducto coletor com pouco transporte ativo, os vasos retos, que mantém a hipertonicidade medular através do fluxo contracorrente, reduzem ainda mais a oxigenação dentro da medula (Chou et al. 1990; Redfors et al. 2010). 


\subsubsection{Regiões afetadas pela hipóxia}

Em caso de hipóxia ou isquemia três fatores determinam a região do rim a ser afetada: o quanto de energia a célula necessita, sua capacidade glicolítica e a gravidade da hipóxia à qual a célula é exposta. As células que têm uma alta capacidade glicolítica são geralmente menos sensíveis à privação de oxigênio que as células que dependem predominantemente ou exclusivamente da respiração mitocondrial (Lameire 2004). Analisando a oxigenação dos diferentes segmentos, a porção externa da medula formada pelos túbulos proximais e parte espessa da alça de Henle é a região mais crítica do rim, pois $80 \%$ de todo o aporte de oxigênio é utilizado (Redfors et al. 2010) (figura 1). Ainda, se formos comparar estas duas porções do rim, as células do túbulo proximal são mais suscetíveis à lesão do que as células da porção espessa da alça de Henle, devido às células tubulares proximais apresentarem um grande número de mitocôndrias e uma menor capacidade glicolítica. As células dos túbulos distais, apesar de receberem pouco oxigênio, necessitam de pouca energia e têm alta capacidade glicolítica sendo mais difíceis de serem lesadas pela hipóxia (Lieberthal and Nigam 1998).

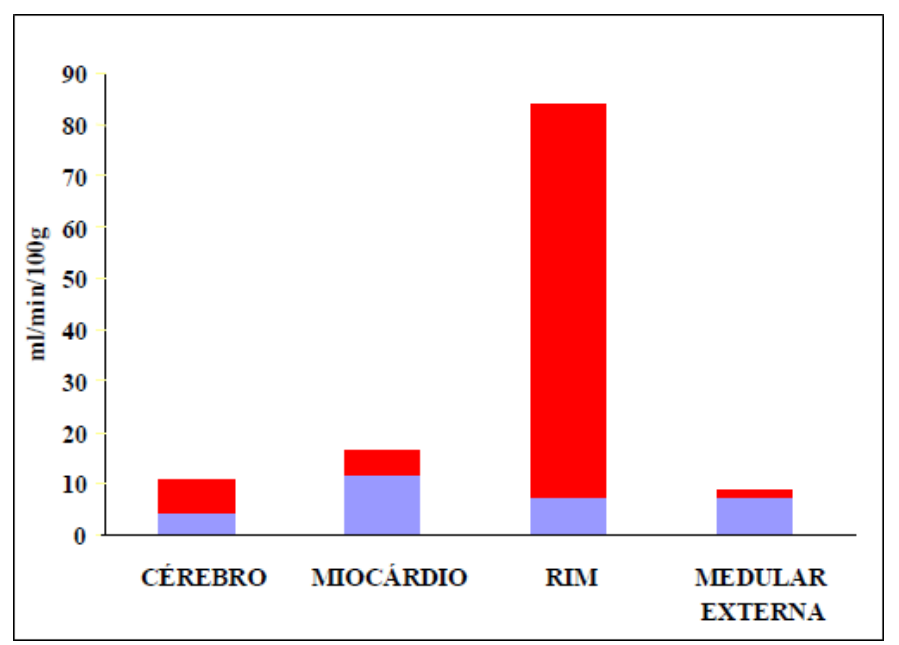

Figura 1 - O rim recebe uma quantidade de oxigênio muito superior à necessária, porém a região medular externa consome mais de $80 \%$ do aporte de oxigênio, superando cérebro e miocárdio. A porção azul da barra representa o consumo de oxigênio, enquanto a altura total da mesma representa o aporte total de oxigênio ao tecido (Zatz 2011). 


\subsection{ISQUEMIA E REPERFUSÃO RENAL}

\subsubsection{Definição e principais causas.}

A isquemia renal é uma das principais causas de LRA (Thadhani et al. 1996), e em casos em que não há reperfusão em um curto intervalo de tempo, pode levar à DRC (Preston and Epstein 1997).

A isquemia renal é o resultado de um declínio generalizado ou localizado do suporte de oxigênio e nutrientes para os tecidos, além de um déficit na remoção de resíduos do metabolismo (Le Dorze et al. 2009). Apesar de não se conhecer a severidade e duração da isquemia capaz de levar à lesão renal em humanos (Lameire 2004), quanto mais rápido o fluxo sanguíneo é restabelecido (reperfusão), maiores são as chances de a área afetada ser restaurada (Conger and Schrier 1980).

O processo de isquemia/reperfusão (I/R) ainda não foi completamente compreendido, mas já existem estudos relatando a diminuição da geração de ATP mitocondrial, perda da permeabilidade seletiva das membranas celulares, diminuição da homeostase iônica celular (aumento de sódio e cálcio), ativação de hidrolases, inflamação e alteração da resposta vascular (Devarajan 2006).

Medicamentos e diversos estados patológicos como: a obstrução dos vasos (trombose e estenose), vasculites, hipovolemia, hipotensão, entre outras, estão entre as causas da isquemia (Thadhani et al. 1996).

\subsubsection{Consequências}

\subsubsection{Respostas vasculares}

A isquemia é responsável pela redução na TFG em portadores de LRA. No entanto, o declínio do fluxo sanguíneo sozinho não é capaz de reduzir a TFG durante o início LRA (Bonventre 2003)(Schrier et al. 2004).

Respostas vasculares surgem como consequência da falta de nutrientes e oxigênio para o tecido, na tentativa de se evitar a perda dos nutrientes restantes e restabelecer o fluxo sanguíneo. Inicialmente, ocorre uma resposta vasoconstritora, tanto nas arteríolas glomerulares, quanto nos vasos retos que alimentam a medula externa. Com a redução do ATP, há 
uma redução na reabsorção de cloreto de sódio que é transportado para a mácula densa, levando a vasoconstrição da arteríola aferente, com o objetivo de diminuir a TFG (feedback túbulo-glomerular) e a consequente perda de mais energia (Rosen and Stillman 2008) (Schnermann 2003). Nas arteríolas, principalmente dos vasos retos, ocorre um aumento do estímulo nervoso simpático e um aumento abrupto de vasoconstritores como a endotelina 1, angiotensina II, tromboxano A2, prostaglandina $\mathrm{H} 2$, leucotrienos C4 e D4 e adenosinas (Conger and Schrier 1980) (da Silveira et al. 2010), acarretando em prejuízo, principalmente para as células da medula externa (Basile 2007).

A isquemia também lesa células endoteliais que, após o insulto, apresentam perda do glicocálice, desarranjo do citoesqueleto e diminuição da adesão celular com desestruturação da matriz perivascular, aumento da permeabilidade microvascular e vazamento do fluido para dentro do interstício (Basile 2007). Além disso, ocorre uma redução dos vasodilatadores acetilcolina, bradicinina e óxido nítrico (Kwon et al. 2009) (Conger 1983) e aumento da adesão leucocitária, capaz de ocluir pequenos vasos e produzir citocinas inflamatórias (Bonventre and Zuk 2004).

Interessantemente, mesmo após a reperfusão essas respostas vasculares persistem e são agravadas pelo aumento do estresse oxidativo. A consequência de todos esses fatores é a redução na TFG, levando ao desarranjo na homeostase do organismo como um todo.

\subsubsection{Respostas tubulares - Necrose tubular aguda (NTA)}

A isquemia pode induzir a morte de células tubulares, a chamada necrose tubular aguda, termo empregado a tecidos que apresentam lesão estrutural renal. No entanto, o termo "necrose" neste contexto, refere-se tanto a necrose quanto a apoptose celular que tem sido relatada em diversos modelos animais de isquemia (Supavekin et al. 2003) (Wei et al. 2006) e em pacientes (Hauser et al. 2004). A contribuição relativa destes dois tipos de morte celular ainda é controversa, e parece depender da intensidade do evento causador. Com a isquemia mais intensa, células do túbulo proximal e porção espessa da alça de Henle, que são mais susceptíveis à isquemia, 
tendem a sofrer maior taxa de necrose em comparação com os segmentos menos sensíveis como os túbulos distais que sofrem apoptose (Gobé et al. 1999) (Oberbauer et al. 1999). No entanto, há indícios também de "necrose secundária", como em casos em que as células apoptóticas não são removidas rapidamente (Lameire 2004).

A necrose ocorre em decorrência de lesão celular grave, com isquemias por longo tempo devido à grande redução no ATP, que leva ao aumento do influxo de cálcio e aumento de espécies reativas de oxigênio (EROs) e enzimas proteolíticas. Já para a apoptose ocorrer, é preciso que haja um mínimo de energia para a condensação da cromatina, desintegração do DNA e de mitocôndria e redução do tamanho da célula. Portanto, a apoptose ocorre em casos de agressão mais leve, já que este é um processo ativo que requer a participação da própria célula (Lameire 2004). No início da NTA, há indícios de que a necrose e a apoptose ocorram simultaneamente (Kaushal et al. 2004), apresentando um caráter ambíguo, ao mesmo tempo em que danifica o túbulo renal o protege de possíveis células danificadas (Devarajan 2006).

A NTA histopatologicamente é caracterizada por supressão e perda da borda em escova dos túbulos proximais, perda do formato dos túbulos, dilatação dos túbulos proximais e distais, obstrução dos túbulos por morte celular e áreas de regeneração (Racusen and Solez 1992).

As proteínas denominadas $\mathrm{Na}^{+} \mathrm{K}^{+}$ATPase e integrinas, são responsáveis pela manutenção da polaridade da célula e suas junções com as células vizinhas para manutenção do formato tubular. Com a I/R, estas proteínas deslocam-se de suas posições na porção basolateral da membrana para a porção apical (borda em escova) do túbulo proximal e desestabilizam o aparato do citoesqueleto, levando a perda estrutural do túbulo com a descamação de células viáveis para o lúmem com possível obstrução deste e extravasamento de filtrado glomerular para o interstício. Devido ao aumento de cálcio intracelular e EROs gerados pela isquemia, a necrose e/ou apoptose das células tubulares também contribue para obstrução do lúmem. Além disso, o deslocamento da $\mathrm{Na}^{+} \mathrm{K}^{+}$ATPase leva a perda da polaridade responsável pela reabsorção de metabólitos do filtrado glomerular 
(Devarajan 2006) (Figura 2). Isso acarreta no prejuízo da reabsorção de sódio tubular e, consequente, aumento da fração de excreção de sódio e redução da TFG por feedback túbulo-glomerular no intuito de economizar energia (Rosen and Stillman 2008) (Schnermann 2003), (Devarajan 2006).

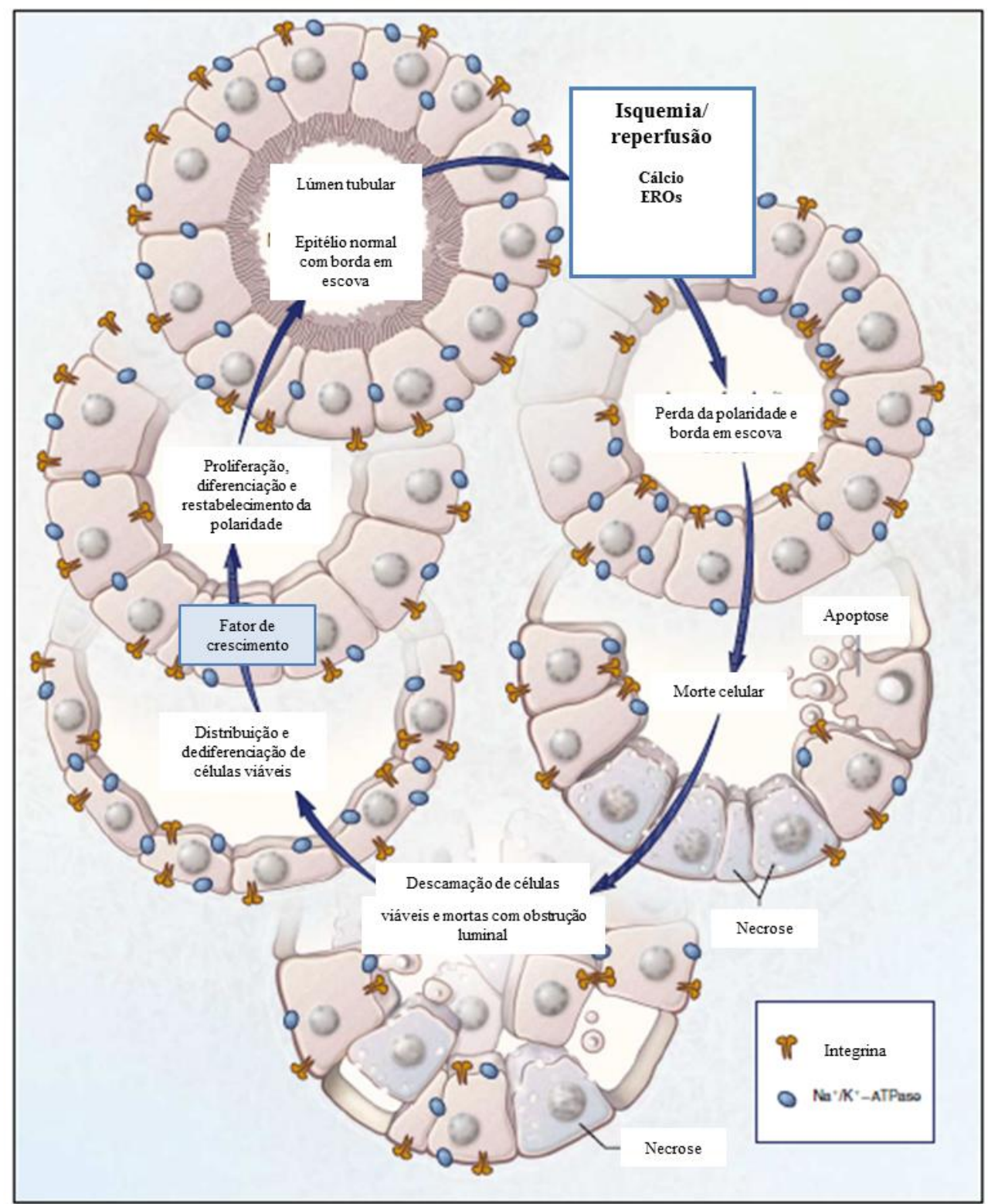

Figura 2 - Lesão e reparo tubular na lesão renal aguda. Após a isquemia/reperfusão ocorre perda da borda em escova dos túbulos proximais, perda de polaridade e redistribuição de integrinas e $\mathrm{Na}+\mathrm{K}+\mathrm{ATPase}$ para a superfície apical com perda do formato tubular. Cálcio e espécies reativas de oxigênio atuam nestas alterações com subsequente morte celular por necrose e/ou apoptose. Células viáveis e inviáveis descamam e seguem para o lúmen obstruindo-o e reduzindo a taxa de filtração glomerular. O rim pode se restaurar completamente espalhando e desdiferenciando células viáveis para substituir as lesionadas. Diversos fatores de crescimento ajudam na restauração dos epitélios tubulares. Esquema modificado de Thadhani et.al, 1996. 
A NTA é uma lesão reversível quando diagnosticada rapidamente, células viáveis se distribuem entre as áreas lesionadas, desdiferenciam e restauram o túbulo danificado (Thadhani et al. 1996). No entanto, até pouco tempo, devido às antigas biopsias renais serem feitas apenas na superfície do córtex, não era possível diagnosticar a NTA. Somente, com a biopsia mais interna, entre o córtex e a medula, foi possível diagnosticá-la em humanos (Han et al. 2002)(Vaidya et al. 2008).

\subsubsection{Processo inflamatório}

A I/R gera uma resposta inflamatória do organismo, e acredita-se que esta resposta seja a mais importante causa das lesões. A I/R ao lesionar o endotélio e aumentar as moléculas de adesão e a permeabilidade microvascular, irá potencializar as interações com leucócitos e plaquetas, conduzindo possivelmente à obstrução mecânica dos vasos sanguíneos pequenos (Bonventre and Zuk 2004). Essas interações leucócito-endotélio são mediadas por quimiocinas reguladas por citocinas inflamatórias como IL-1 e TNF- $\alpha$ e EROs (Donnahoo et al. 1999). Incialmente os neutrófilos são mais abundantes, sendo substituídos em relação à quantidade por macrófagos e linfócitos T na fase de recuperação (Cao et al. 2004).

Além das células endoteliais, as células epiteliais tubulares também colaboram para a resposta inflamatória, produzindo citocinas próinflamatórias e modulando a atividade de linfócitos (Bonventre and Zuk 2004).

\subsubsection{Estresse oxidativo}

A NTA e a disfunção orgânica geradas pela I/R renal têm como um dos seus indutores o aumento das espécies reativas de oxigênio e nitrogênio durante isquemia, e principalmente após a reperfusão, devido ao aumento abrupto do suporte de oxigênio. O estresse oxidativo desencadeia a peroxidação lipídica, levando a destruição das membranas celulares, quebra de DNA, além de oxidação ou nitração de proteínas para estados inativos (Li and Jackson 2002).

O principal mecanismo de estresse oxidativo dos túbulos renais 
gerado pela $\mathrm{I} / \mathrm{R}$, está associado a conversão da hipoxantina em xantina, que induz o aumento de peróxido de hidrogênio e superóxido na célula. $\mathrm{Na}$ presença de ferro $\left(\mathrm{Fe}^{++}\right)$, o radical peróxido de hidrogênio torna-se um radical hidroxil altamente oxidativo e tóxico à célula. Já, o superóxido reage rapidamente com o óxido nítrico $(\mathrm{NO})$, formando o peroxinitrito $\left(\mathrm{ONOO}^{-}\right)$ que danifica a célula com sua capacidade de oxidação, nitrosilação e nitração de proteínas (Devarajan 2005). Figura 3.

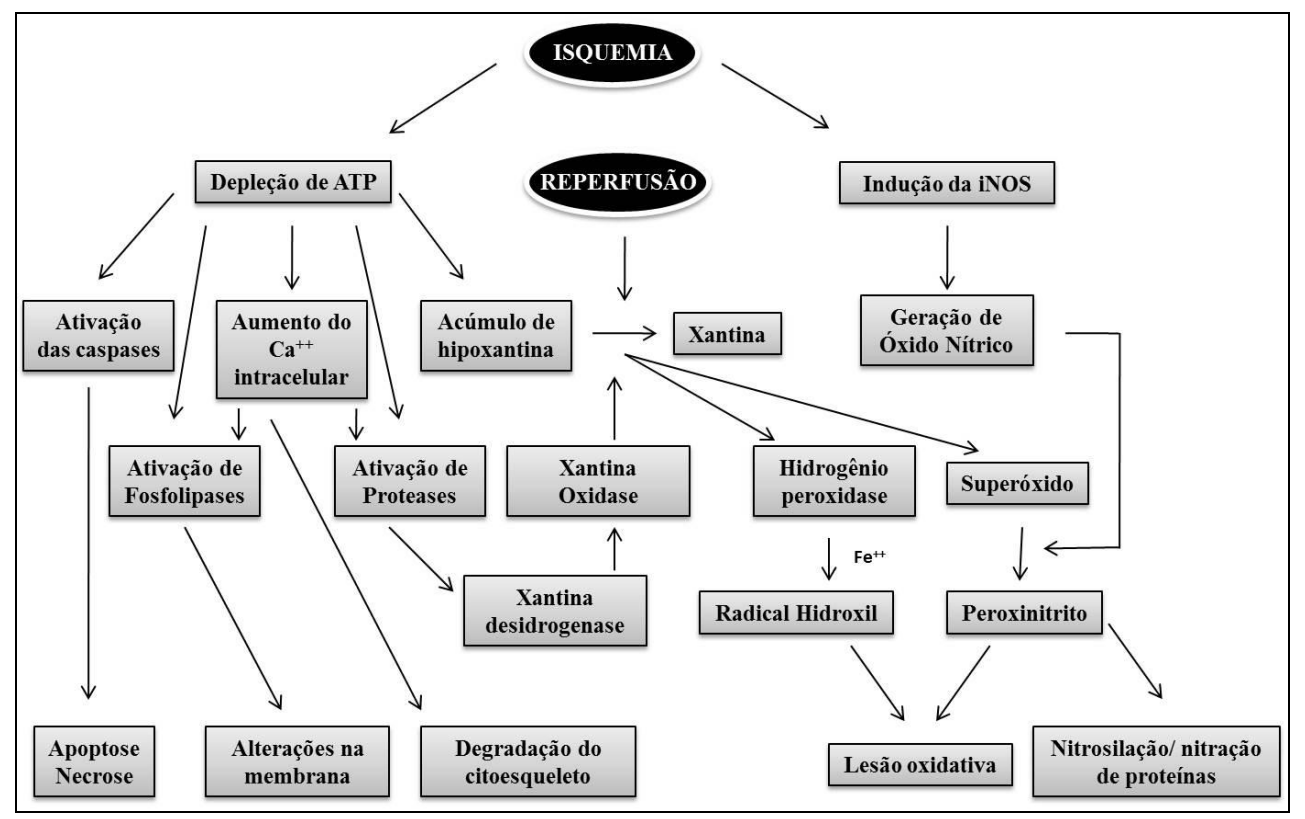

Figura 3 - Alterações no metabolismo das células dos túbulos após LRA isquêmica. A fase inicial da isquemia é caracterizada pela depleção de ATP, que através da ativação de caspases, fosfolipases e aumento de $\mathrm{Ca}^{++}$intracelular levam a morte celular. A isquemia prolongada seguida de reperfusão reduz a ativação de morte celular por necrose, mas causa lesão oxidativa e modificações proteicas, principalmente pela via da hipoxantina. Modificado de (Devarajan 2006).

A reação do $\mathrm{ONOO}^{-}$com a tirosina da proteína é rápida e irrevesível, tornando a nitração proteica uma forma indireta de dosagem de estresse oxidativo, que têm sido utilizada em diversos estudos. Em modelos animais de isquemia têm-se observado aumento de proteínas nitradas no rim após 6 e 24h de reperfusão (Chiao et al. 1997) (Walker et al. 2000). 


\subsection{BIOMARCADORES}

\subsubsection{Definição}

Biomarcadores são aqueles definidos como capazes de se alterar antes ou em paralelo ao desenvolvimento das lesões e que estão altamente correlacionados com o desenvolvimento da doença. Eles devem estar intimamente relacionados com o tamanho da lesão, serem passíveis tecnicamente de detecção, e se alterarem com a redução da mesma. Além disso, devem de preferência ser de fácil aquisição como por métodos nãoinvasivos (Goodsaid et al. 2009).

A creatinina sérica, até o momento, continua sendo o principal biomarcador de LRA, mesmo sendo tardia e não diagnosticando lesão estrutural inicial sem perda da função renal. Isso porque até o momento, não foi descoberto um biomarcador melhor, sendo de extrema importância a descoberta de novos biomarcadores para LRA, principalmente para I/R renal que é uma das principais causas, para que a lesão possa ser revertida e o rim preservado (Macedo et al. 2008).

Assim, diversos biomarcadores têm sido estudados (Simsek et al. 2013), sendo os mais promissores para LRA a lipocalina associada com gelatinase de neutrófilos - NGAL (do inglês Neutrophil gelatinaseassociated lipocalin), Molécula 1 de lesão renal - KIM-1 (do inglês kidney injury molecule 1), interleucina-18 (IL-18), proteina ligada a ácidos graxos no fígado - L-FABP (do inglês liver fatty acid binding proteins), inibidor tecidual de metaloproteases 2 TIMP-2 ( do inglês tissue inhibitor of metalloproteinases 2), e proteína ligadora do fator de crescimento ligado à insulina 7 de proteína IGFBP7 (do inglês insulin growth factor-binding protein 7) (Lieske et al. 2014).

\subsubsection{NGAL}

A NGAL faz parte das proteínas da família das lipocalinas que transportam pequenas moléculas hidrofóbicas como esteroides e lipídios (Kjeldsens et al. 1993) e sequestra ferro via sideróforos impedindo a ligação deste com EROs, prejudicial as células. (Mori et al. 2005). Ela tem-se 
destacado como marcador de lesão de túbulo proximal (Schmidt-Ott et al. 2007).

A NGAL, urinária ou sérica, é o biomarcardor mais promissor na literatura até o momento, e já está sendo aplicado a estudos clínicos (Nguyen and Devarajan 2008)-(Mishra et al. 2005). A NGAL é facilmente detectada no plasma ou na urina após I/R, aparecendo aumentada de 2 a $6 \mathrm{~h}$ após o desenvolvimento de uma lesão renal aguda em pacientes (Mishra et al. 2005).

No entanto, apesar de aparentemente sensível é um marcador pouco específico, pois esta proteína é expressa por neutrófilos e vários epitélios; além de apresentar aumento de expressão pelo túbulo distal com LRA, podendo seus resultados serem influenciados por doenças sistêmicas ou renais pré existentes e ainda infecções do trato urinário (Nickolas et al. 2008). Estudos da NGAL em modelo suíno de isquemia detectaram aumento nas concentrações urinárias de animais isquêmicos (Silberstein et al. 2013)-(Hunter et al. 2012). Avaliações séricas de NGAL mostraram aumento desta em 48h pós transplante (Jochmans et al. 2011) e após 8 horas de I/R bilateral de 120 minutos de isquemia com grande lesão (Matějková et al. 2013).

\subsubsection{KIM-1}

A KIM-1 é um receptor de fosfatidilserina responsável pela depuração dos detritos apoptóticos do lúmen tubular, direcionando as células mortas para os lisossomos, evitando a ativação da resposta imune. Além disso, esta molécula também está relacionada com a fagocitose pelas células proximais de lipoproteínas oxidadas e células necróticas. (Ichimura 1998). Após I/R os níveis de KIM-1 aumentam abruptamente no túbulo proximal (Ichimura 1998) (Vaidya et al. 2008), e seus níveis teciduais e urinários podem ser utilizados como biomarcadores de LRA (Vaidya et al. 2006) (Han et al. 2002). Pacientes com NTA isquêmica apresentaram biopsias com enorme expressão de KIM-1 e maior excreção urinária desta proteína comparada a outros tipos de lesões renais (Han et al. 2002). 
O aumento de KIM-1 urinária pôde prever LRA em pacientes após 3h de cirugia cardíaca (Han et al. 2009) e foi altamente correlacionado aos altos índices de diálise e morte em pacientes em UTI (Liangos et al. 2007). No entanto, o aumento da KIM-1 não é específico para LRA, pois está relacionada com um amplo número de doenças renais como glomerulonefrites, nefropatias, rejeição aguda, hipertensão entre outras (Timmeren et al. 2007).

\subsubsection{IL-18}

A IL 18 é uma citocina pró inflatória sintetizada por macrófagos, monócitos e células epiteliais do túbulo proximal renal (Simsek et al. 2013). Pacientes com rejeição a transplantes têm apresentado níveis elevados de IL-18 no córtex renal e no soro comparado àqueles sem complicações (Striz et al. 2005). Através dos níveis de IL-18 na urina, conseguiram predizer a LRA em pacientes após 4-6 horas da cirurgia cardíaca (Parikh et al. 2006) e correlacionar seus valores com o aumento de internação dos pacientes em UTI (Parikh et al. 2011).

\subsubsection{L-FABP}

O L-FABP é responsável pela transferência de ácidos graxos entre as membranas intracelular e extracelular (Simsek et al. 2013) e tem sido correlacionada com o fluxo sanguíneo capilar, tempo de isquemia, transplante renal e tempo de hospitalização (Yamamoto et al. 2007).

A elevação urinária do L-FABP foi capaz de predizer pacientes que terão LRA após $4 \mathrm{~h}$ de cirurgia cardíaca e ainda relacionar-se com nefropatias (Yokoyama et al. 2009), nefrotoxicidade (Negishi et al. 2009) e choque séptico (Nakamura et al. 2009).

\subsubsection{TIMP-2 e IGFBP-7}

O TIMP-2 é um inibidor tecidual de metaloproteinases, com papel importante na modulação da proteólise da matriz extracelular e única entre 
os membros da família TIMP, capaz de suprimir diretamente a proliferação de células endoteliais (NCBI).

A IGFBP-7 tem um papel importante no crescimento, diferenciação e proliferação celular de mamíferos, atuando como um potencial supressor tumoral para diversos tipos de câncer (Chen et al. 2013).

Ambas as proteínas estão envolvidas com o a parada do ciclo celular em G1 durante as fases iniciais da lesão celular (Seo et al. 2006). Semelhante a outros epitélios, as células tubulares renais possuem um curto período de G1 para detenção do ciclo celular após lesão por septicemia (Quan-hui et al. 2009) ou isquemia (Witzgall et al. 1994). Acredita-se que esta parada celular evita que DNAs danificados sejam replicados nas células filhas; em G1 a célula fica esperando o seu reparo ou segue para morte celular (Rodier et al. 2007). Durante a LRA, proteínas como TIMP-2 e IGFBP7 na urina podem fornecer uma marcação, antes mesmo da lesão do epitélio renal, podendo este ser recuperado sem danos permanentes ao órgão (Kashani et al. 2013).

Além da isquemia, uma grande variedade de processos fisiológicos e patológicos (inflamação, estresse oxidativo, diminuição da proliferação celular, radiação ultravioleta, drogas e toxinas) (Johannes, Boonstra and Jan Andries 2004) podem levar a alterações nessas proteínas, o que pode ajudar na compreensão da LRA com diversas outras etiologias. Em um estudo multicêntrico, TIMP-2 e IGFBP-7 urinárias foram considerados os melhores biomarcadores de LRA comparado aos demais citados anteriormente. Devido o IGFBP-7 ter sido superior a TIMP-2 em pacientes cirúrgicos, e o TIMP-2 ter sido melhor em LRA induzida por sepse, ambas foram usadas juntas no diagnóstico de LRA (Kashani et al. 2013).

Apesar de vários candidatos a biomarcadores renais, nenhum deles apresentou, até o momento, características ideais para um biomarcador, seja pela inespecificidade ou mesmo falta de sensibilidade. Assim como a TIMP2 e IGFBP-7 juntas aumentaram o poder de detecção da LRA (Kashani et al. 2013), outros estudos unindo diversos desses marcadores também conseguiram aumentar a sensibilidade na detecção da doença (Han et al. 
2009), sendo sugerido um painel desses biomarcadores para o diagnóstico da LRA (Simsek et al. 2013).

\subsubsection{Normalização da concentração urinária}

Por fim, existe uma preocupação com a concentração desses biomarcadores urinários na LRA devido a hidratação e fluxo urinário de cada amostra e de cada indivíduo. Atualmente para normalização destes aspectos é feita a normalização por creatinina urinária. Em pessoas saudáveis a excreção de creatinina é estável, diferente dos pacientes com LRA em que a creatinina urinária se altera com mudanças dinâmicas iniciais e durante a fase de recuperação da TFG. Portanto, os biomarcadores urinários normalizados pela variável creatinina continuam apresentando o mesmo problema da dosagem por creatinina sérica, podendo apresentar falhas nos valores bioquímicos dos biomarcadores de LRA (Waikar et al. 2011).

Em estudos clínicos, a normalização de biomarcadores urinários a concentração de creatinina urinária melhorou a predição de LRA, mas não no diagnóstico de LRA estabelecida (Ralib et al. 2012). Talvez, a análise sanguínea possa apresentar biomarcadores tão sensíveis e específicos quanto os da urina sem a interferência nutricional e de metabolização como acontece na urina.

\subsection{MODELO DE ISQUEMIA/REPERFUSÃO RENAL}

Os modelos animais surgem com o objetivo de se obter respostas fisiológicas a um único insulto estudado. Eles apresentam vantagens por se tratar de um organismo completo (diferente de estudos celulares), não serem portadores de outras doenças e seus órgãos poderem ser analisados funcionalmente e estruturalmente. Portanto, são ideais para estudos de respostas fisiológicas e patológicas, tratamentos e descoberta de biomarcadores.

Diversos estudos têm utilizado camundongos (Matthijsen et al. 2007) ${ }^{-}$(Susa et al. 2009), ratos (Bhalodia et al. 2009)-(Damianovich et al. 
2006), coelhos (Zhen-Qiang et al. 2012)-(Formiga et al. 2011) e cachorros (Tsuji et al. 1993)-(Yatsu et al. 1998) como modelos animais de isquemia/reperfusão renal. No entanto, para a melhor compreensão dos aspectos pato(fisiológicos) da isquemia/reperfusão renal e a identificação de novos biomarcadores é necessário um modelo controlado e com características o mais similares possíveis aos seres humanos, para que futuramente descobertas feitas neste modelo, possam ser mais próximas às reações ocorridas em pacientes.

Os porcos apresentam maiores semelhanças com os humanos em relação aos roedores, tanto no que diz respeito a sua anatomia renal (multilobular, multipapilar), quanto no que diz respeito à embriologia, sistema linfático, habilidade de concentrar urina, sistema imunológico, homologia genética e tolerância a isquemia (Lieberthal and Nigam 2000) (Piriou-guzylack and Salmon 2008)-(Lunney 2007). Sugerindo assim, que os porcos são os melhores modelos para o estudo das consequências da isquemia/reperfusão em humanos e de biomarcadores para este insulto (Lieberthal and Nigam 2000)-(Simmons et al. 2008) (Figura 4).

Os suínos têm sido utilizados amplamente em modelos pré-clínicos para doenças cardiovascular (Ho et al. 2009), intestinal (Korth U et al. 2003) e transplante renal (Jochmans et al. 2011).

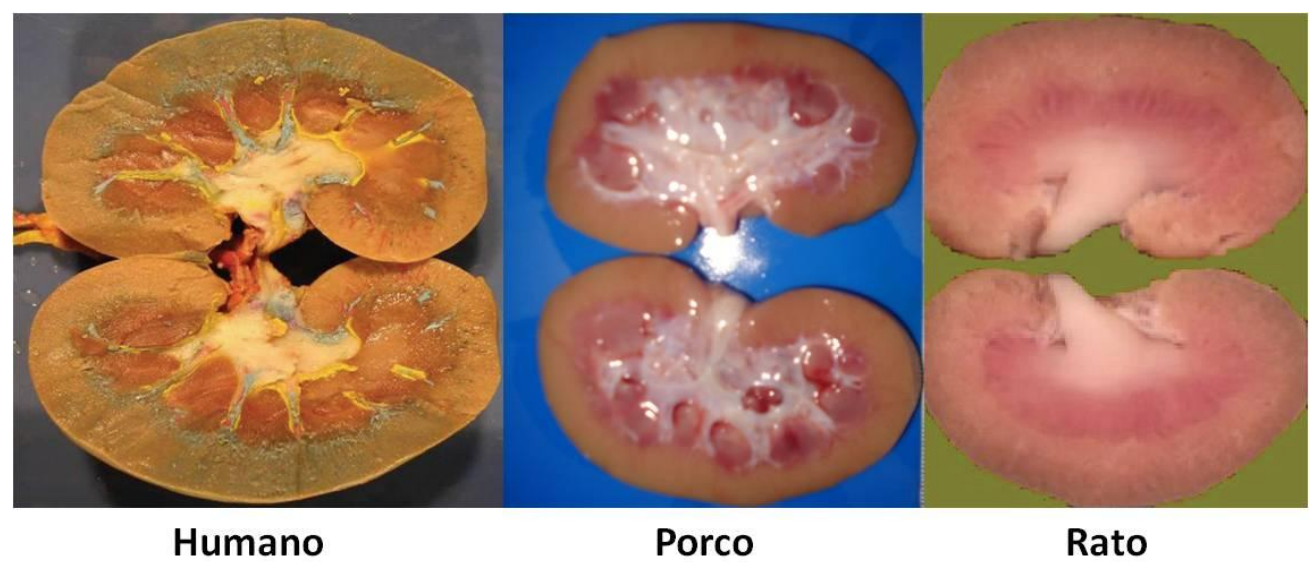

Figura 4 - Comparação morfológica entre os rins de humano, porco e rato. Os rins de suínos são mais similares aos humanos por apresentarem anatomia multilobular e arquitetura multipapilar, diferente dos rins de rato e também dos cachorros e coelhos que apresentam anatomia unilobular e arquitetura unipapilar. 


\subsection{METABOLÔMICA}

A metabolômica é o resultado final da soma de fatores genéticos e ambientais e pode ser considerada o maior preditor de fenótipo (D’Alessandro et al. 2012). É caracterizada pela identificação de eventos bioquímicos globais associados ao sistema celular e biológico (Nicholson et al. 1999). Em particular condições (pato) fisiológicas, a metabolomica é capaz de fornecer um diferenciado painel metabólico "fingerprint" permitindo uma visão de cenários complexos.

Distintas mudanças na composição metabólica podem nos fornecer uma melhor compreensão da fisiopatologia da doença, e também identificar novos biomarcadores para diagnóstico, prognóstico e monitoramento da resposta terapêutica (Holmes et al. 1997).

Há dois métodos principais para a análise metabolômica: a espectrometria de massas e a ressonância magnética nuclear (RMN). Apesar da espectrometria de massas ser uma técnica muito sensível (limite de detecção em pico molar, contra micro molar detectado na RMN) (Noto et al. 2013), e considerada padrão ouro, os protocolos envolvem grande manipulação da amostra, sendo necessárias, muitas vezes, derivações e padrões para quantificações e detecções, o que limita o número de metabólitos diretamente quantificados (Pasikanti et al. 2008).

Já a técnica de RMN é uma ótima técnica para análises não invasivas com uso de biofluidos (soro, urina) por ser não derivada, não seletiva (todos os metabólitos são analisados ao mesmo tempo), não destrutiva (as amostras podem ser reaproveitadas para outras análises) e com uso de pequenos volumes para análises. A principal vantagem desta técnica é sua análise qualitativa e quantitativa baseadas em propriedades químicas das moléculas, capazes de diferenciar até moléculas levógiras de dextrogeras (MaletMartino and Holzgrabe 2011).

Recentemente, estudos com RMN têm mostrado potenciais biomarcadores em doenças cardiovasculares (Barderas et al. 2011), hepáticas (Kalhan et al. 2012) e renais (Serkova et al. 2005) (Gao et al. 2012) (Sun et al. 2012). 
Diante deste cenário no aumento da incidência de indivíduos portadores de doenças renais crônicas ou agudas, aliado à ausência de um ensaio sensível e específico para diagnóstico e monitoramento destes pacientes, o presente estudo buscou identificar novos biomarcadores para I/R renal através da técnica de RMN a partir de um modelo suíno de isquemia e reperfusão controlada. 


\section{OBJETIVOS}




\section{OBJETIVOS}

\subsection{OBJETIVO GERAL}

$\mathrm{O}$ presente estudo tem como objetivo o desenvolvimento e caracterização de um modelo suíno de I/R renal, seguido da identificação de alterações nos perfis metabólicos séricos durante à $\mathrm{I} / \mathrm{R}$ renal aguda.

\subsubsection{Objetivos específicos}

I) Desenvolvimento e caracterização de um modelo suíno controlado de isquemia/reperfusão renal;

II) Caracterização dos metabólitos alterados durante a isquemia e reperfusão renal. 
3. MÉTODOS 


\section{MÉTODOS}

\subsection{MODELO ANIMAL DE ISQUEMIA/REPERFUSÃO RENAL AGUDA}

Para a obtenção do modelo precoce de I/R renal aguda, foram selecionadas 5 fêmeas saudáveis de porcos domésticos da espécie Sus scrofa domesticus, pertencentes à linhagem MS60 EMBRAPA e provenientes da Granja RG, Suzano - São Paulo. Os animais tinham de 8 a 12 semanas de vida e peso entre 15 e $20 \mathrm{~kg}$. Esta faixa de idade foi escolhida por não haver comprometimento da maturidade com interferências hormonais (4 a 6 meses) (Smith and Swindle 2006) e também facilitar o manejo dos animais. Todo o protocolo experimental foi aprovado pelo Comitê de Ética segundo as leis brasileiras (CAPPesq Protocolo 179/11).

Antes da realização do experimento, os animais foram clinicamente avaliados, não demostrando nenhum sintoma associado a doenças. Os animais foram aclimatizados por 48 horas para redução do estresse gerado pelo transporte dos mesmos e permaneceram 12 horas em jejum. Após a indução de I/R, eles receberam água e alimento ad libitum.

Os animais foram pré-anestesiados com uma injeção intramuscular de uma solução contendo hidrocloreto de midazolam $(0,5 \mathrm{mg} / \mathrm{kg}$, Dormonid®, Roche, Rio de Janeiro, Brasil) e cloridrato de cetamina (8 mg/kg, Dopalen®, Vetbrand, São Paulo, Brasil). Após 10-20 minutos, os animais foram anestesiados, via veia auricular, com tiopentato de sódio $\left(12,5 \mathrm{mg} / \mathrm{kg}\right.$, Thiopentax ${ }^{\circledR}$, Cristalia, São Paulo, Brasil).

$\mathrm{O}$ animal foi mantido anestesiado durante toda a cirurgia através de intubação orotraqueal (7 a 7,5 $\mathrm{mm}^{3}$, Chilecom) acompanhada do anestésico volátil isoflurano (1.5\% to $2.5 \%$ - Isothane ${ }^{\circledR}$ Baxter, Guayama, Porto Rico) em 100\% de oxigênio (Origami Ergo System - Takaoka). 


\subsubsection{Indução percutânea de isquemia renal aguda}

Para o procedimento cirúrgico, os animais anestesiados foram colocados em posição supina. Após a assepsia da região abdominal, um cateter de Foley foi suturado na bexiga urinária de cada animal para a coleta de amostras de urina.

Após a assepsia da região inguinal direita, uma bainha vascular 6 French (F) (Merit Medical's) foi introduzida por dissecção da veia femoral comum direita, seguida pela canulação com um cateter reto da veia cava inferior, acima das veias renais, para a coleta sanguínea. Para evitar a coagulação sanguínea no cateter, foram administradas 10.000 unidades de heparina $\left(\mathrm{Hemofol}^{\circledR}\right.$, Cristalia, São Paulo, Brasil). O cateter foi preso à pele dos animais com pontos na parte dorsal. Outra bainha vascular foi introduzida por dissecção da artéria femoral comum direita com a cateterização da artéria renal direita usando um um cateter-guia $6 \mathrm{~F}$ e uma corda-guia com 0,035 " seguida pela injeção de $5 \mathrm{~mL}$ de contraste iodado (diatrizoato de meglumina e diatrizoato de sódio, Pielograf 76\%, Bracco, Madri, Espanha) e uma angiografia basal para a confirmação da posição do cateter. O equipamento utilizado para a fluoroscopia foi o Philips BV pulsera.

Para a oclusão da artéria renal direita, uma corda-guia 0.014” (Merit Medical Systems, Inc.,Utah, EUA) foi introduzida, seguida por um cateterbalão $6 \mathrm{~F}(5 \times 20 \mathrm{~mm}$, Cordis M3 PTA dilatation catheter, NJ, USA). O tamanho do balão foi selecionado de acordo com o diâmetro e o comprimento da artéria renal e inflado até a completa oclusão da artéria renal, interrompendo o fluxo sanguíneo do rim direito por 120 minutos. Após duas horas da isquemia, o cateter-balão foi lentamente desinflado e o fluxo sanguíneo foi restabelecido, confirmado pela infusão de $20 \mathrm{~mL}$ de contraste. $\mathrm{O}$ cateter e a corda-guia foram removidos da artéria que em seguida foi suturada. Os animais foram monitorados em ventilação mecânica até o restabelecimento normal das funções vitais (pelo menos 3 horas). Durante todo o procedimento uma solução de cloreto de sódio $0,9 \%$ foi infundida a $170 \mathrm{~mL} / \mathrm{h}$ para evitar a desidratação e lesões renais decorrentes do uso do contraste radiológico. 


\subsubsection{Coleta sanguínea e urinária}

Amostras de sangue e urina foram coletadas durante $24 \mathrm{~h}$ em intervalos seriados. As amostras sanguíneas foram coletadas a partir da veia cava inferior, próxima às veias renais, em tubo Vacuette® com gel de separação para soro (Clot Activator with gel of separation, VACUETTE®). Os primeiros $4 \mathrm{~mL}$ de sangue foram descartados e coletados os posteriores $5 \mathrm{~mL}$. Para evitar a coagulação sanguínea dentro do cateter, $10 \mathrm{~mL}$ de soro eram administrados após as coletas. O sangue foi centrifugado a 2950xG por 30 minutos a $4^{\circ} \mathrm{C}$, e os soros aliquotados com inibidores de proteases (P8340 - Sigma e PMSF) e coquetéis de inibidores de fosfatase (P5726 e P0044 - Sigma). Alíquotas foram estocadas a $-80^{\circ} \mathrm{C}$ para análises posteriores ou mantidas a $4^{\circ} \mathrm{C}$ para a dosagem de creatinina e uréia.

A urina foi coletada em um coletor de urina sistema aberto, do qual eram coletados $50 \mathrm{~mL}$ de urina por período, sendo descartada a urina restante. Os tubos com as amostras de urina também foram centrifugados a 2950xG por 30 minutos para a retirada de debris celulares e estocados em freezer $-20^{\circ} \mathrm{C}$.

Todo o procedimento cirúrgico e as coletas sanguíneas e urinárias foram realizadas e aliquotadas em material estéril.

As coletas sanguíneas foram feitas antes do procedimento de indução de isquemia (0), durante a isquemia $(15,30,60,90$ e 120 minutos de oclusão) e após o início da reperfusão (135, 150, 180 minutos, e em intervalos de 60 minutos até 24 horas a patir do início de reperfusão), Figura 5.

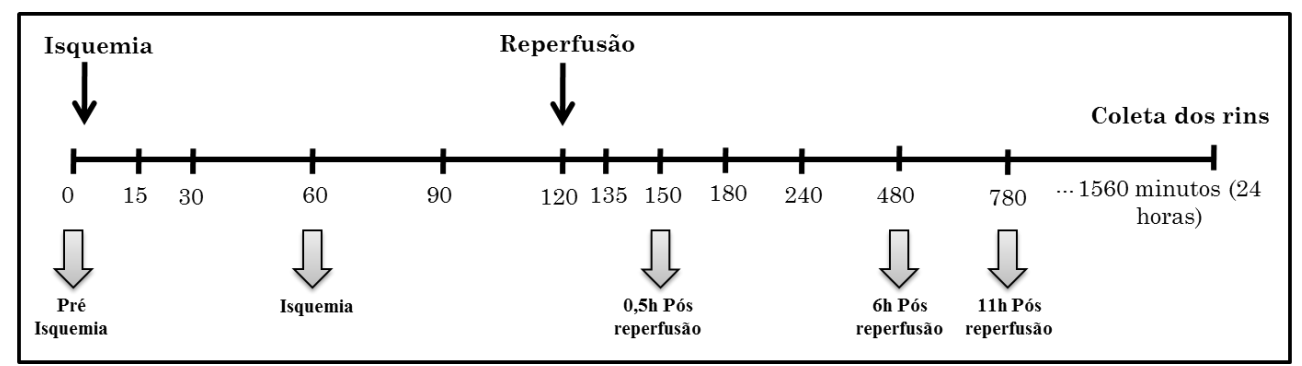

Figura 5 - Períodos das coletas sanguíneas e urinárias. Foram feitas coletas antes do procedimento de indução de isquemia (0 minutos), durante a isquemia (15, 30, 60, 90 e 120 minutos) e após o início da reperfusão $(135,150$ e 180 minutos e em intervalos de 60 minutos até completar 24 horas após o início de reperfusão). Os rins foram explantados após as $24 \mathrm{~h}$ de reperfusão. Os tempos representativos da resposta a isquemia/reperfusão, 
baseados no perfil de creatinina sérica estão representados pelas setas cinzas. Estes tempos foram selecionados para as análises de metabolômica sérica e dosagens bioquímicas urinárias.

Após 24 horas de reperfusão, o animal foi novamente pré-anestesiado com a mistura de hidrocloreto de midazolam (0,5 mg/kg; Roche), e cloridrato de Cetamina ( $8 \mathrm{mg} / \mathrm{kg}$, Vetbrands), seguido de uma dose elevada do tiopentato de sódio (30 mg/kg; Cristalia) e injeção intravenosa de 20 a $30 \mathrm{~mL}$ de cloreto de potássio $0,9 \%$ para que viessem a óbito.

\subsubsection{Dosagem de creatinina e uréia}

Para avaliação da resposta da função renal durante o procedimento de I/R renal, a creatinina e a uréia séricas foram dosadas em cada uma das amostras sanguíneas. As dosagens foram realizadas no laboratório central do Hospital das Clínicas da Faculdade de Medicina da USP através dos métodos colorimétrico cinético (método Jaffé) e cinético automatizado (UV UREASI/GLDH), respectivamente.

Os animais foram classificados com LRA de acordo com AKIN (Mehta et al. 2007), no qual o primeiro estágio da LRA é definido por um aumento nos níveis de creatinina superior ou igual a $150 \%$ do valor basal.

Com base na concentração de creatinina sérica, foram selecionados os seguintes tempos representativos para análise metabólica do soro e análises urinárias: Pré isquemia (0), Isquemia (60 minutos), Pós reperfusão (0,5h 150 minutos), Pós reperfusão (6h - 480 minutos) e Pós reperfusão (11h 780 minutos), figura 3.

\subsubsection{Análise Histopatológica}

Após as 24 horas da reperfusão do rim direito, foram retirados os dois rins para caracterização morfológica do modelo de I/R renal. Após registros macroscópicos, secções de córtex e medula foram fixados em paraformaldeído $4 \%$ por 48 horas (com trocas de paraformaldeído a cada $24 \mathrm{~h}$ devido à grande quantidade de sangue).

O material foi colocado em cassetes histológicos e processado em um ciclo de 12 horas para desidratação, diafanização e parafinização (Leica TP1020 - Leica) com 2 banhos de uma hora de álcool 95\%, 4 banhos de 
álcool $100 \%$ e 3 banhos de citrisolv e paraplast $58^{\circ} \mathrm{C}$. Os blocos foram mantidos a $-20^{\circ} \mathrm{C}$ para facilitar os cortes no micrótomo. Foram feitos cortes de $5 \mu \mathrm{m}$ de espessura e colocados em lâminas silanizadas ou com carga elétrica para uma melhor aderência dos cortes.

Para a caracterização de lesão renal após a $\mathrm{I} / \mathrm{R}$, foi feita uma coloração de Hematoxilina-Eosina e Ácido periódico de Schiff (PAS EP12-20014 - Erviegas) segundo recomendações do fabricante. As análises foram feitas por um patologista renal experiente que não conhecia o estudo, (teste cego), através da microscopia de luz. Devido à $\mathrm{I} / \mathrm{R}$ afetar primordialmete o córtex renal logo acima da medula, secções deste foram examinadas quanto a perda da borda em escova e do formato do túbulo proximal, restos celulares intratubulares e dilatação tubular, características estas da NTA. Foram analisadas lâminas de córtex isquêmico e contralateral, sendo analisados todos os campos, com áreas de aproximadamente $2 \mathrm{~cm}^{2}$. Foi realizado análise semiquantitativa de NTA em intervalos de $10-25 \%, 26-50 \%$ e $51-100 \%$ de acordo com a porcentagem de necrose na área analisada.

\subsubsection{Neutrophil gelatinase-associated lipocalin (NGAL)}

A dosagem sérica da NGAL foi feita através do kit de ELISA específico para porco (Kit 044, LOD 1 pg/mL, Bioporto, Gentofte, Dinamarca), segundo recomendações do fabricante.

\subsubsection{Excreção proteica}

A excreção urinária proteica foi quantificada através do kit Sensiprot (Labtest) segundo a recomendação do fabricante e analisada qualitativamente através de eletroforese SDS-PAGE (10\%), com posterior marcação por prata (Proteosilver Plus kit- Invitrogen). Foi submetido a eletroforese o volume de urina correspondente a $10 \mu \mathrm{g}$ de creatinina de cada amostra. Albumina de soro bovino (BSA), 2ug, foi utilizada como controle positivo. 
Para todas as análises foram feitos os pontos representativos: Pré isquemia (0), Isquemia (60 minutos), Pós reperfusão (0,5h - 150 minutos), Pós reperfusão (6h - 480 minutos) e Pós reperfusão (11h - 780 minutos).

\subsubsection{Gasometria}

A medida de $\mathrm{pH}$, pressão parcial de dióxido de carbono $\left(\mathrm{pCO}_{2}\right)$ e as concentrações de sódio, potássio e cloreto no soro e na urina foram realizadas por meio de gasometria utilizando Radiometer ABL800Flex (Radiometer Medical, Bronshoj, Demmark). O bicarbonato urinário foi calculado pela equação de Handerson-Hasselbach - $\mathrm{pH}=\mathrm{pKa}_{\mathrm{H} 2 \mathrm{CO}_{3}}+\log _{10}-$ $\left(\left[\mathrm{HCO}_{3}{ }^{-}\right] /\left[\mathrm{H}_{2} \mathrm{CO}_{3}\right]\right.$.

\subsubsection{Nitração proteica}

Com o objetivo de avaliar de maneira indireta o estresse oxidativo gerado pela I/R renal, as proteínas nitradas séricas foram quantificadas através do kit de antinitrotirosina por ELISA sandwich (Eastbiopharm China) segundo recomendações do fabricante.

Para a análise da nitração de proteínas totais na urina foi necessário concentrá-las. Em filtros com cut-off de 3kDa (Amicon, Merck Millipore) foi adicionado $4 \mathrm{~mL}$ de urina e centrifugado a $3005 \mathrm{xG}$ por 30 minutos a $4^{\circ} \mathrm{C}$. As proteínas retidas pelo filtro (concentradas 3 vezes) foram então utilizadas para análise de Dot-Blot. As amostras representativas de urina $(2 \mu \mathrm{L})$ - pré isquemia $(0)$, durante isquemia (60 minutos) e reperfusão (135, 180, 1080 minutos) foram aplicadas na membrana de nitrocelulose. Como controle da reação, foram utilizados $2 \mu \mathrm{L}$ de BSA nitrado (controle positivo) e $2 \mu \mathrm{L}$ de BSA (controle negativo). Após a secagem, a membrana foi bloqueada por 40 minutos com uma solução de bloqueio: $5 \%$ de leite desnatado em pó diluído em tampão PBST (140 mM de $\mathrm{NaCl}, 2,7 \mathrm{mM}$ de $\mathrm{KCl}, 10 \mathrm{mM}$ de $\mathrm{Na}_{2} \mathrm{HPO}_{4}$ e $1,8 \mathrm{mM}$ de $\mathrm{KH}_{2} \mathrm{PO}_{4}$ ) e adicionado $0,1 \%$ de Tween 20 - PBST 0,1\%. A membrana foi lavada 3 vezes por 5 minutos com PBST 0,1\% e incubada 2 horas sob agitação em temperatura ambiente contra o anticorpo policlonal nitrotirosina (Millipore \#06-284), na concentração $0,7 \mu \mathrm{g} / \mathrm{mL}$ (diluído na solução de bloqueio). A membrana foi 
lavada com PBST $0,1 \%$, por 3 vezes durante 5 minutos e em seguida colocada sobre agitação por 1 hora a temperatura ambiente com anticorpo secundário anti-IgG de coelho marcado com fosfatase alcalina (816122, ZYMED) na concentração de $0,33 \mathrm{mg} / \mathrm{mL}$. Novamente a membrana foi lavada com PBST $0,1 \%$ por 3 vezes durante 5 minutos e revelada com NBT/BCIP (Ref. 00-2209 - Invitrogen). A quantificação dos pixels foi feita pelo programa ImageQuant TL (GE). As mesmas amostras foram dosadas por Bradford (BioRad \#500-0001) para quantificar a concentração total de proteínas. A concentração de proteínas nitradas foi corrigida pela concentração total de proteínas e creatinina de cada amostra.

\subsection{METABOLÔMICA}

\subsubsection{Purificação das amostras de soro}

Devido à presença de uma grande quantidade de proteínas no soro, foi necessária a desproteinização da amostra para a melhor análise dos metabólitos através de filtração. Primeiramente, os tubos de 1,5mL com filtro de $3 \mathrm{KDa}$ (Amicon, Merck Millipore) foram lavados 4 vezes com $500 \mu \mathrm{L}$ água MilliQ por 30 minutos a $18620 \times \mathrm{xG}$ para retirada de todo o resíduo de glicerol. Em seguida foram adicionados $350 \mu \mathrm{L}$ de soro em cada tubo com filtro, e centrifugados por 2 horas a $13680 \mathrm{xG}$ a $4{ }^{\circ} \mathrm{C}$. $\mathrm{O}$ material retido foi descartado e o volume filtrado (contendo os metabólitos) foi armazenado a $-80^{\circ} \mathrm{C}$ até a análise de $\mathrm{RMN}$ no Centro Nacional de Pesquisa em Energia e Materiais (CNPEM) no Laboratório Nacional de Biociências (LNBio) em Campinas.

\subsubsection{Preparo das amostras para a análise na Ressonância Magnética Nuclear de Hidrogênio ( H $^{\mathbf{1}}$ RMN)}

Tampão fosfato $1 \mathrm{M}$ com Trimetilsilil Propionato (TSP) $5 \mathrm{mM}$ $\underline{(\mathrm{pH}=7,4)}$

Após o preparo do tampão fosfato $1 \mathrm{M}$, foi adicionado a ele como referência interna da amostra, Trimethylsilyl propionate 5mM (TSP). 
Devido à baixa solubilidade, o tampão com TSP foi deixado em banho maria até a sua completa diluição.

Primeiramente, os tubos foram tratados com metanol para evitar aderência das amostras com o plástico. Foram adicionados aos $200 \mu \mathrm{L}$ de filtrado de soro, $60 \mu \mathrm{L}$ do tampão fosfato de sódio $1 \mathrm{M}$ para equilíbrio do $\mathrm{pH}$, com TSP $5 \mathrm{mM}$ como padrão interno, $60 \mu \mathrm{L}$ de água deuterada (Deuterium oxide, 99\% Sigma) para o ajuste do campo magnético e 280uL de água MilliQ. Após a homogeneização, foi verificado o $\mathrm{pH}$, que deveria estar próximo a 7,0 . Os $600 \mu \mathrm{L}$ de amostra foram transferidos para tubos especiais de RMN.

\subsubsection{Aquisição de dados}

\subsubsection{Ajuste do aparelho}

Para as análises de metabolômica foi utilizado o aparelho de Ressonância Magnética Nuclear Agilent, Inova AS 600MHz, equipado com sonda criogênica. Os metabólitos foram avaliados pelo método de uma dimensão (1D), sendo a frequência de ressonância para o próton de $599.844 \mathrm{MHz}$

Antes da análise das amostras, foi feita uma sequencia de pulso para saturação da água com irradiação solvente no intervalo de relaxamento (4 segundos) e tempo de mistura (100 milisegundos). Os espectros foram adquiridos usando 256 scans, com pontos de $64 \mathrm{k}$, janela de $8000 \mathrm{~Hz}$, tempo de aquisição de 4 segundos e um total de pulsos no intervalo da reciclagem de 5,42 segundos. O "Shimming" foi aprimorado, ou seja, a resolução do sinal foi melhorada ao otimizar a homogeneidade do campo magnético por ajustes nos eixos espaciais $\mathrm{x}, \mathrm{y}$ e $\mathrm{z}$ da amostra dentro da sonda, para que todos os campos da amostra se situassem no mesmo campo magnético. Como referência interna foi utilizado o TSP.

\subsubsection{Análise das amostras}

As amostras preparadas foram colocadas na RMN e seus espectros obtidos. Foram analisados os inibidores de protease adicionados no soro e urina (inibidores de fosfatase e protease) e os medicamentos utilizados na cirurgia, para posterior exclusão do espectro. Os decaimento de livre 
indução (FIDs do inglês free induction decays) adquiridos foram multiplicados pela função exponencial correspondente a $0,3 \mathrm{~Hz}$ do alargamento da linha antes da transformada de Fourier. Todas as fases e linhas de base foram corrigidas manualmente e os metabólitos de todas as amostras foram identificados e quantificados utilizando o processador e a biblioteca metabólica do programa Chenomx NMR suíte 7.6 (Chenomx Inc, Edmoton, Alberta, Canadá). Esta versão da biblioteca do Chenomx contém 304 componentes espectrais gerados pela RMN.

\subsubsection{Análise estatística}

Para a verificação da normalidade das variáveis continuas foi aplicado o teste Kolmogorov-Smirnov. Posteriormente, foi feita a análise de variancia (ANOVA - One-way) para medidas repetidas com post hoc de Bonferroni, para as analises bioquímicas de caracterização do modelo de I/R renal; e teste ' $t$ ' de Student pareado para análises de diferença de expressão proteica por western blot. Para ambas as análises foi adotado como significância $p<0,05$. Os valores foram apresentados como médiaterro padrão da média e os gráficos feitos no software GraphPad Prism 5 (GraphPad Software Inc, San Diego, CA).

A concentração dos metabólitos foi normalizada pelo z-score dentro dos valores apresentados pelo próprio animal nos diversos tempos, ou seja, foi feita a subtração da média de cada metabólito da concentração em mM encontrada, seguida pela divisão pelo desvio padrão. Os valores normalizados foram dividos em quintis e aplicado um valor corresponde ao número do quintil. As médias destes valores foram utilizadas para a geração de mapa de calor (figura 6). 


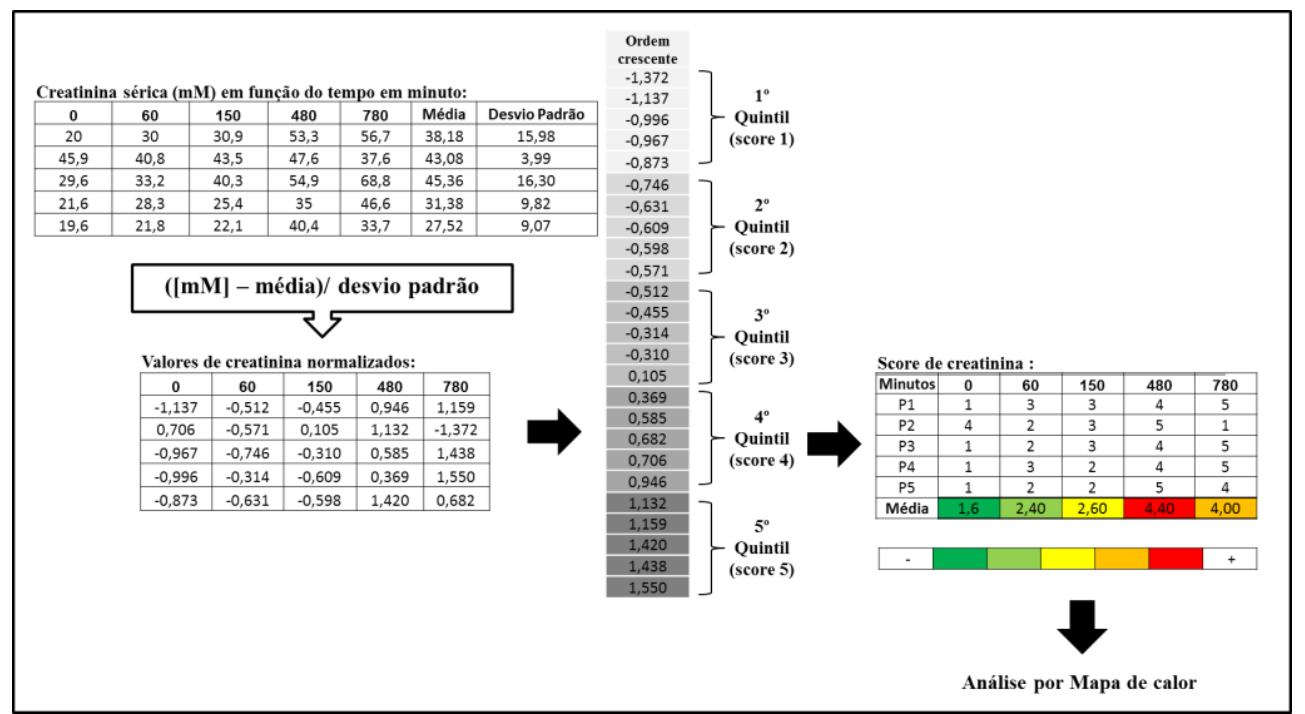

Figura 6 - Fluxograma da análise estatística por quintil. Os valores séricos em milli Molar $(\mathrm{mM})$, por exemplo da creatinina, foram normalizados dentro dos valores apresentados pelo próprio animal nos diversos tempos $(0,60,150,480,780$ minutos $)$. Foi feita a subtração da média para cada valor, seguida pela divisão pelo desvio padrão. Os valores normalizados obtidos foram colocados em ordem crescente e feita a divisão por quintil. Cada quintil recebeu um score ( 1 a 5 ) e a média destes scores foram usadas para a ilustração por mapa de calor. Esta análise foi feita para cada metabólito identificado na análise por RMN.

Análise de componente principal (PCA) e análise de discriminantes dos mínimos quadrados parciais (PLS-DA) foram feitas para identificação de metabólitos que contribuíram para discriminação dos cenários clínicos (isquemia e reperfusão).

A análise de PCA é um método não supervisionado objetivando encontrar a direção que melhor explica a variância em um grupo de dados (x) sem referência à classe (y). Já o PLS-DA é um método supervisionado que usa múltiplas técnicas de regressão multivariada para extrair, via combinação linear de variáveis originais (x), a informação que pode predizer os membros de cada classe (y).

Para avaliar a significância da discriminação das classes, foi feito um teste de permutação. Para minimizar a possibilidade de a separação observada ser dada ao acaso, foi feito um teste de permutação usando o numero ótimo de componentes determinado pela validação cross (LOOCV leave one out cross validation). Este método envolve repetir 1000 vezes a retirada de um membro da classe e colocá-lo novamente no modelo com 
diferentes randomizações, usando o teste de distância de separação (B/W). Quando a separação das classes não é ao acaso, temos que $\mathrm{p}<0,05$.

Para ranquear os metabólitos, baseado em sua importância em distinguir as classes, analisamos a variável de importância na projeção (VIP). Metabólitos com altos valores no eixo x e y são melhores para distinção das classes. As análises multivariadas de PCA e PLS-DA foram feitas no MetaboAnalyst (www.metaboanalyst.ca), assim como os gráficos obtidos com estas análises (Xia et al. 2012) (Xia et al. 2009).

\subsubsection{Análise de biologia de sistemas}

Após a análise estatística, os metabólitos responsáveis pelas separações das classes foram analisados em dois softwares para análise de vias metabólicas: MetaCore versão 6.14 (ㅂTTP://portal.geneco.com) e Ingenuity Pathway Analysis (Ingenuity systems Inc., Redwood City, CA, EUA)(HTTP//www.ingenuity.com).

As analises feitas no Metacore foram processadas usando o algoritmo shortest-path. As vias foram visualizadas graficamente através de nós representando os metabólitos e setas representando a interação com estes metabólitos. Usando este processo, vias hipotéticas foram construídas entre os metabólitos diferenciais e o banco de dados do Metacore. O enriquecimento do processo biológico foi baseado em um teste hipergeométrico e mapas de vias relevantes foram, então, priorizados de acordo com a sua significância estatística. Análise similar foi gerada pelo Ingenuity, no entanto este associou além de metabólitos, proteínas e fatores de transcrição.

\subsubsection{Western blot}

Para a extração de proteínas nucleares do córtex renal, coletado após 24 horas de reperfusão, foi utilizado o protocolo adaptado de (Kiroycheva et al. 2000). Inicialmente foi pesado setenta e cinco miligramas de córtex renal tanto do contralateral quanto do isquêmico, e lavado duas vezes com $500 \mu \mathrm{L}$ de PBS para retirar o excesso de sangue contido nos mesmos. Em seguida acrescentamos $700 \mu \mathrm{L}$ do tampão de extração I (10mM TrisHCl - pH 7,5, 
1,5mM MgCl $2,10 \mathrm{mM} \mathrm{KCl,} \mathrm{2mM} \mathrm{de} \mathrm{Dithiothreitol} \mathrm{-} \mathrm{DTT,} 20 \%$ de glicerol, inibidores de proteases (P8340 - Sigma e PMSF) e coquetéis de inibidores de fosfatase (P5726 e P0044 - Sigma)) e homogeinizamos no Dounce. Foi centrifugado por $10 \mathrm{~min}$ a $10621 \mathrm{xG}$ a $4^{\circ} \mathrm{C}$ e descartado o sobrenadante de proteínas citoplasmática. Ao pellet, foi adicionado o tampão de extração II (20mM TrisHCl - pH 7,5, 1,5 mM $\mathrm{MgCl}_{2}, 0,42 \mathrm{mM} \mathrm{KCl}, 2 \mathrm{mM}$ de Dithiothreitol - DTT, 20\% de glicerol, inibidores de proteases (P8340 Sigma e PMSF) e coquetéis de inibidores de fosfatase (P5726 e P0044 Sigma)). Após a homogeinização manual, foi centrifugado por 30min a $10621 x \mathrm{xa} 4^{\circ} \mathrm{C}$. O sobrenadante composto pelas proteínas nucleares de interesse foi coletado. A quantificação proteica foi feita por método Bradford.

Foi feito um gel de eletroforese SDS-PAGE 10\%, onde foram analisadas $50 \mu \mathrm{g}$ de proteínas totais. Em paralelo às proteínas, foram inseridos no gel dois padrões de peso molecular (BioRad Kaleidoscope \#161-0324) e (MagicMark XP Western Protein Standard, Novex \#LC5603). Após a migração das proteínas no gel, as proteínas foram transferidas para uma membrana de PVDF (GE HybondP \#25006567) no sistema submerso por 6 horas em $500 \mathrm{~mA}$ a $4^{\circ} \mathrm{C}$. Após a transferência, a membrana permaneceu por $30 \mathrm{~min}$ a $37^{\circ} \mathrm{C}$ para secagem. Em seguida, a membrana foi bloqueada por 1 hora com $5 \%$ de leite desnatado em pó diluído em tampão PBST $0,1 \%$. Após 3 lavagens com PBST $0,1 \%$, parte da membrana foi incubada com anticorpo monoclonal de coelho anti-huntingtina para região n-terminal (Abcam \#ab109115) e parte com anticorpo policlonal de coelho anti-GAPDH (Abcam \#ab22555), ambos por 16 horas a $4^{\circ} \mathrm{C}$ sob agitação na diluição recomendada pelo fabricante, diluído em 5\% BSA diluído em PBST $0,1 \%$. Após seguidas lavagens, a membrana foi incubada por 1 hora com anticorpo policlonal anti-IgG de coelho feito em cabra conjugado com HRP (Sigma \#A0545), lavada novamente e revelada pelo método de quimioluminescência (ECL). As bandas foram quantificadas pelo programa Image $\mathbf{J}$. 
4. RESULTADOS 


\section{RESULTADOS}

\subsection{CARACTERIZAÇÃO DO MODELO DE I/R RENAL}

\subsubsection{Avaliação do procedimento de isquemia/reperfusão renal}

A duração da cirurgia foi de $64 \pm 9$ minutos, desde a localização arterial até a sutura da pele do animal. Através das imagens angiográficas foi possível avaliar todo o procedimento de I/R. No início do procedimento foram obtidas imagens dos rins direito (Figura 7A e B), nas quais foi possível observar a completa irrigação do órgão antes da isquemia, sem nenhuma obstrução. Posteriormente, foram captadas imagens após a introdução do cateter-guia, já na porção proximal da artéria renal direita (Figura 7C). Com o cateter guia posicionado, pode-se observar o cateter balão ocluindo totalmente a artéria renal, confirmando a isquemia total do rim direito, sem irrigação por vasos ramificados (Figura 7D e E). Após 120 minutos de oclusão, para confirmar a reperfusão, uma última imagem foi feita mostrando o retorno do fluxo sanguíneo para o órgão (Figura 7F). Nenhum espasmo significante, capaz de continuar obstruindo o fluxo renal, foi observado na artéria após a deflação do balão (seta branca na Figura 7F). Durante todo o procedimento, os animais foram monitorizados, não havendo alterações na frequência cardíaca ou na saturação do oxigênio. 

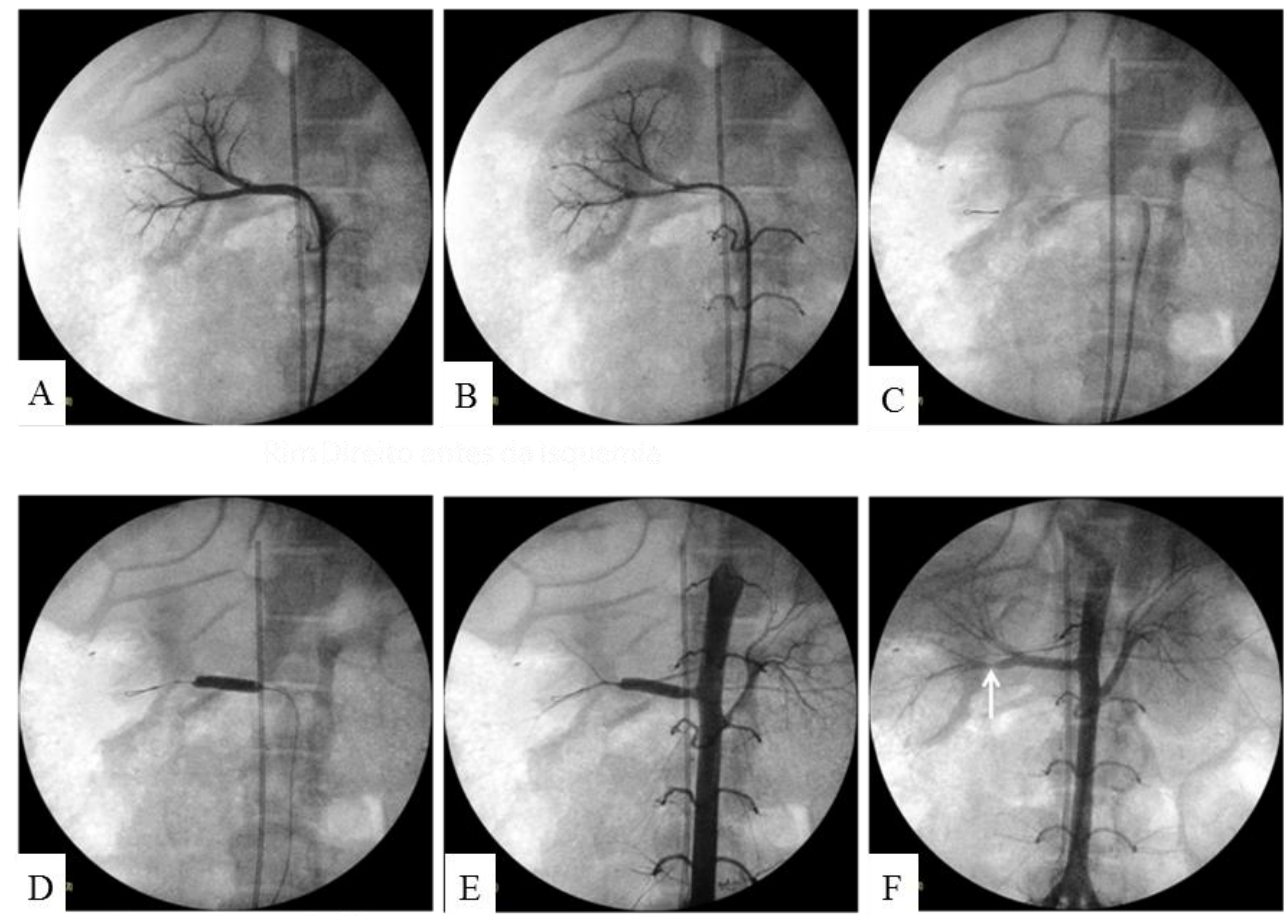

Figura 7 - Imagens angiográficas do sistema renal direito suíno obtidas durante procedimento de isquemia/reperfusão. A) Angiografia da artéria renal direita pré-isquemia demonstrando total vascularização do órgão. B) Angiografia da artéria renal direita préisquemia com total vascularização parenquimal do rim. C) Uma corda-guia de 0,014 " foi introduzida dentro da artéria renal direita,. D) Um catete-balão $5 \times 20 \mathrm{~mm}$ foi inflado na porção proximal da artéria renal direita para total oclusão do fluxo renal por 120 minutos. E) Angiografia da aorta abdominal confirmando a isquemia, com completa ocusão da artéria renal, sem vascularização.F) Angiografia final da aorta abdominal e artérias renais, mostrando a reperfusão renal com um pequeno espasmo na porção distal da artéria após a retirada do balão (seta branca), mas sem interferência na reperfusão. Note em todas as imagens um cateter localizado dentro da veia cava inferior acima das veias renais.

\subsubsection{Análise morfológica}

A morfologia apresentada pelos rins foi heterogêna entre os animais, tanto para o rim isquêmico quanto para contralateral. Os rins isquêmicos não apresentaram alterações no tamanho do órgão, apresentaram, em média, $8,5 \mathrm{~cm}$ de altura e 5,0 $\mathrm{cm}$ de largura e, exceto para o animal 1, apresentaram necrose na parte inferior ou medial em diferentres graus. Já os rins contralaterais apresentaram o mesmo tamanho dos rins isquêmicos, exceto para os animais 4 e 5 em que os rins apresentaram, aproximadamente, $10 \mathrm{~cm}$ de altura e 4,8 cm de largura, uma diferença anatômica entre os animais (figura 8). 


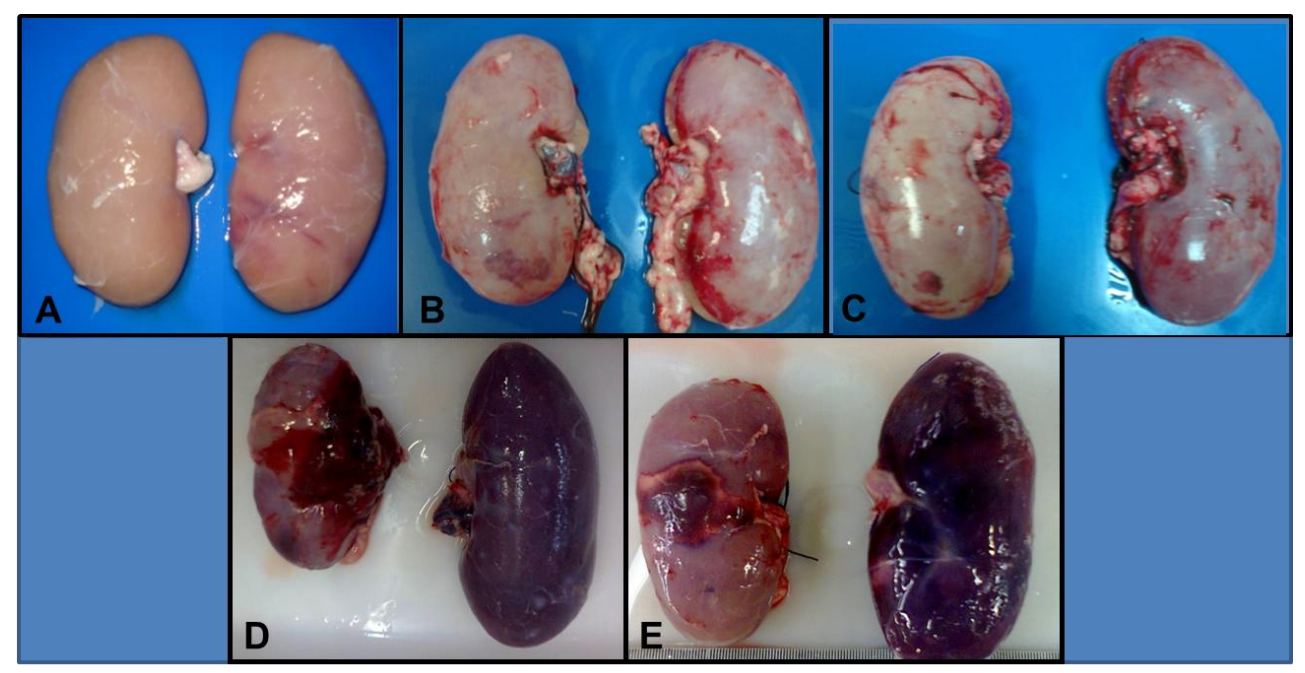

Figura 8 - Morfologia dos rins dos animais que sofreram I/R. A) Animal 1; B) Animal 2; C) Animal 3; D)Animal 4; E) Animal 5. Os rins do lado esquerdo são os que sofreram isquêmia e os do lado direito, os contralaterais. Exceto para o animal 1, apresentaram necrose na parte inferior ou medial em diferentes graus. Já os rins contralaterais apresentaram o mesmo tamanho dos rins isquêmicos, exceto para os animais 4 e 5 .

\subsubsection{Avaliação histolopatológica}

A partir de análises histológicas não foram identificadas mudanças estruturais no rim contralateral (Figura 9A). No entanto, o rim isquêmico apresentou áreas típicas de NTA e/ou áreas com necrose hemorrágia ou branca (exceto animal 1) (Figura 9B-C). Foram identificadas alterações morfológicas como: perda da borda em escova dos túbulos proximais, perda da estrutura celular dos túbulos, dilatação de túbulos proximais e resto de células no interior dos túbulos no rim isquêmico (Figure 9D).

A NTA foi identificada entre $10-25 \%$ dos campos corticais representativos do animal 1 e entre 51 a $100 \%$ nos outros animais (figura 9B-E), demonstrando que o modelo tipicamente apresenta uma taxa importante de lesão. 


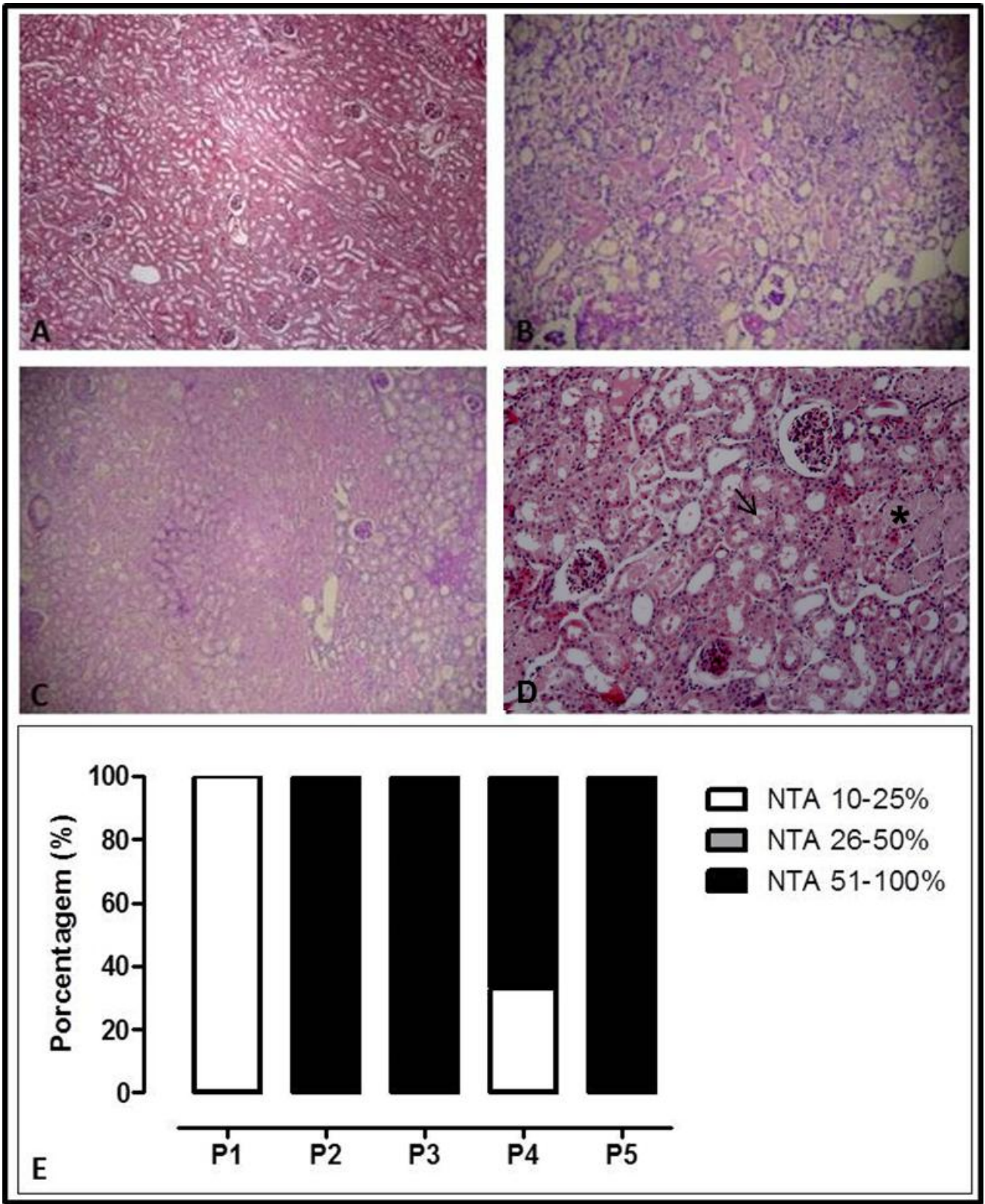

Figura 9 - Avaliação histopatológica dos córtices renais. Gráfico indicando a porcentagem de área de córtices renais analisados com NTA. A) Rim contralateral sem o insulto isquêmico e sem NTA. B) NTA em 10-25\% do córtex renal isquêmico do animal 1. C) Necrose branca e NTA em mais de $51 \%$ do córtex renal. Representativo dos animais P2,P3,P4 e P5. Coloração por ácido periódico de Schiff (PAS), magnitude de 50X. D) Caracterização de NTA em maior aumento. Note as alterações tubulares como restos celulares intratubulares $(*)$ e perda da borda em escova $(\downarrow)$. Coloração por hematoxilinaeosina, magnitude de 200X. E) Quantificação da porcentagem de NTA em rins isquêmicos de diferentes animais (P1, P2, P3, P4, P5). Necrose tubular aguda (NTA).

\subsubsection{Creatinina e uréia séricas}

As dosagens das concentrações de creatinina e uréia séricas foram feitas para avaliar a função renal dos animais. Em todos os animais foi 
observado um aumento significativo tanto da creatinina, quanto da uréia sérica após a isquemia, logo no início da reperfusão (figura 10). Ambas chegaram ao platô dentro das $24 \mathrm{~h}$, não mostrando tendência de subida após este período.
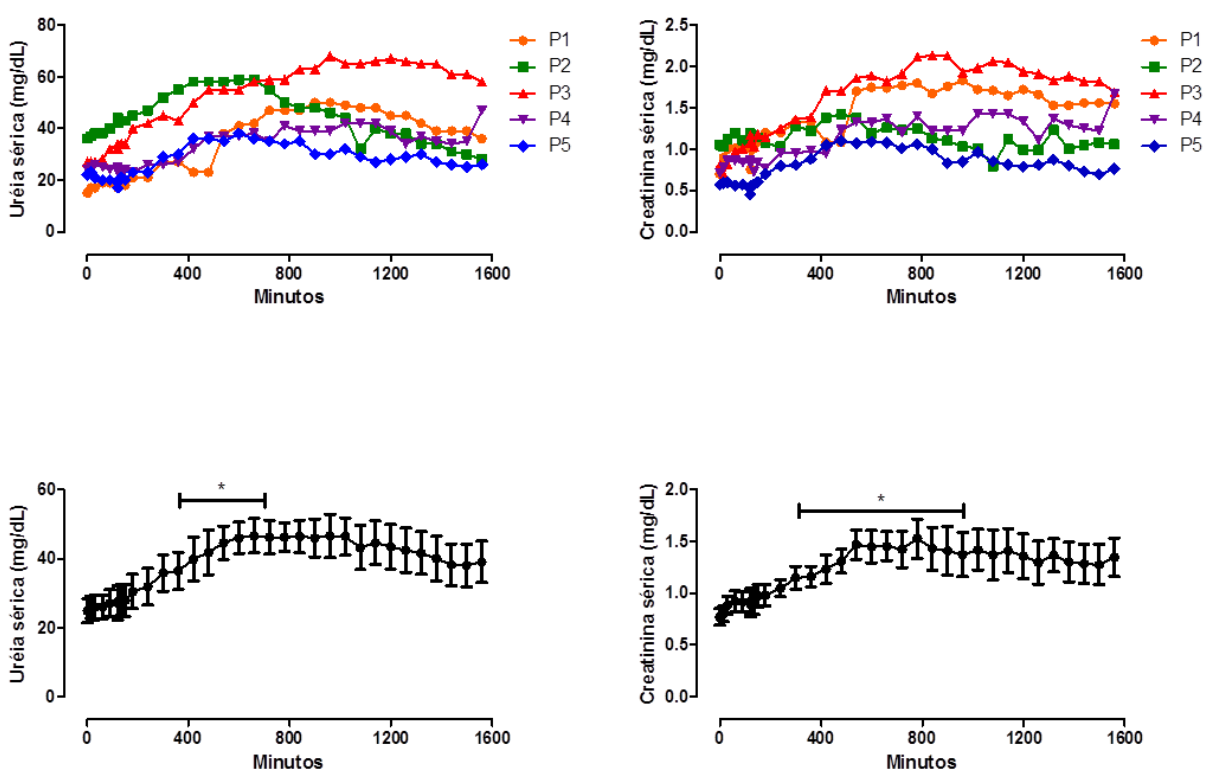

Figura 10 - Valores das concentrações de uréia e creatinina séricas dos animais antes e após indução de isquemia/reperfusão. A uréia e a creatinina foram dosadas em todos os momentos: pré-isquemia (0), durante a isquemia (1 a 120min) e durante a reperfusão (135 a $1560 \mathrm{~min}$ ). A concentração de ambas aumentaram significamente comparadas ao tempo préisquemia. A) Valores de uréia sérica plotados individualmente $(\mathrm{mg} / \mathrm{dL})$ durante todo o experimento; B) Valores de creatinina sérica plotados individualmente $(\mathrm{mg} / \mathrm{dL})$ durante todo o experimento $(\mathrm{mg} / \mathrm{dL})$; C) Médiaterro padrão da média dos valores de uréia sérica para todos os animais $(\mathrm{mg} / \mathrm{dL})$; D) Médiaterro padrão da média dos valores de creatinina sérica para todos os animais $(\mathrm{mg} / \mathrm{dL})$. Análise para medidas repetidas (ANOVA) com * $\mathrm{p}<0,05(\mathrm{n}=5)$ em relação ao valor basal.

No entanto, baseado na nova definição do AKIN (Mehta et al. 2007) para diagnóstico de LRA (creatinina acima de $150 \%$ do valor basal), a maioria dos animais sujeitos a I/R renal não foi classificada como portador de LRA. Esses resultados não corroboram os dados encontrados na análise histopatológica (Figura 9). As análises percentuais do aumento da creatinina foram plotadas em um gráfico de taxa de creatinina, independentemente do tempo de coleta (figura 11). Apenas alguns pontos coletados dos animais $3 \mathrm{e}$ 4 apresentaram valores acima dos da referência para o diagnóstico de LRA. 


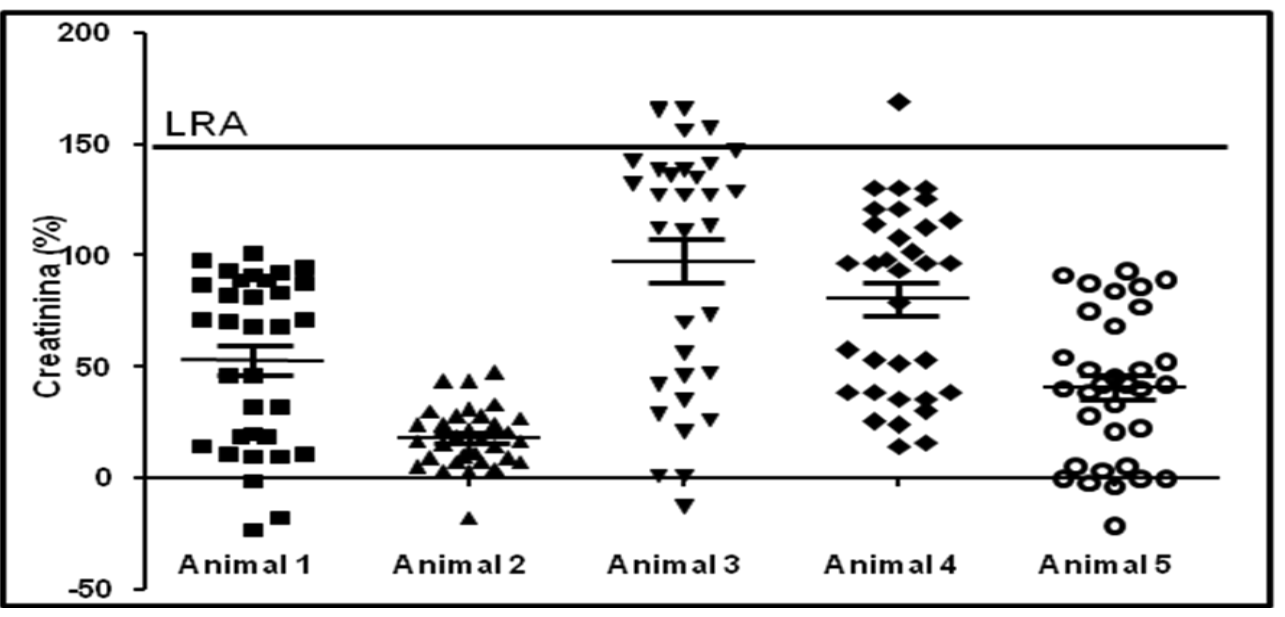

Figura 11 - Análise percentual do aumento na creatinina sérica em relação ao valor basal, independente do tempo de coleta. A linha sob a sigla LRA indica o valor limite do aumento de creatina em $48 \mathrm{~h}$ para uma função renal normal. Acima deste valor (150\% em relação ao valor basal) o indivíduo é diagnosticado como tendo lesão renal aguda (LRA) segundo AKIN (Mehta et al. 2007). Note que apenas os animais 3 e 4 apresentaram creatinina sérica acima de $150 \%$, sendo classificados com LRA.

\subsubsection{NGAL sérica}

Como promissora candidata a biomarcador de lesão renal, a concentração da NGAL sérica foi dosada. No entanto, verificamos que, para o modelo desenvolvido no presente projeto, esse marcador foi mais tardio que a creatinina e a uréia séricas. Dois perfis estatisticamente diferentes foram observados: 1) durante a isquemia, houve redução da concentração de NGAL sérica; e 2) após a reperfusão a concentração foi se elevando acima do valor basal (pré-isquemia), porém apenas a partir de 12 horas de reperfusão. Neste período a NGAL sérica começou a apresentar diferença significativa comparada a isquemia (Figura 12).
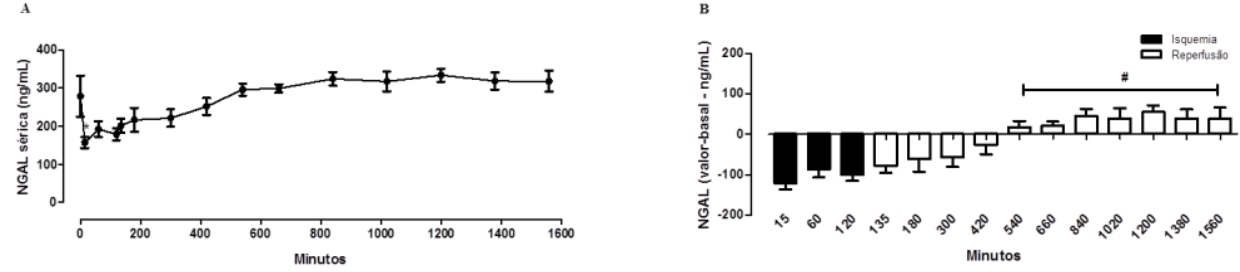

Figura 12 - Concentração sérica de Neutrophil gelatinase-associated lipocalin (NGAL) no soro dos animais ao longo do tempo de isquemia e reperfusão. A) Valores de concentração da NGAL (ng/mL) ao longo do tempo de coleta. B) Diferença da concentração dos valores pós isquemia em relação ao basal (pré-isquemia), destacando a redução estatisticamente significativa da NGAL durante a isquemia e o aumento após a reperfusão. Os valores foram 


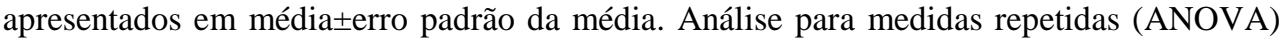
* $\mathrm{p}<0,05$ para comparação com o valor basal e \# $\mathrm{p}<0,05$ para comparação com os valores durante a isquemia $(n=5)$.

\subsubsection{Nitração proteica - estresse oxidativo}

A I/R gerada por único insulto via cateter balão, assim como em outras isquemias, aumentou o estresse oxidativo. Uma maneira indireta de quantificar o estresse oxidativo é através da quantificação de nitração proteica. Sistemicamente, foi observado um aumento significativo das proteínas nitradas totais após a reperfusão no soro (Figura 13 A e B). Interessantemente, houve um aumento durante a isquemia com valor significativo, comparado ao basal, na excreção de proteínas nitradas durante o início da reperfusão. Após este período a nitração proteica retorna aos seus valores basais (Figura 13C). O aumento de proteínas nitradas na urina durante a isquemia vai em concordância com a diminuição destas no soro. 


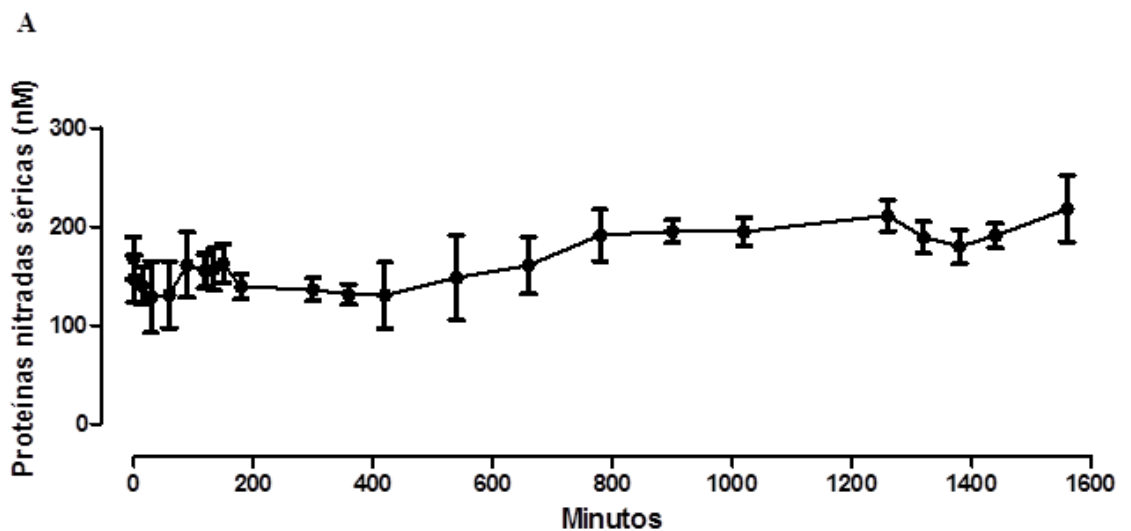

B

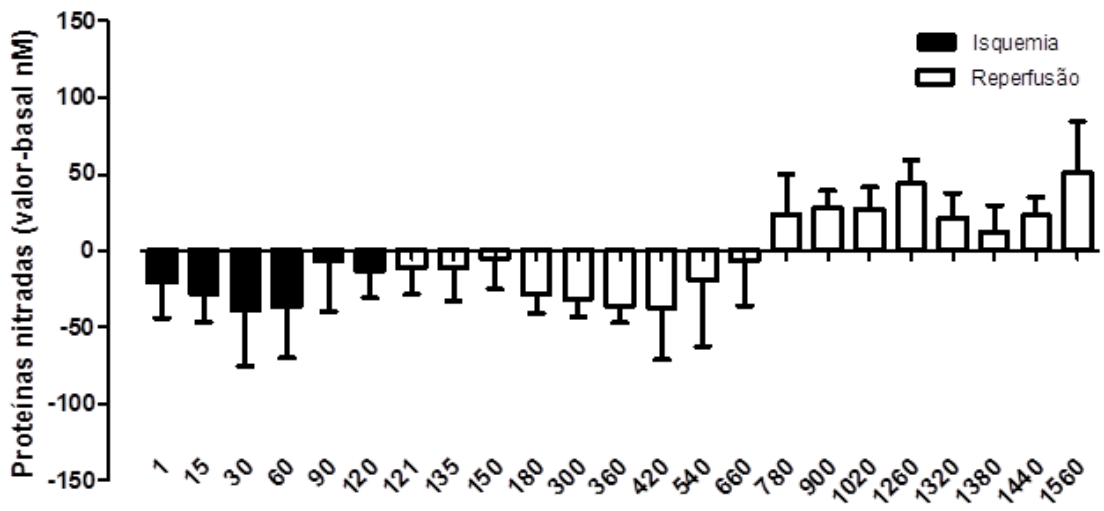

Minutos

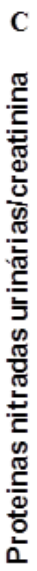

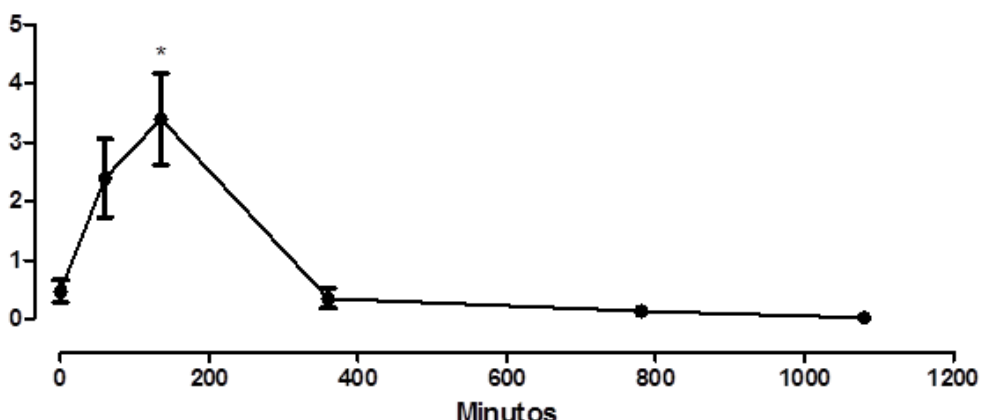

Figura 13 - Análise de estresse oxidativo através de quantificação de concentração de proteínas nitradas séricas e urinárias durante a isquemia e reperfusão. A) Concentração de proteínas nitradas totais no soro $(\mathrm{nM})$ demonstrando o aumento após reperfusão. B) Diferença entre os tempos pós isquemia e basal (pré-isquemia), destacando o aumento pós reperfusão. C) Aumento do estresse oxidativo renal durante a isquemia caracterizado pelo aumento na excreção de proteínas nitradas normalizada pela concentração de creatinina urinária $(n=4)$. Todos os valores foram apresentados como média \pm erro padrão da média 
com aumentos estatisticamente significativos. Análise para medidas repetidas (ANOVA) $\mathrm{p}$ $<0,05$, sendo * comparado ao valor basal.

\subsubsection{Excreção de proteínas e glicose}

Após a isquemia, foi verificado um aumento da excreção de proteína e glicose na urina (Figura 14). A excreção de proteínas totais mostrou um aumento significativo com pico em 360 minutos após a oclusão da artéria renal, diminuindo a níveis basais após 18 horas de reperfusão (Figura 14 A). Não só a quantidade de proteínas na urina, mas também o padrão de proteínas urinárias excretadas foi alterado após a oclusão. Curiosamente, proteínas maiores do que albumina foram observadas após isquemia (Figura 14 B). Enquanto isso, a excreção urinária de glicose apresentou o mesmo padrão de proteínas nitradas, com um aumento significativo durante a isquemia e início da reperfusão, atingindo um pico máximo em 360 minutos após a oclusão da artéria renal (Figura 14 C). Apesar dos níveis de glicose apresentarem uma posterior queda até as 18 horas de reperfusão, eles não se restabeleceram a níveis basais até o último ponto avaliado. 
A

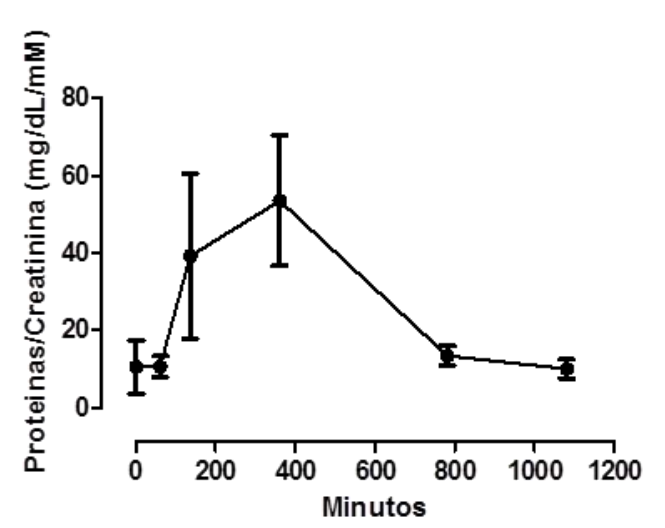

B

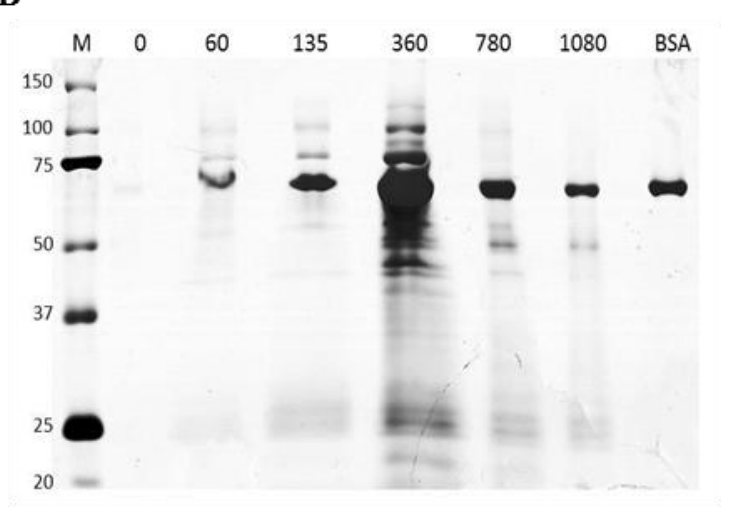

C

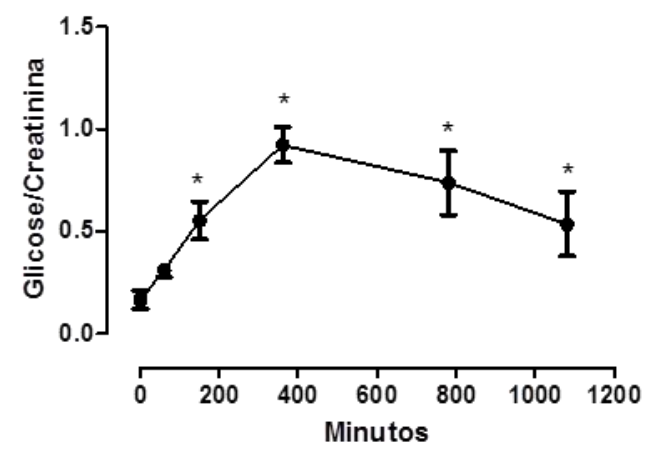

Figura 14 - Análise da excreção urinária de proteínas e glicose. A) Razão da concentração de proteinas por creatinina $(n=5)$ observando um aumento da excreção de proteínas em 360 minutos B) Padrão de proteínas urinárias em SDS-PAGE. As bandas mais escuras são bandas de albumina (69KDa), observação confirmada pelo uso do padrão BSA, (bovine serum albumin, $2 \mu \mathrm{g}$ ). Nota-se uma alteração do perfil de tamanho das proteínas excretadas após isquemia/reperfusão. C) Razão entre concentrações de glicose e creatinina $(n=4)$. As excreções de proteínas e glicose aumentaram significativamente com a isquemia. Os

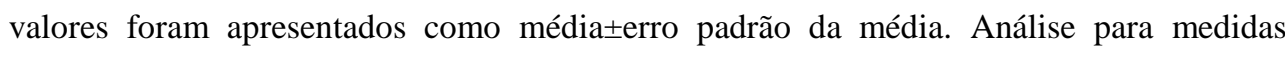
repetidas (ANOVA); $\mathrm{p}<0,05 *$ comparado ao valor basal. 


\subsubsection{Fração de excreção de íons}

Após a isquemia, foi observado um aumento na fração de excreção de íons. A fração de excreção de sódio aumentou de forma significativa no início da reperfusão, retornando aos valores basais após 360 minutos de I/R (Figura 15A). Da mesma forma, a fração de excreção de potássio aumentou significativamente após a isquemia, porém de forma mais tardia (360 minutos após a oclusão da artéria renal; Figura 15B). Como esperado, a fração de excreção de cloreto e a relação bicarbonato/creatinina seguiu o mesmo padrão do íon sódio (Figura 15C-D). Como uma consequência da excreção de bicarbonato, o pH da urina também aumentou no início da reperfusão (Figura 15E).

A

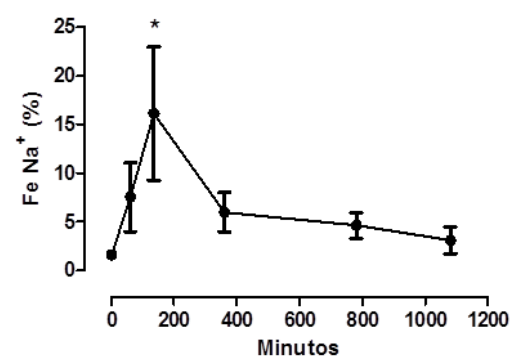

C
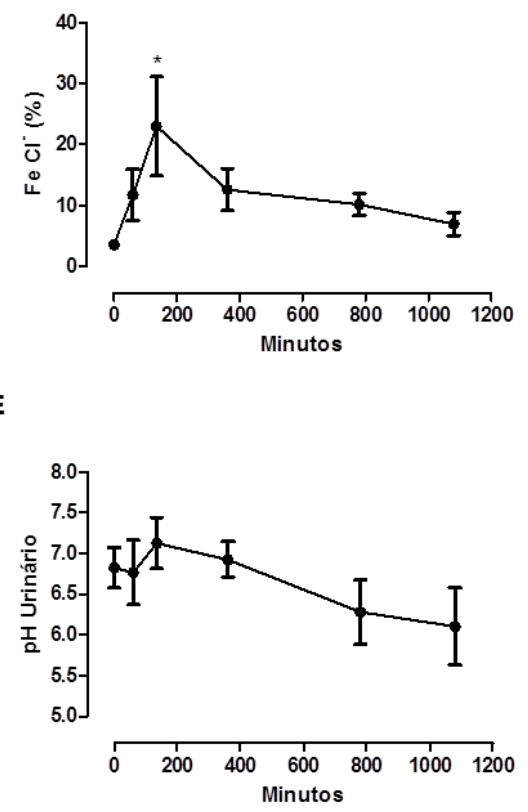

B

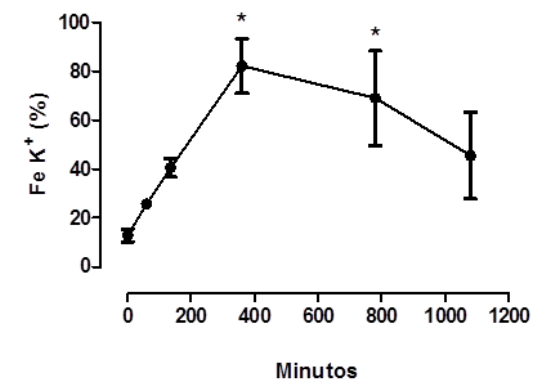

D

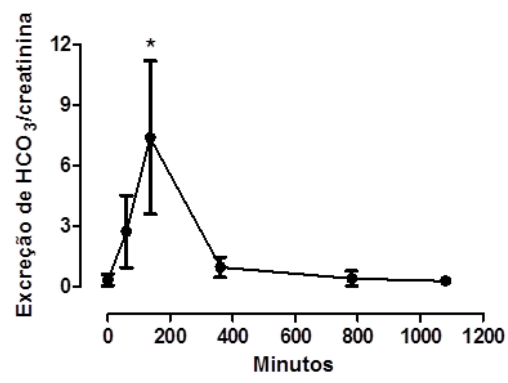

Figura 15 - Análise bioquímica da excreção de íons durante a isquemia e reperfusão. A) Fração de excreção de sódio $\left(\mathrm{FeNa}^{+}\right)$com um evidente aumento após isquemia e retorno dos valores basais na reperfusão. B) Fração de excreção de potassio $\left(\mathrm{FeK}^{+}\right)$com aumento 
tardio após isquemia/reperfusão. C) Fração de excreção de cloreto $\left(\mathrm{FeCl}^{-}\right)$apresentando o mesmo perfil identificado na fração de excreção de $\mathrm{Na}^{+}$. D) Excreção de bicarbonato $\left(\mathrm{HCO}_{3}{ }^{-}\right)$normalizado por creatinina, ainda mantendo o mesmo padrão dos demais íons. E) Medida de $\mathrm{pH}$ urinário, com um leve aumento durante a isquemia. Todas as análises apresentaram diferença estatisticamente significativa. Os valores foram apresentados como média terro padrão da média. Análise para medidas repetidas (ANOVA); $\mathrm{p}<0,05(\mathrm{n}=5)$. * comparado ao valor basal.

\subsection{METABOLÔMICA}

\subsubsection{Identificação e seleção de metabólitos alterados pela I/R renal.}

Através da técnica de RMN $600 \mathrm{MHz}$, foram obtidos espectros representativos das amostras séricas em diferentes tempos da isquemia e reperfusão, como exemplificado na figura 16.

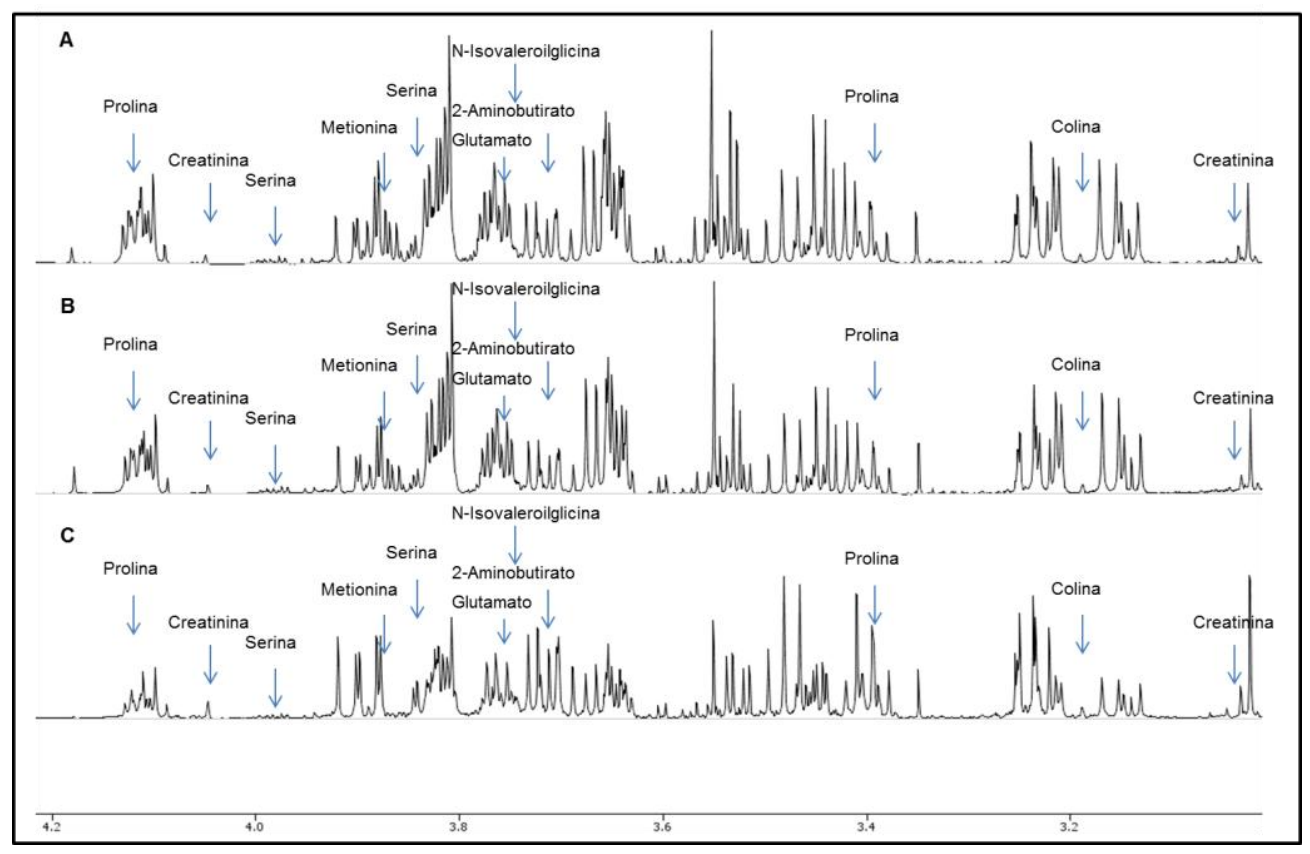

Figura 16 - Representação de espectros de 600MHz H1 RMN com o perfil de metabólitos típicos encontrados nas amostras de soro dos animais. Nota-se a diferença das concentrações de alguns metabólitos (seta em azul) no decorrer do processo de isquemia/reperfusão. A) Espectro de metabólitos pré-isquemia. B) Espectro com metabólitos durante a isquemia. C) Espectro com metabólitos após 11 horas de reperfusão.

Os espectros de RMN obtidos das amostras de soro foram analisados no software Chenomx NMR versão 7.6 (Chenomx Inc., Edmonton, Canadá). De acordo com a literatura e a biblioteca de $600 \mathrm{MHz}$ deste software, 55 metabólitos foram identificados no soro de todos os animais (Figura 17). Como podem ser observado nas figura 17, a lista dos 
metabólitos mais abundantes e que foram identificados na maioria das amostras, inclui alcoois, amidas, aminas, ácido orgânico, éster, componentes alimentícios e medicamentosos, açúcares e principalmente aminoácidos e seus derivados.

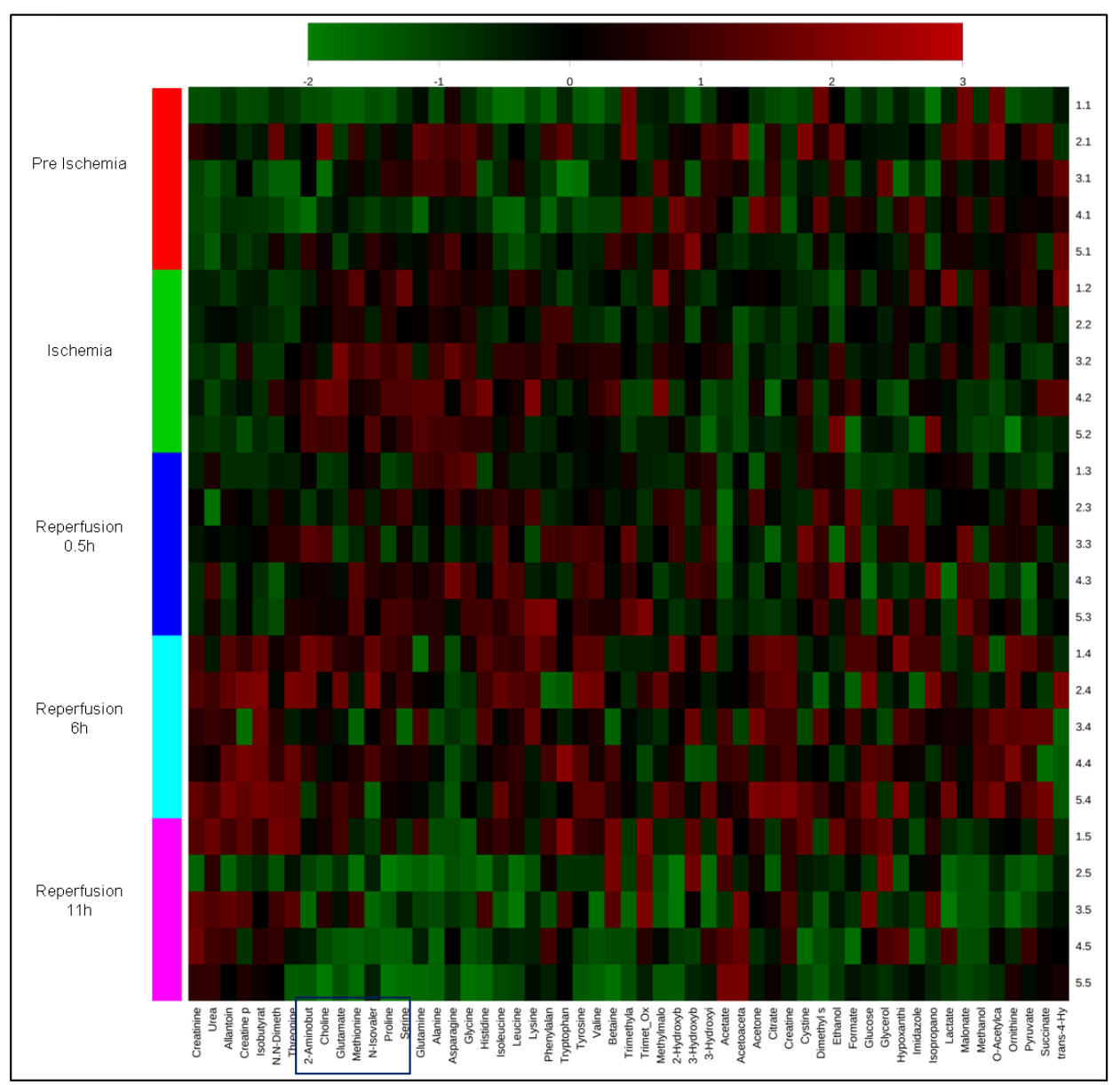

Figura 17 - Representação por mapa de calor dos 55 metabólitos encontrados no modelo de isquemia/reperfusão renal. O retângulo azul destaca os metabólitos que aumentaram a concentração (valores de cada animal normalizados) após 60 minutos da isquemia. Os valores de concentração variam em uma escala de menor concentração, em verde, até os metabólitos mais concentrados, em vermelho.

Após a normalização dos metabólitos encontrados, foram calculados os quintis e a média dos valores, os quais foram representados individualmente em ordem de expressão relativa (mapa de calor) para os diferentes pontos: pré isquemia, isquemia, pós reperfusão $(0,5 \mathrm{~h})$, pós reperfusão (6h) e pós reperfusão (11h) (Figura 18). 


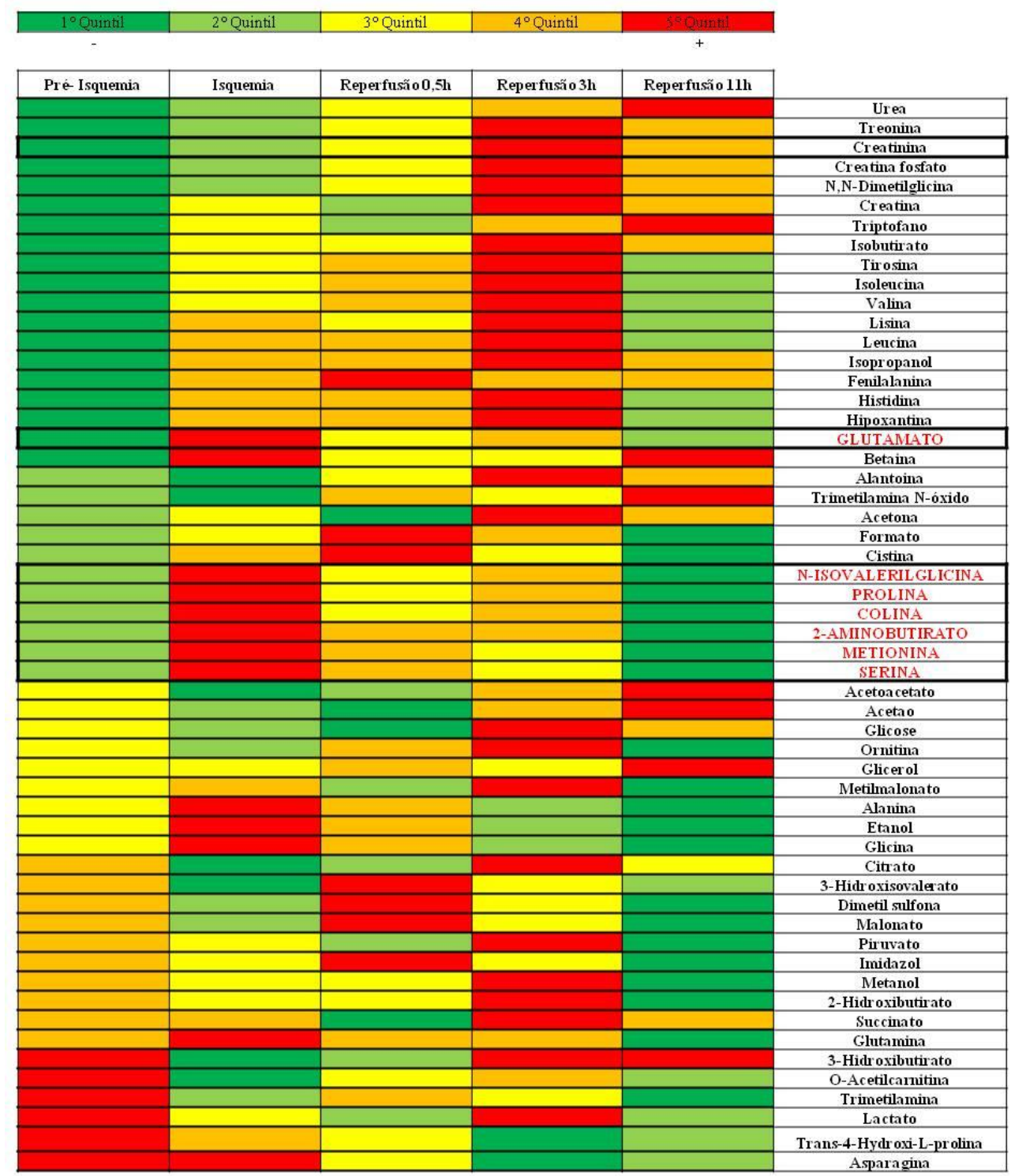

Figura 18 - Representação por mapa de calor dos 55 metabólitos encontrados no modelo de isquemia/reperfusão renal (I/R) após a divisão por quintil. Os metabólitos em letras maiúsculas vermelhas destacam os metabólitos escolhidos como candidatos a biomarcadores de I/R devido ao aumento rápido da concentração destes durante a isquemia com posterior queda após a reperfusão (L-glutamato, L-serina, $\mathrm{N}$-isovaleroilglicina, Lmetionina, L-prolina, 2-aminobutirato e colina). A creatinina também foi selecionada para futuras comparações em painel metabólico. Os valores de concentração variam dos menos concentrados, em verde, até os mais concentrados, em vermelho.

Os candidatos a biomarcadores de isquemia foram selecionados baseados no rápido aumento, ou queda, logo após o início da isquemia e retorno às condições basais após reperfusão. Além disso, a creatinina também foi selecionada para futuras comparações em painel metabólico. Assim, oito metabólitos foram escolhidos para análise estatística e análise 
de sistema biológico de acordo com seus perfis. Os metabólitos selecionados foram: L-glutamato (HMDB00148), L-serina (HMDB00187), $\mathrm{N}$-isovaleroilglicina (HMDB00678), L-metionina (HMDB00696), L-prolina (HMDB00162), 2-aminobutirato (HMDB00452), colina (HMDB00097) e creatinina (HMDB00562). As mudanças nos níveis metabólicos foram representadas pela análise do mapa de calor usando o programa Metaboanalyst (figura 19) na determinação de padrões metabólicos entre os momentos pré-isquemia, isquemia e os diferentes tempos de reperfusão. A cor de cada célula representa no mapa de calor uma concentração metabólica, indicando diferentes padrões metabólicos entre os momentos.

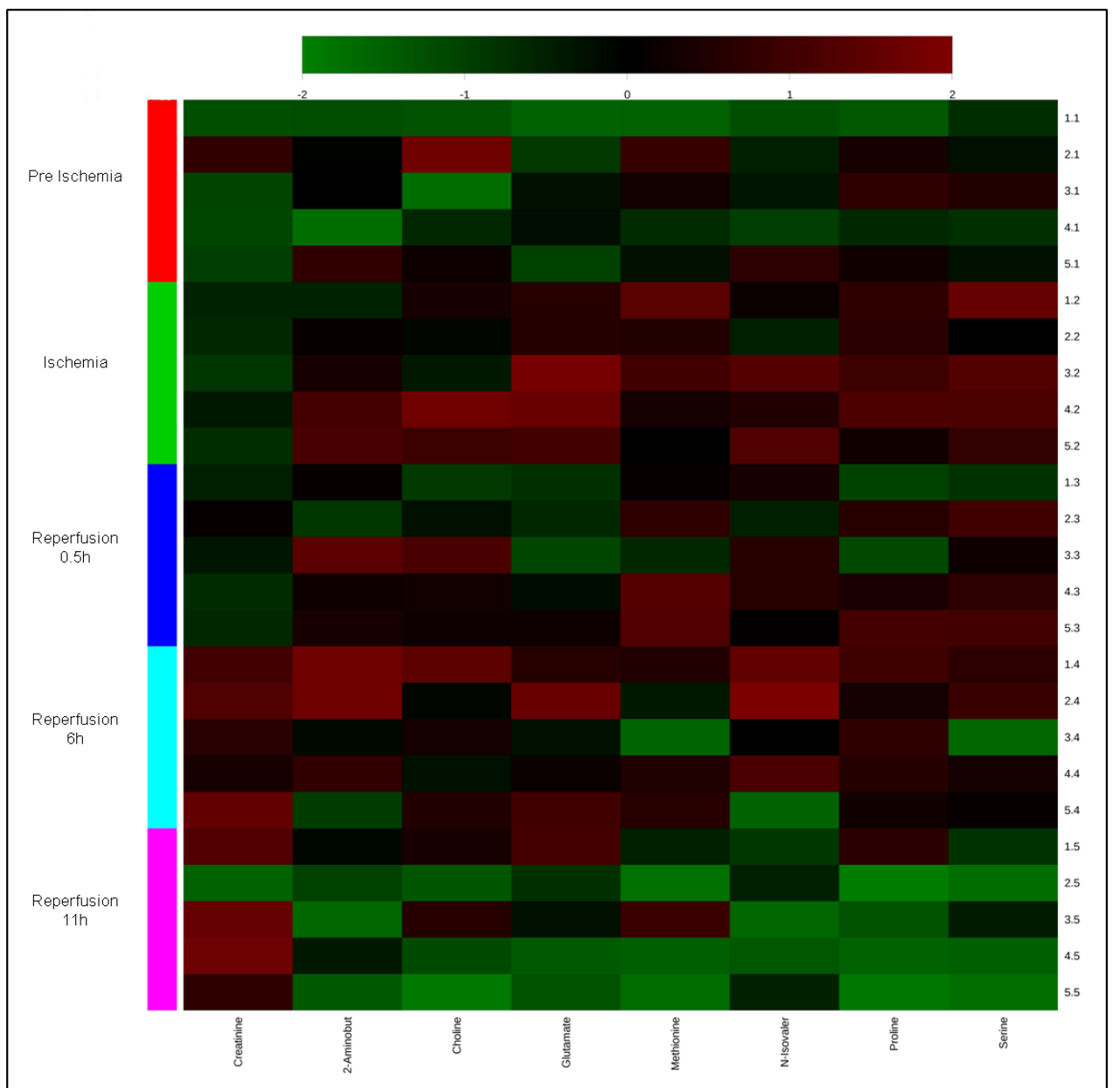

Figura 19 - Mapa de calor dos 8 metabólitos selecionados devido a diferenças nas concentrações metabólicas dos momentos pré isquemia, isquemia e reperfusão. Os valores de concentração variam dos menos concentrados, em verde, até os mais concentrados, em vermelho. 


\subsubsection{Análise multivariada dos metabólitos alvos}

A análise estatística foi iniciada com uma análise de componentes principais (PCA) para os metabólitos selecionados, porém somente com esta análise não foi possível separar os momentos pré-isquêmico, isquêmico e os vários tempos pós-reperfusão. Em seguida foi realizada uma análise multivariada PLS-DA e através desta análise foi possível distinguir o momento pré-isquêmico do isquêmico (Figura 20), assim como o momento isquêmico e pós-reperfusão (11h) (Figura 21). Não foi possível distinguir os momentos menores de $11 \mathrm{~h}$ de reperfusão do momento da isquemia, provavelmente pela lenta queda destes metabólitos após o insulto. Também, não foi possível diferenciar os momentos pré-isquemia e pós reperfusão 11h, demonstrando assim, um retorno das concentrações desses metabólitos aos valores basais. Baseado no teste de permutação para os diferentes momentos, pode-se inferir que a distinção desses momentos não foi ao acaso, com $\mathrm{p}<0,05$.

A separação do momento pré-isquemia e isquemia ocorreu através de 2 ou 3 componentes latentes com acurácia de 0,8 e 0,7 , validação $\left(Q^{2}\right)$ de 0,40 e 0,22 e calibração $\left(R^{2}\right)$ de 0,68 e 0,78 , respectivamente. Já a separação do momento isquêmico e pós reperfusão $11 \mathrm{~h}$ ocorreu por 2 ou 3 componentes latentes com acurácia de 0,9 e $0,8, Q^{2}$ de 0,73 e 0,75 e $R^{2}$ de $0,83,0,89$, respectivamente.

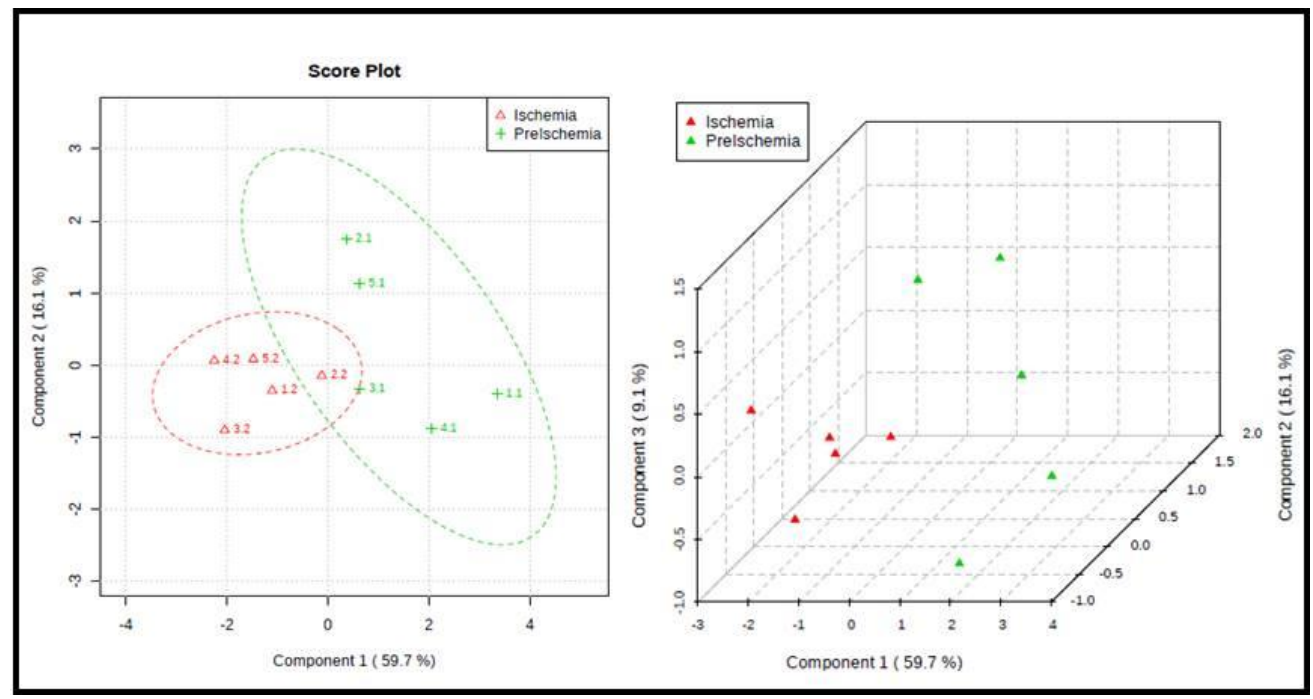

Figura 20 - Representação 2D e 3D da análise de PLS-DA. Os momentos pré-isquemia (PreIschemia) e isquemia (Ischemia) puderam ser separados através de 2 ou 3 componentes, respectivamente. Pré-isquemia (verde) e isquemia (vermelho). 


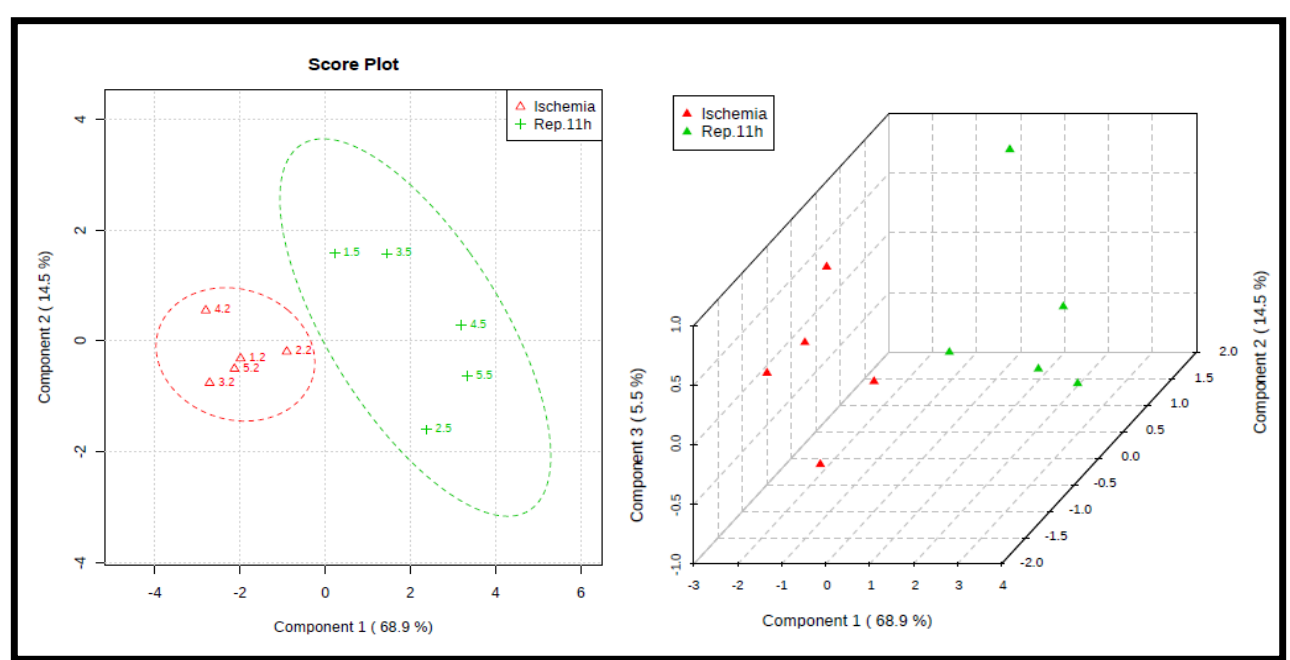

Figura 21 - Representação 2D e 3D da análise de PLS-DA. Os momentos isquemia (Isquemia) e pós reperfusão 11h (Rep 11h) puderam ser separados através de 2 ou 3 componentes, respectivamente. Isquemia (vermelho) e pós reperfusão $11 \mathrm{~h}$ (verde).

Os metabólitos responsáveis pela diferença entre os grupos foram sumarizados na figura 22. A concentração dos metabólitos L-glutamato, Lserina, N-isovaleroilglicina, L-metionina, L-prolina, 2-aminobutirato e colina foram relativamente menores na pré isquemia comparado a isquemia. Após a reperfusão, estes valores tendem a voltar aos basais. Como esperado, a creatinina não se mostrou o metabólito mais importante para a distinção dos momentos pré-isquemia da isquemia. 

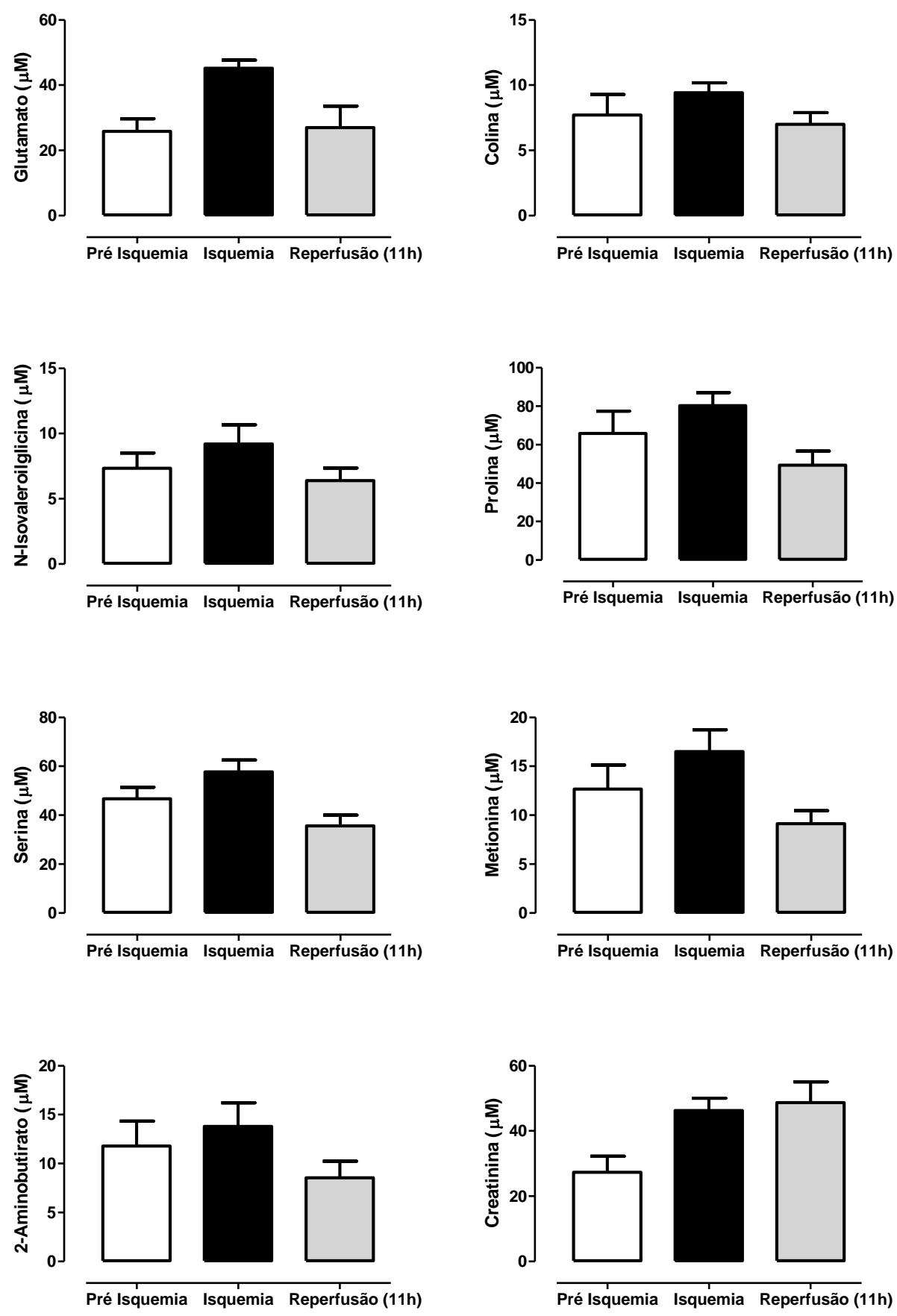

Figura 22 - Perfil de metabólitos estatisticamente capazes de distinguir momentos préisquemia, isquemia e pós reperfusão (11h). Média \pm erro padrão da média.

Através do índice VIP foi possível identificar os metabólitos em sua ordem de importância para o modelo que distingue pré-isquemia da isquemia, sendo em ordem decrescente: L-glutamato, L-serina, $\mathrm{N}$ - 
isovaleroilglicina, L-metionina, L-prolina, 2-aminobutirato, colina e creatinina (Figura 23).

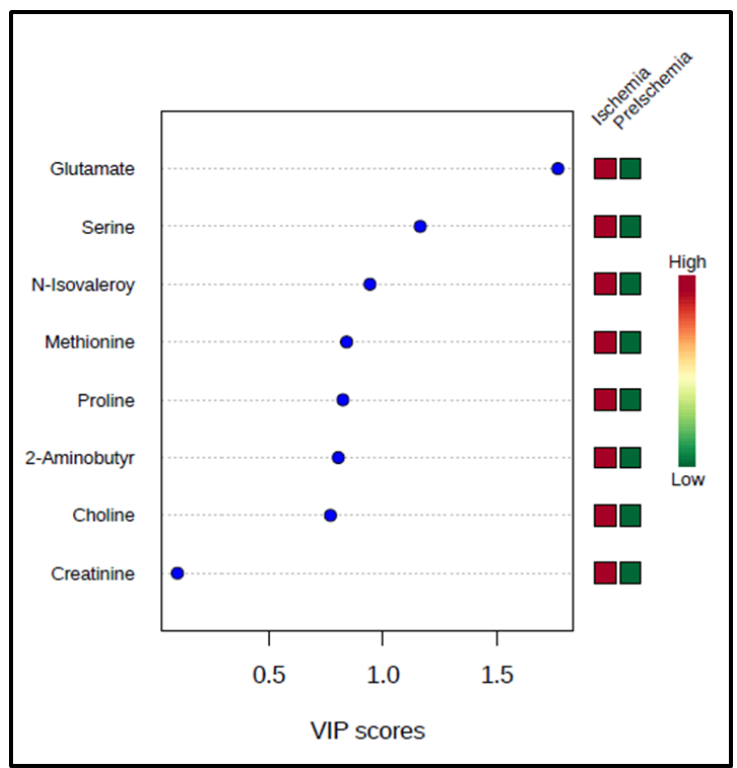

Figura 23 - Representação da importância da variável na projeção (VIP) listando em ordem decrescente de importância os metabólitos capazes de distinguir os momentos pré-isquemia da isquemia. As cores dos quadrados indicam se a concentração do metabólito está mais alta (vermelha) ou mais baixa que o outro momento (verde). L-glutamato, L-serina, $\mathrm{N}$ isovaleroilglicina, L-metionina, L-prolina, 2-aminobutirato, colina e creatinina seguiram em sua ordem de importância para o modelo.

\subsubsection{Análise de biologia de sistemas}

Para uma melhor compreensão da função exercida por estes metabólitos na fisiopatologia da isquemia e reperfusão renal, foi feita uma análise de sistema com enriquecimento no programa MetaCore (Figura 24 e 25) e Ingenuity (Figura 26).

$\mathrm{Na}$ análise de enriquecimento, a via do metabolismo e transporte de aminoácidos foi a mais significante para os grupos de metabólitos analisados (Figura 24). 


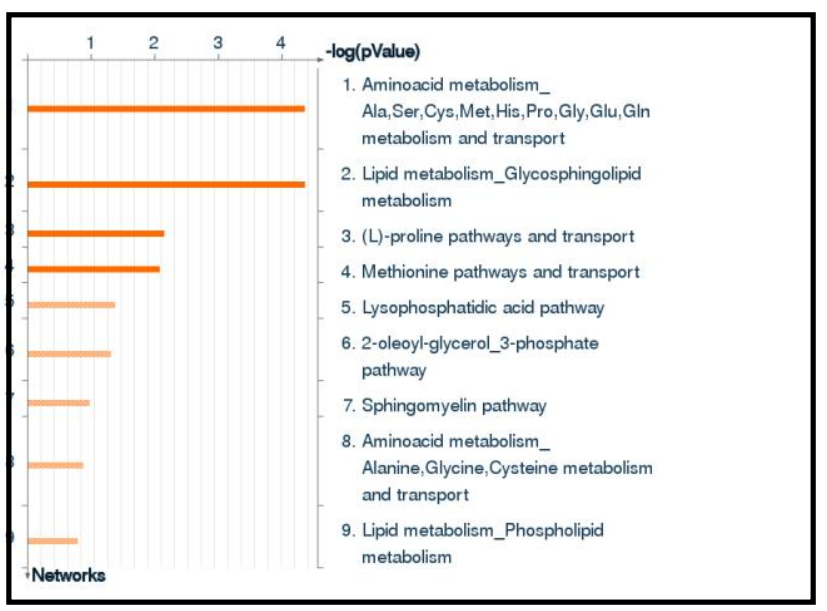

Figura 24 - Principais vias associadas aos metabólitos candidatos identificadas através de uma análise de enriquecimento do programa MetaCore.

Após a conexão dos metabólitos baseados em suas vias, pode-se notar que as alterações geradas pela isquemia e reperfusão estão altamente relacionadas com o transporte de íons $\left(\mathrm{H}^{+}, \mathrm{Na}^{+}\right.$and $\left.\mathrm{Cl}^{-}\right)$(Figura 25).

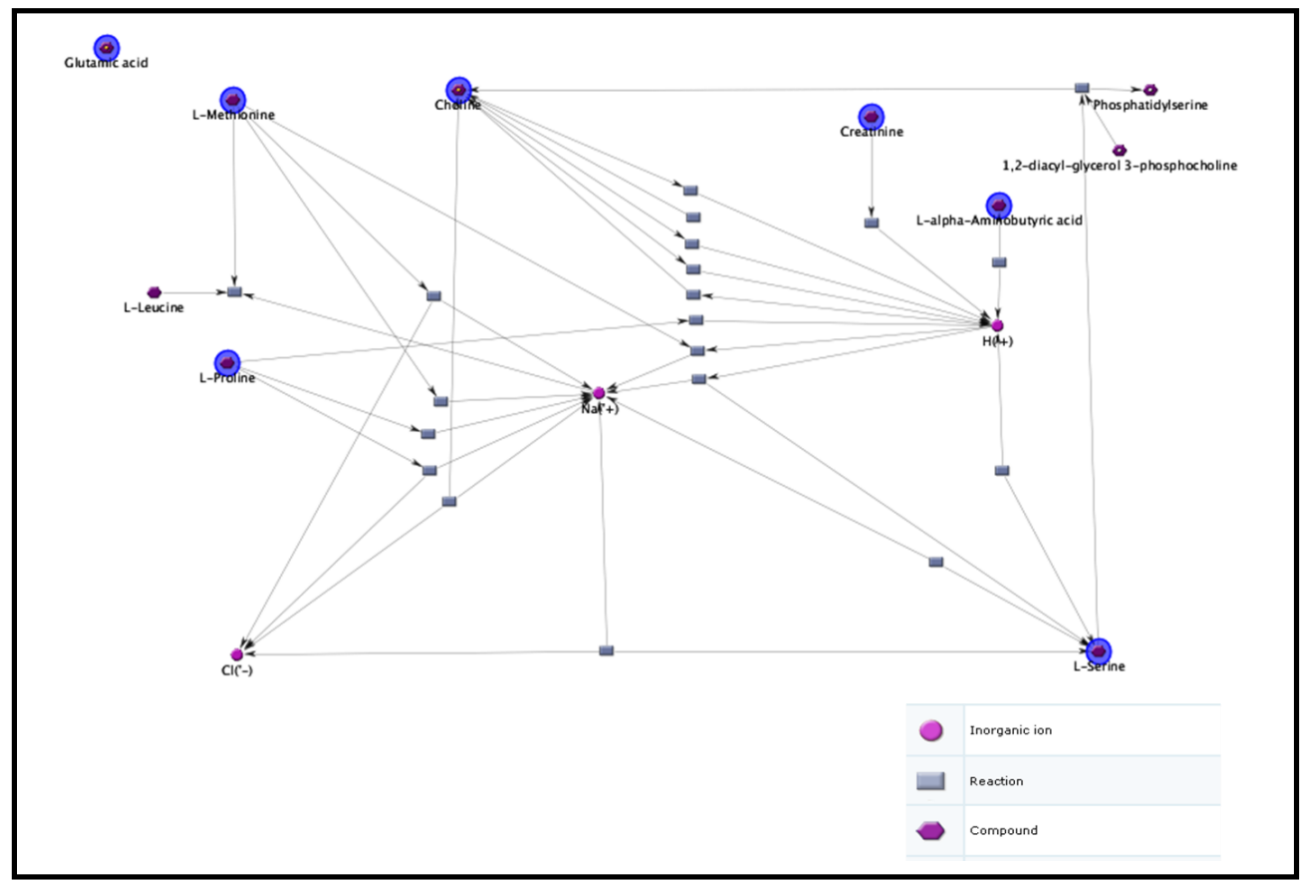

Figura 25 - Rede relacionada aos metabólitos candidatos a biomarcadores (MetaCore). Lglutamato (glutamic acid), L-Serina, L-metionina, L-prolina, 2-aminobutirato (L-alphaAminobutyric acid), colina e creatinina. O glutamato apresentou uma via única, não demostrada, e o $\mathrm{N}$-isovaleroilglicina não foi encontrado no MetaCore . Todos estes metabólitos foram associados com transportadores de hidrogênio $\left(\mathrm{H}^{+}\right)$, sódio $\left(\mathrm{Na}^{+}\right)$e cloreto $\left(\mathrm{Cl}^{-}\right)$. 
$\mathrm{Na}$ análise de sistemas gerada pelo programa Ingenuity, metabólitos foram associados com proteínas, fatores de transcrição e outros metabólitos (Figura 26), dos quais merecem destaque o fator nuclear kappa B (Nuclear Factor-KappaB - NFkB), huntingtina (huntingtin - HTT) e proinsulina (insulina), que estão, baseado em dados de literatura, altamente conectados com os metabólitos selecionados neste estudo.

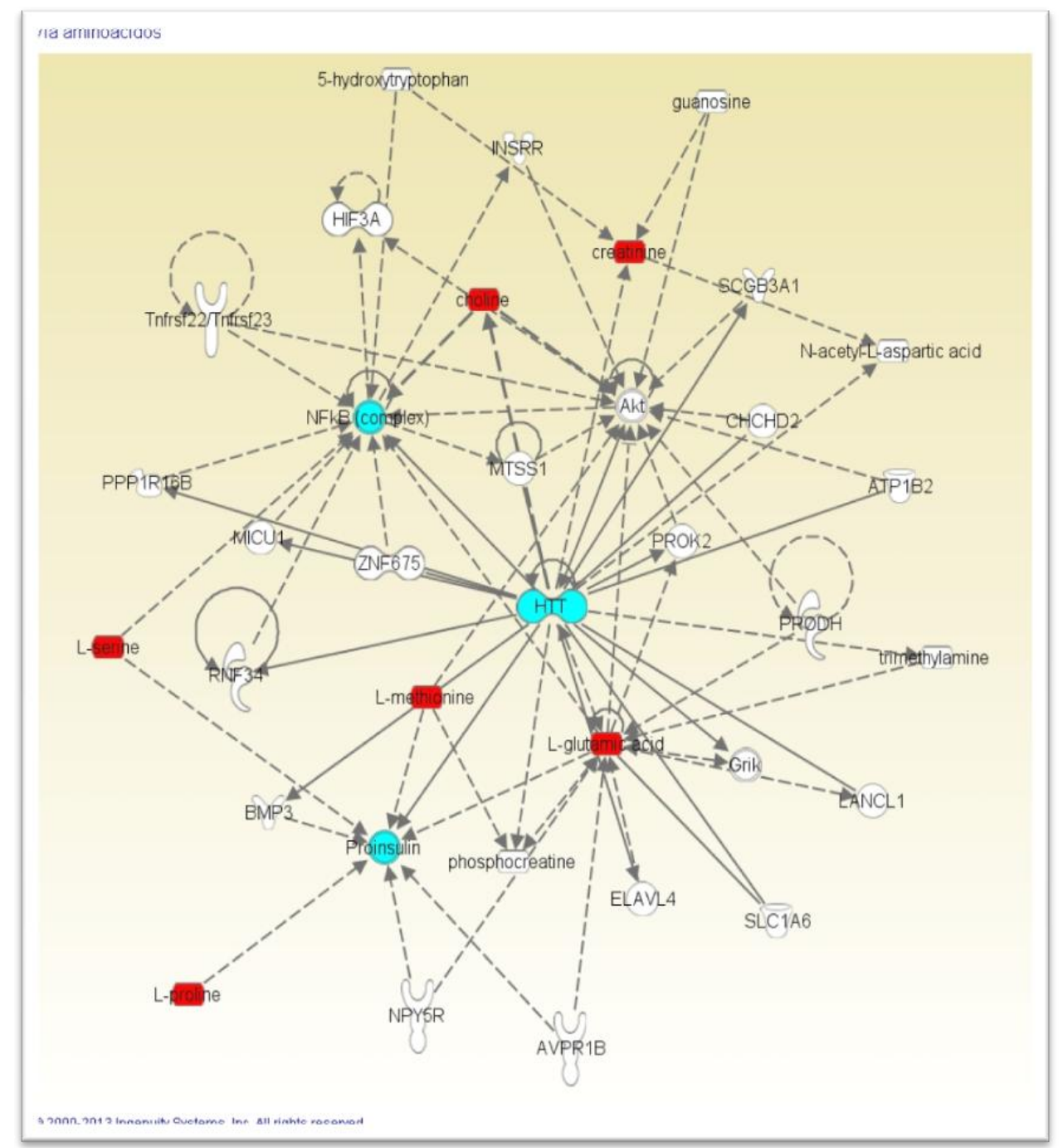

Figura 26 - Conecções dos metabolitos candidatos (vermelho) a proteinas, fatores de transcrição e outros metabótitos através do programa Ingenuity. Nesta rede, destacam-se o fator nuclear kappaB (NFאB), huntingtina (HTT) e proinsulina. Glutamato (L-glutamic acid), L-Serina (L-serine), L-metionina (L-methionine), L-prolina (L-proline), colina (choline) e creatinina (creatinine).

Para validação da provável rede apresentada pelo Ingenuity, a proteína HTT presente nos rins contralateral e isquêmico foi analisada por western blot. Não foi encontrada a proteína HTT intacta no rim, porém foram 
detectados dois fragmentos com diferentes intensidades entre os grupos. O fragmento de $55 \mathrm{KDa}$ foi significativamente reduzido no rim isquêmico enquanto o fragmento de $65 \mathrm{KDa}$ apresentou uma tendência ao aumento (Figura 27).

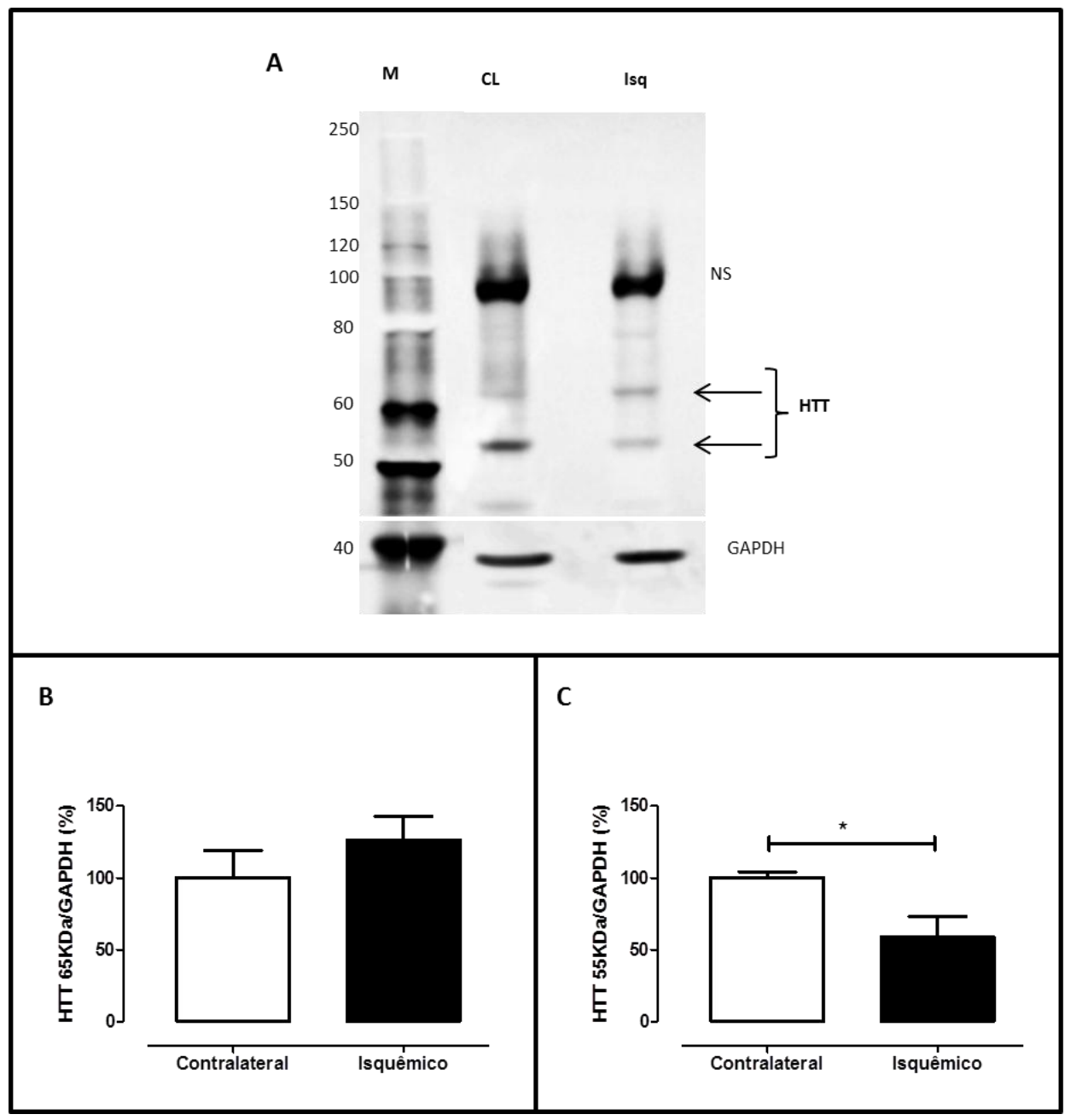

Figura 27 - Análise do fragmento N-terminal da proteína huntingtina no rim. A) Western blot da fração nuclear de córtex renal com uso do anticorpo monoclonal para região $\mathrm{N}$ terminal da huntingtina (HTT). O anticorpo da HTT reconheceu duas bandas no extrato renal: $65 \mathrm{KDa}$ e $55 \mathrm{KDa}$ e o GAPDH foi utilizado como normalizador. As bandas foram quantificadas por densitrometria. A) Densitometria da banda de $65 \mathrm{KDa} / \mathrm{GAPDH}$, apresentando uma maior intensidade no individuo isquêmico. B) Densitometria da banda de $55 \mathrm{KDa} / \mathrm{GAPDH}$, demostrando uma redução significativa do fragmento de HTT no extrato de rim isquêmico. A coluna branca no gráfico indica o rim contralateral à isquemia e a preta indica o rim isquêmico. Os valores foram apresentados como médiaterro padrão da média. Teste ' $\mathrm{t}$ ' de Student pareado com *p $<0,05(\mathrm{n}=5) . \mathrm{M}=$ Marcador, $\mathrm{CL}=$ rim contralateral, Isq= rim isquêmico, $\mathrm{NS}=$ não específica 


\subsection{SUMÁRIO DOS RESULTADOS}

\subsubsection{Avaliação do procedimento de isquemia/reperfusão renal}

Conseguimos desenvolver um modelo de $\mathrm{I} / \mathrm{R}$ renal com características já descrita na literatura:

- Lesão estrutural - NTA;

- Aumento de uréia, creatinina e NGAL séricas;

- Aumento do estresse oxidativo via soro e urina;

- Aumento da excreção $\mathrm{Na}^{+}, \mathrm{K}^{+}, \mathrm{Cl}^{-}$e bicarbonato;

- Aumento da excreção de proteínas e glicose;

Apenas 2 animais foram classificados com LRA de acordo com os níveis de creatinina pelo AKIN; e verificou-se aumento na excreção de glicose em resposta aguda da LRA, não reportada em outros modelos não diabéticos.

\subsubsection{Identificação e seleção de metabólitos alterados pela I/R renal.}

Foi identificado um painel com oito marcadores metabólicos capazes de distinguir o período isquêmico: L-glutamato, L-serina, Nisovaleroilglicina, L-metionina, L-prolina, 2-aminobutirato, colina e creatinina.

Estes metabólitos são altamente representativos da via dos aminoácidos e suas alterações estão relacionadas com o transporte iônico prejudicado pela falta de ATP e NTA.

Além disso, foi identificada a HTT como uma nova proteína alterada durante a isquemia renal. 
5. DISCUSSÃO 


\section{DISCUSSÃO}

\subsection{DESENVOLVIMENTO E CARACTERIZAÇÃO DO MODELO SUÍNO DE I/R RENAL}

No presente estudo, fornecemos evidências de que o modelo de I/R renal em suínos, gerado por cateter balão, é um método adequado, minimamente invasivo, preciso e reprodutível para oclusão da artéria renal. Este método não é acompanhado por nefrectomia e não apresentou mortalidade, que é frequentemente observada em modelos cirúrgicos convencionais. (Keller et al. 2008; Sabbagh et al. 2011).

Modelos de I/R renal em animais de grande porte são necessários para descoberta de novos biomarcadores, estudos de transplante renal, mecanismos de prevenção de lesão, entre outras aplicações clínicas. Os suínos apresentam-se como fortes candidatos a este modelo, devido à semelhança do sistema renal ao dos humanos, seja na anatomia e homologia do órgão, ou mesmo na resposta imunológica (Lieberthal and Nigam 2000), (Piriou-guzylack and Salmon 2008) (Lunney 2007). Modelos suínos de doenças renais já vêm sendo utilizados em estudos de I/R (Lieberthal and Nigam 2000) (Simon et al. 2008) e transplante (Fonouni et al. 2011) (Fonouni et al. 2012) (Yang et al. 2012), objetivando novos marcadores e abordagens terapêuticas (Hunter et al. 2012). No entanto, os modelos mais utilizados fazem uso de clamp para a oclusão da artéria e/ou veia renal, nefrectomia do rim contralateral e/ou microdiálise para captação de metabólitos (Weld et al. 2008a) (Hunter et al. 2012).

Partículas de embolização, como as de álcool polivinílico (PVA), também têm sido utilizadas para provocar isquemia, porém este método fornece apenas uma oclusão parcial do vaso, sem controle sobre a reperfusão. Além disso, esse método possui algumas particularidades como: as partículas devem ter um tamanho específico capaz de ocluir o lúmen da artéria, que varia entre os animais (Misra et al. 2006); são utilizadas em modelos que realizam longos períodos de isquemia; e podem fornecer resultados heterogêneos em relação à resposta isquêmica (Keller et al. 
2009). Ambos os modelos, oclusão por injeção de PVA ou clamp, não têm apresentado diferenças histológicas (Flacke et al. 2012).

Os modelos baseados na oclusão por cateter-balão têm sido utilizados por serem menos invasivos do que a inserção do clamp (Simon et al. 2011). Um desses modelos foi desenvolvido em suínos com a introdução do cateter-balão na artéria aorta abdominal, com o objetivo de ocluir ambas as artérias renais. No entanto, esta isquemia bilateral causou uma lesão renal acentuada, quando comparada ao nosso modelo, com danos glomerulares (dilatação do espaço de Bowman, inchaço da célula de Bowman capsular (Matějková et al. 2013) e tubularização glomerular (Simon et al. 2011).

Vários estudos têm descrito modelos de $\mathrm{I} / \mathrm{R}$ unilateral com nefrectomia (Flacke et al. 2012) (Hunter et al. 2012) (Susa et al. 2009) ou I/R renal bilateral (Matějková et al. 2013) (Bhalodia et al. 2009). No entanto, independente da técnica utilizada (PVA, clamp, cateter-balão) estes estudos têm mostrado um grau de lesão histológica inferior ao do nosso estudo, devido a esforços de compensação de um único rim ou pelo condicionamento pneumoperitonial pré-isquemia gerado pelo uso da técnica de laparoscopias (Weld et al. 2008a). Os rins isquêmicos, com excessão do animal 1, apresentaram áreas de necrose na porção inferior do rim, lugar onde a porcentagem de hemoglobina oxigenada é menor durante a isquemia (Crane et al. 2003). Lesões do tipo NTA só foram encontradas nos rins isquêmicos e não nos rins contralaterais do nosso modelo, podendo estes serem usados como controles do próprio indivíduo, como têm sido utilizados em outros estudos (Sabbagh et al. 2011) (Damianovich et al. 2006).

A lesão renal aguda (LRA) é caracterizada pela aumento dos níveis de creatinina no soro, tanto para animais quanto para humanos, pois o aumento desta estima a perda da função renal. Devido aos suínos apresentarem grande variação na creatinina sérica basal (1 a $2,7 \mathrm{mg} / \mathrm{dL}$ ) (Kaneco, 1997), adotamos como diagnóstico para LRA, os valores sugeridos por AKIN, ou seja, iguais ou superiores a $150 \%$ da dosagem basal de creatinina do indivíduo em 48h (Mehta et al. 2007). Baseado nesses valores, apenas dois animais seriam classificados com LRA em nosso 
estudo, sendo um deles em apenas uma medição, o que contraria os dados histológicos de NTA para todos os animais (a maioria dos animais também apresentou necrose branca ou hemorrágica).

No entanto, os níveis de creatinina foram significativamente maiores do que os níveis basais, não corroborando com alguns estudos em suínos como Weld e colaboradores. Neste trabalho, após uma isquemia unilateral de 90 e 120 minutos de oclusão, não foram observadas alterações dos níveis de creatinina sérica após 5 horas de reperfusão (Weld et al. 2008b). Além disso, em outro estudo com oclusão de 120, 150 e 180 minutos, a creatinina sérica só aumentou após 24 horas de reperfusão da oclusão de 180 minutos (Weld et al. 2008a). Esta falta de aumento da creatinina sérica ocorreu provavelmente porque os níveis de creatinina sérica basal gerados pela cirurgia ou nefrectomia já eram muito elevados (aproximadamente $1.5 \mathrm{mg} / \mathrm{dL}$ ) ou ainda, devido ao fato de a avaliação da creatinina sérica ser realizada precocemente, antes de 6 horas após a reperfusão, uma vez que no nosso modelo foi observado um aumento após este período. Por fim, como seria de esperar, o nosso modelo foi caracterizado por um aumento tardio da creatinina, em comparação com os modelos que ocluíram os dois rins através da aorta, durante 90 minutos (Simon et al. 2011) e 120 minutos (Matějková et al. 2013), que mostraram um aumento dos níveis de creatinina sérica, após 2 e 4 horas, respectivamente.

Como o diagnóstico de LRA utilizando creatinina no soro é conhecido por ter várias limitações, diversos biomarcadores diferentes têm sido estudados (Simsek et al. 2013). A NGAL tem sido amplamente utilizada em estudos (Boldt et al. 2009) (Mishra et al. 2005) como um marcador mais precoce que a creatinina na LRA (Clerico et al. 2012). Sugere-se que a isquemia estimula o aumento da NGAL no tecido e no soro, porém o mecanismo permanece não esclarecido (Chakraborty et al. 2012). Modelos suínos prévios de I/R renal apresentaram aumento urinário (Hunter et al. 2012) (Silberstein et al. 2013) e sérico (Silberstein et al. 2013) (Jochmans et al. 2011) (Matějková et al. 2013) de NGAL. Silberstein e colaboradores mostraram aumento de NGAL sérica após isquemia, apesar de não terem encontrado diferença entre o grupo de I/R unilateral por clamp 
hilar e o grupo controle (Silberstein et al. 2013), podendo ser uma resposta a lesão cirúrgica. Outros estudos mostraram aumento após $48 \mathrm{~h}$ de transplante renal (Jochmans et al. 2011) e após 8 horas de reperfusão da I/R renal bilateral de 120 minutos (Matějková et al. 2013). Nosso estudo não apresentou aumento significativo da NGAL após 24h. Esta observação pode ter ocorrido devido ao fato de que o ponto inicial foi coletado após indução cirúrgica e antes da oclusão por balão, e a dosagem pode ter sido influenciada pela cirurgia. Ou ainda, a concentração de NGAL pode estar diluída entre o sangue proveniente do rim isquêmico e contralateral saudável, diluindo assim a concentração final aferida.

Em nosso modelo, foi observada uma redução significativa após 15 min de isquemia, seguida de posterior aumento durante a reperfusão. No presente modelo, o uso da NGAL sérica mostrou diferenciar apenas os momentos de isquemia e reperfusão, apresentando menor desempenho em relação ao diagnóstico por creatinina.

Outra característica importante da $\mathrm{I} / \mathrm{R}$ renal, e um dos fatores responsáveis pela NTA, é o aumento das EROs e ERNs. Esse estresse provoca alterações em biomoléculas como a peroxidação lipídica, levando à destruição das membranas celulares; quebra do DNA e oxidação e nitração de proteínas ( $\mathrm{Li}$ and Jackson 2002). Tanto sistemicamente (via soro) quanto localmente (via urina) houve um aumento do estresse oxidativo mensurado indiretamente pelo aumento de proteínas nitradas. Durante a isquemia houve um aumento na excreção destas proteínas com posterior queda após a reperfusão, em concordância com o perfil sérico observado. $\mathrm{O}$ fato de haver um declínio das concentrações séricas tanto de proteínas nitradas como NGAL durante a isquemia e no início da reperfusão (observado em todos os animais), pode ter ocorrido devido a um aumento da excreção de proteínas totais neste período. Essa excreção pode ocorrer tanto por lesão glomerular, quanto por lesão tubular. A I/R pode levar a uma série de alterações como aumento de permeabilidade do capilar glomerular (Rippe et al. 2006), alterações no glicocálice endotelial (Platts et al. 2003) e redução da expressão e atividade de transportadores iônicos nos túbulos proximais (Di 
Sole et al. 2011) (Alejandro et al. 1995), que contribuem para a presença de proteínas na urina.

No padrão de proteínas excretadas que apresentamos neste estudo, encontramos proteínas com alto peso molecular presentes na urina durante a isquemia e no início da reperfusão, similar ao descrito em indivíduos transplantados (Artz et al. 2014) (Stefanidis et al. 1996). Desde o início da isquemia, os podócitos são submetidos ao achatamento e espalhamento (Racusen et al. 1984) associado à perda de heparan sulfato da membrana basal glomerular, levando a redução da seletividade por carga e tamanho, e assim, aumentando os poros glomerulares e excretando proteínas de maior peso melocular. Quanto maior o tempo da isquemia, maior a lesão (Rippe et al. 2006). Além disso, por se tratar de uma excreção apenas no período de isquemia e início da reperfusão, não se sustentando por $18 \mathrm{~h}$, este aumento pode estar relacionado a uma ligeira lesão estrutural glomerular, confirmada, inclusive, pela excreção de nefrina (dados não mostrados). Esta pequena lesão pode ter ocorrido devido ao grande aumento da pressão glomerular gerada pela isquemia de um rim, com aumento de fluxo no contralateral, seguido pelo aumento de fluxo no rim isquêmico pós reperfusão.

No entanto, a principal lesão renal gerada pela I/R ocorre no túbulo proximal (Ponticelli and Graziani 2012). A isquemia renal reduz a reabsorção iônica pela falta de ATP para as $\mathrm{Na}^{+} \mathrm{K}^{+} \mathrm{ATPase}$. Isto gera uma perda estrutural dos transportadores, com a perda da borda em escova, e também a redução na diferença do potencial eletroquímico, necessário principalmente para o transporte de $\mathrm{Na}^{+}, \mathrm{Cl}^{-}, \mathrm{HCO}_{3}^{-}, \mathrm{K}^{+}$e glicose. Esta deficiência no transporte, leva a um aumento da excreção desses metabólitos (Kim et al. 1995) (Spiegel et al. 1989) como demonstrado em nosso modelo. Notamos inicialmente, durante a isquemia e início da reperfusão, um aumento na excreção de $\mathrm{Na}^{+}, \mathrm{Cl}^{-}, \mathrm{HCO}_{3}{ }^{-}$devido à perda de ATP e NTA. No entanto, após restabelecidos os níveis de ATP durante a reperfusão, notamos que estes metabólitos retornam aos seus níveis basais com elevação na excreção de $\mathrm{K}^{+}$. A NTA também não permite a reabsorção normal de $\mathrm{Na}^{+}$ pelos túbulos proximais, sobrecarregando a porção espessa da alça de 
Henle, o final do túbulo distal e ducto coletor, que ao reabsorverem $\mathrm{Na}^{+}$, eliminam $\mathrm{K}^{+}$.

O aumento de glicose na urina, visto em nosso modelo, também caracteriza a lesão tubular sofrida pela I/R, visto que toda a glicose filtrada é reabsorvida. Trabalhos anteriores com insultos isquêmicos mostraram glicosúria por redução e comprometimento em transportadores de glicose tubulares (Runembert et al. 2004).

Com o nosso modelo de $\mathrm{I} / \mathrm{R}$ renal unilateral por cateter-balão em suínos, foram identificadas respostas fisiológicas importantes, tais como: NTA, aumento do estresse oxidativo, morte celular e aumento da excreção urinária de proteínas e íons, . Características estas apresentadas também por pacientes com LRA. Assim, nosso modelo é passível de utilização para análises de respostas fisiológicas agudas semelhantes às humanas, bem como, acrescentar novas informações como o observado aumento de glicose urinária não previamente descrito em pacientes não-diabéticos.

\subsection{METABOLÔMICA}

Após o desenvolvimento e caracterização de um modelo de $\mathrm{I} / \mathrm{R}$ renal, foi possível a aplicação desde modelo na identificação de novos marcadores de lesão renal aguda por meio de técnicas metabolômicas. Através de softwares para identificação e quantificação de metabólitos pela técnica de RMN, conseguimos identificar metabólitos que são capazes de se elevarem rapidamente no sangue após o insulto da isquemia, antes mesmo do aumento da creatinina sérica.

Na prática clínica, o diagnóstico de lesão renal por creatinina sérica é pouco sensível, pois só há o aumento deste metabólito no sangue quando já existe uma lesão nefrótica importante (Shemesh et al. 1985). Atualmente, novos biomarcadores têm sido propostos, incluindo NGAL e cistatina $\mathrm{C}$ em soro, e L-FABP , IL-18 e KIM-1 na urina. Embora, promissores, estes candidatos a biomarcadores só tiveram suas concentrações aumentadas no 
mínimo após 1-2 horas de reperfusão (Slocum et al. 2012) e não mostram especificidade renal.

A isquemia, uma das principais causas de LRA, é parte do processo dos transplantes e é muito incidente em pacientes que sofreram cirurgia cardíaca ou estão em UTI (Mariscalco et al. 2011). Nestes casos, o desenvolvimento de biomarcadores precoces, capazes de diagnosticar o insulto de isquemia, podem antecipar o tratamento e reverter o quadro de lesão.

Em busca de novos biomarcadores e uma maior compreensão das doenças, a metabolômica torna-se essencial, visto que o perfil metabólico é o maior preditor de fenótipo, englobando modificações epigenéticas determinadas por fatores ambientais (Fanos et al. 2013). Porém, ainda existem poucos estudos de metabolôma com LRA.

Em um estudo utilizando RMN e ratos após transplante renal, foi encontrado um perfil metabólico sérico diferente entre grupo sham e transplantados após a reperfusão, com aumento sérico de trimetilamina-Noxido (TMAO) e alantoina, demostrando alteração na via da hipoxantina (ativada por EROs). Estes metabólitos foram correlacionados com o aumento do período de isquemia fria (Serkova et al. 2005). Já, em um estudo de I/R com oclusão bilateral das artérias renais de ratos, foi observado aumentos séricos principalmente de lisofosfolipidios, ácidos graxos livres e nitrotirosinas e redução de acetil-carnitina e carnitina após 24 horas de reperfusão. Focando na terapia, com a suplementação de cartinina o perfil alterado dos metabólitos foi atenuado, o que indica a atuação da carnitina na melhora da perda energética e aumento do estresse oxidativo gerados pela I/R (Liu et al. 2012).

Em humanos, os estudos de metabolômica para LRA tornam-se um pouco mais complicados devido esta ser uma condição, na maioria das vezes, secundária a outras doenças. Estudo piloto com 17 pacientes diagnosticados com LRA detectou aumento da concentração sérica de homocisteína, dimetilarginina assimétrica - ADMA (do inglês asymmetric dimethylarginine) e piroglutamato (Sun et al. 2012) Chiarla \& Giovannini (2013) sugerem ainda a adição da busca por citrulina nesses pacientes 
(Chiarla and Giovannini 2013). O aumento da homocisteína já é bem correlacionado com o aumento das doenças cardiovasculares (Wald et al. 2002).

Em nosso estudo de metabolôma, não encontramos alterações no TMAO e na alantoína. Já os outros metabólitos identificados como biomarcadores nos demais estudos (Liu et al. 2012)(Sun et al. 2012), não foram encontrados em nossos resultados porque utilizamos RMN que, apesar de quantitativa, não é uma técnica tão sensível quanto o espectrômetro de massas usado nesses estudos.

Apesar de não encontramos os metabólitos já relatados, nosso estudo se aproxima muito do estudo em humanos (Sun et al. 2012), pois encontramos um aumento de seus precursores ou intermediários: metionina, colina, serina e glutamato. A homocisteína, é formada pela demetilação da metionina ou por via alternativa da betaína, sintetizada por colina (Kumagai et al. 2002). Já foi relatado aumento de metionina em pacientes com LRA devido o aumento de homocisteína, pois a reação é reversível. Eles encontraram uma correlação significativa do aumento de metionina com a mortalidade $(\mathrm{r}=0,56 ; \mathrm{p}=0,001)$ (Sun et al. 2012)

A serina, tem um papel importante para a transformação de homocisteína em cistationina (Koning et al. 2003), diminuindo seu efeito deletério sobre o endotélio. No próprio estudo, Sun (2012) especula que a depleção de glutationa pelo estresse oxidativo pode elevar a produção de cisteína e glutamato via $\gamma$-glutamil-cisteina. Assim, o glutamato serviria de substrato para a a síntese de piroglutamato.

Quanto à nitrotirosina, encontrado no estudo de Liu (2012) não conseguimos detectar seu aumento pela metabolômica, mas detectamos pelo método ELISA na caracterização do nosso modelo.

Marcadores detectados via metabolômica urinária, também têm sido estudados. Pacientes submetido a cirurgias cardíacas e que desenvolveram LRA, apresentaram uma concentração menor de carnitina urinária que os indivíduos que não desenvolveram a lesão, tornando possível a predição de LRA após 4h da cirurgia cardíaca (Zacharias et al. 2012). 
Marcadores urinários são muito específicos de eventos renais, porém o volume urinário e a hidratação alimentar têm um efeito direto sobre as concentrações dos metabólitos. Para eliminar a influência destas variáveis, tem sido feita a normalização pela creatinina urinária que, como discutimos no início do tópico, varia com gênero, idade, massa muscular e outros fatores (Zuppi, 1997). Além disso, é altamente dependente da taxa de filtração glomerular que se encontra alterada nos indivíduos com LRA, dificultando os valores de referência. Variação do volume de urina , como resultado da ingestão de líquidos na dieta, tem um efeito direto sobre a concentração absoluta dos metabólitos. Além disso, o soro apresenta maiores modificações que a urina, visto que a urina é um processo secundário ao soro (Ganti, 2012).

O rim é o responsável direto por evitar a perda de aminoácidos pelo organismo através da sua reabsorção, co-transportados junto com $\mathrm{Na}^{+}, \mathrm{H}^{+} \mathrm{e}$ $\mathrm{Cl}^{-}$no túbulo proximal. Além disso, ele é o maior representante na síntese e exportação de aminoácidos não essenciais, como a L-serina, para outros órgãos (Kuhlmann and Kopple 1990). Nosso estudo identificou 6 aminoácidos alterados após I/R. Visto que a isquemia gera uma alteração na excreção iônica, são esperadas alterações em metabólitos altamente representativos da via de metabolismo e transporte de aminoácidos, como apresentado pelo software metacore ao analisar o nosso painel metabólico isquêmico. Estudos com nefrotoxidade e a reanimação após choque hemorrágico também têm visto alterações nessa via (Wettersten and Weiss 2013) (Lusczek et al. 2012). Ainda, se a isquemia persiste, os processos de necrose e apoptose também podem se instalar, aumentando a concentração de metabólitos, principalmente aminoácidos por ação proteolítica (Sui et al. 2012).

Através do índice VIP, encontramos um aminoácido, o glutamato, como metabólito mais importante na distinção do momento isquêmico. O glutamato, também conhecido como ácido L-glutâmico é um aminoácido não essencial, importante para eliminação de resíduos nitrogenados através do ciclo do ácido cítrico, e que são marcadores de isquemia celular (Fonouni et al. 2011). Alguns estudos feitos em modelos suínos já detectaram um 
aumento sérico dos níveis deste metabólito durante a isquemia renal com pico máximo em 30 e 60 minutos durante a isquemia (Keller et al. 2009) (Weld et al. 2008a)-(Weld et al. 2008b), enquanto que na isquemia quente e/ou fria em transplantados, o pico máximo ocorreu após 20 minutos de reperfusão (Fonouni et al. 2011). Esse aumento do glutamato pode ocorrer pelo aumento do estresse oxidativo via glutationa (Sun et al. 2012) ou pela acidificação metabólica verificada em LRA, gerada pela despolarização das células tubulares com excreção de bicarbonato, como observado em nosso modelo (Han et al. 2007). Um aumento rápido da reabsorção de glutamato e glutamina é necessário para a produção de bicarbonato de amônio, objetivando o aumento do $\mathrm{pH}$ sanguíneo ( $\mathrm{Mu} \mathrm{X}$ 1996). Estudos em pacientes com acidose metabólica crônica mostraram aumento de glutamina e glicina no sangue arterial (Garibotto 2004).

A maioria dos metabólitos descritos comoalterados na LRA está associado ao aumento do estresse oxidativo. No entanto, as alterações encontradas em nosso modelo, L-glutamato, L-serina, L-metionina, Lprolina, $\mathrm{N}$-isovaleroilglicina, creatinina, colina e 2-aminobutirato, podem ter sido geradas também pela perda da polaridade celular gerada pela falta de ATP, NTA ou mesmo por alterações na taxa de filtração glomerular.

A redução da síntese e biodisponibilidade de ATP durante a isquemia pode aumentar as concentrações de glutamato por diversas vias. Sem ATP não há a conversão de glutamato em glutamina e polarização da membrana pelo transportador $\mathrm{Na}^{+} \mathrm{K}^{+}$ATPase, que passa a permitir o transporte inverso de glutamato para o espaço extracelular (Nicholls and Attwell 1990) e acumular $\mathrm{K}^{+}$no sangue, impedindo a absorção de glutamato pelas células (Keller et al. 2008). Além disso, este déficit energético e o aumento de EROs aumentam a entrada de cálcio na célula gerando a ativação de proteases, fosfolipases e endonucleases culminado na necrose ou apoptose (Meldrum et al. 2002) das células tubulares e liberação do ácido araquidônico no espaço celular, que também inibe a captação de glutamato pelas células (Hagberg et al. 1985). Assim, o aumento sérico de glutamato reflete tanto o processo inicial de absorção gerado pela isquemia quanto o seu fenômeno de transporte inverso para o sangue, sendo um biomarcador 
precoce da isquemia. Com a reperfusão, há um aumento do ATP e restabelecimento da função e síntese da glutamina sintase, diminuindo a concentração de glutamato extracelular (Fonouni et al. 2011). Este fenômeno pode ser visto em outros tecidos com isquemia, como o coração (Song and Phillis 1996), intestino, peritoneo (Korth U et al. 2003) e cérebro (Irving et al. 2000), os quais também apresentam aumento na concentração de glutamato em fases precoces de isquemia.

A perda da polaridade da célula e redução da absorção de $\mathrm{Na}+$, leva também ao acúmulo sérico de L-prolina, sintetizada a partir do glutamato, de 2-aminobutirato e da colina.

A L-serina é outro aminoácido não essencial, derivado da degradação intra-renal de peptídeos (Fakuda and Kopple 1980) e exportado para outros tecidos numa concentração quase constante, que persiste, mesmo após a acidose metabólica (Tizianello et al. 1982). Ela pode ser derivada da alimentação, biossíntese glicolítica, da glicina e da degradação de proteínas e fosfolipídios. Está relacionada à proliferação celular, como fonte de carbono para a síntese de nucleotídeos de purina e de pirimidina deoxitimidina monofosfato (Snell et al. 1987); além de participar da síntese de outros aminoácidos como cisteína e taurina, e moléculas mensageiras de lipídeos como a fosfatidilserina, molécula chave na via de sinalização da apoptose (Tyurina et al. 2000). A alteração deste aminoácido durante a isquemia pode estar relacionado à sinalização da apoptose de células tubulares ou devido ao aumento da via glicolítica na falta de ATP.

A L-metionina é um aminoácido essencial necessário para a manutenção do balanço de nitrogênio, crescimento do organismo e importante para o processo de remetilação (Slyshenkov et al. 2002). Esse aminoácido é o mais reativo e importante antioxidante que atua através do processo de oxidação/redução nas proteínas, recepcionando radicais livres (Vogt 1995) e assim, aumentando a concentração de glutationa reduzida (Slyshenkov et al. 2002). Com base nesta função, a metionina tem um importante papel no controle da homeostase em sistemas biológicos (Vogt 1995). O aumento da metionina no soro pode ser relacionado não somente à 
redução da taxa de filtração glomerular como também ao aumento do estresse oxidativo induzido pela isquemia.

Já o N-isovaleroilglicina é um metabólito formado para eliminação não tóxica de isovalerato pela urina. Nossos dados sugerem, que com um menor fluxo urinário, este se acumula no soro.

Para melhor compreensão do papel desses biomarcadores, foi realizada mais uma análise de biologia de sistemas, desta vez, conectando os metabólitos a proteínas, fatores de transcrição e outros metabólitos. Interessantemente, encontramos uma alta associação dos metabólitos selecionados no estudo com o NFKB, Huntingtina (HTT) e pró insulina (Figura 10).

Devido a rápida degradação da insulina e sinalização do NFkB, ambas não foram analisadas para validação dos dados. No entanto, é amplamente

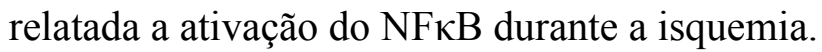

De fato, a isquemia induz a ativação do NFKB em células tubulares renais, mediando a apoptose destas células (Meldrum et al. 2002) e inibindo a sinalização da insulina (Hue et al. 2002). Tal inibição pode colaborar com a perda de $\mathrm{K}^{+}$pelas células, visto que a insulina é um dos fatores que promove a entrada de $\mathrm{K}^{+}$na célula através da ativação da $\mathrm{Na}^{+} \mathrm{K}^{+}$ATPase, independente da glicose (Nguyen et al. 2011).

A HTT tem sido muito estudada em células neurais, devido a sua alta expressão e à caracterização de uma mutação que leva a doença de Hungtiton, uma doença neurodegenerativa. Em menor proporção, a HTT é expressa em diversos outros tipos celulares e está envolvida na regulação da apoptose, transporte de vesículas e transcrição (Kegel et al. 2002). Além disso, atualmente tem sido relacionada a metabólitos presentes na via de síntese de ATP, bem como estrutura e integridade de mitocondria (Ismailoglu et al. 2014). A HTT é alvo da ação de uma série de proteases e pode ser facilmente clivada por caspases, metaloproteases e calpainas, não se apresentando em sua forma intacta no rim, como em outros órgãos (Van Raamsdonk et al. 2006). No entanto, fragmentos $\mathrm{N}$-terminais de vários tamanhos participam ativamente das funções desta proteína e, durante estresse celular, migram do reticulo endoplasmático para o núcleo, afim de 
exercerem suas funções ainda não muito bem estabelecidas (Desmond et al. 2013).

No presente estudo, observamos uma diferença no perfil de fragmentação da HTT nos grupos isquêmicos em relação ao contralateral. Fragmentos de $65 \mathrm{KDa}$ e $55 \mathrm{KDa}$ também foram encontrados em tecido cerebral na presença de calpaina 2 (Kim et al. 2001).

O aumento da atividade de enzimas como caspases, metaloproteínases e calpaínas já foram amplamente descritos na literatura e associados a eventos isquêmicos a partir de influxo de cálcio, início do processo apoptótico. Dessa maneira, a isquemia causada nos modelos animais desse trabalho pode estar modulando a HTT através da ativação dessas proteases, capazes de fragmentá-la e fornecendo, assim, o estresse celular necessário para a migração destes para o núcleo. Novos experimentos visualizando a relação da HTT com a I/R renal devem ser realizados.

Interessantemente, um grande número de proteínas majoritariamente expressas em células neurais tem sido encontradas também em podócitos (Brunskill et al. 2011) o que mostra uma grande ligação desses dois grupos celulares.

Assim, o painel de metabólitos descrito, compreendendo Lglutamato, L-serina, L-metionina, L-prolina, N-isovaleroilglicina, creatinina, colina e 2-aminobutirato foi importante para a compreensão da isquemia e reperfusão renal, além de apresentar marcadores precoces para isquemia/reperfusão renal (aumenta durante a isquemia e diminui pós reperfusão). Este painel pode ser valioso para o monitoramento de pacientes hospitalizados, com diagnóstico de LRA, horas antes da alteração de creatinina, podendo-se reverter o quadro. 
6. CONCLUSÕES 


\section{CONCLUSÕES}

Foi possível desenvolver e caracterizar um modelo de isquemia/reperfusão renal percutâneo em suínos de forma adequada, capaz de permitir o desenvolvimento de estudos para explorar respostas fisiopatológicas e novos biomarcadores isquêmicos renais.

O painel de metabólitos encontrado contribui para o estudo da fisiopatologia gerada pelo insulto da isquemia e pode tornar-se uma ferramenta promissora para a identificação precoce de pacientes com LRA geradas pela I/R renal. 
7. ANEXO 


\title{
7 ANEXO
}

\section{$\operatorname{sic} 3611 / 11 / 029$ \\ Ait IIIII \\ MEDICINA \\ COMITÊ DE ÉTICA EM PESQUISA}

\begin{abstract}
APROVAÇÃO
O Coordenador da CEUA do Comitê de Ética em Pesquisa da Faculdade de Medicina da Universidade de São Paulo, em 25.05.2011, após atendimento a diligência encaminhada APROVOU ad-referendum o Protocolo de Pesquisa $n^{\circ}$ 179/11 intitulado: "IDENTIFICAÇÃo DE PROTEÍNAS NITRADAS COM POTENCIAL DIAGNÓSTICO E PROGNÓSTICO EM DOENÇAS RENAIS ISQUÊMICAS.", apresentado pela Comissão Científica do Incor.
\end{abstract}

Cabe ao pesquisador elaborar e apresentar ao CEP-FMUSP, o relatorio final sobre a pesquisa, ( Lei Procedimentos para o Uso Científico de Animais - Lei No 11.794 -8 de outubro de 2008).

Pesquisador (a) Responsável: Alexandre da Costa Pereira

Pesquisador (a) Executante: Pamella Araujo Malagrino

CEP-FMUSP, 25 de maio de 2011.

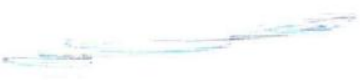

Dr. Eduardo Pompeu

Coordenador

Comissão de Ética no Uso de Animais

Plieminn.

Prof. Dr.Roger Chammas

Coordenador UUHWTSSÃO CIENTTIFICA
RECEBIDO

Comitê de Ética em Pesquisa 
8.REFERÊNCIAS

BIBLIOGRÁFICAS 


\section{REFERÊNCIAS BIBLIOGRÁFICAS}

Alejandro VS, Nelson WJ, Huie P, Sibley RK, Dafoe D, Kuo P, et al. Postischemic injury, delayed function and $\mathrm{Na}+/ \mathrm{K}(+)$-ATPase distribution in the transplanted kidney. Kidney Int. 1995;48(4):1308-15.

Arnaoutakis GJ, Bihorac A, Martin TD, Hess PJ, Klodell CT, Ejaz a A, et al. RIFLE criteria for acute kidney injury in aortic arch surgery. $J$ Thorac Cardiovasc Surg. 2007; 134(6):1554-60.

Artz MA, Dooper PMM, Meuleman EJH, Vliet JA van der, Wetzels JFM. Time-course of proteinuria after living-donor kidney transplantation. Transplantation. 2014;76(2):421-3.

Bagshaw SM, George C, Dinu I, Bellomo R. A multi-centre evaluation of the RIFLE criteria for early acute kidney injury in critically ill patients. Nephrol Dial Transplant. 2008; 23(4):1203-10.

Barderas MG, Laborde CM, Posada M, de la Cuesta F, Zubiri I, Vivanco F, et al. Metabolomic profiling for identification of novel potential biomarkers in cardiovascular diseases. J Biomed Biotechnol. 2011.

Basile DP. The endothelial cell in ischemic acute kidney injury: implications for acute and chronic function. Kidney Int. 2007;72(2):151-6.

Bhalodia Y, Kanzariya N, Patel R, Patel N, Vaghasiya J, Jivani N, et al. Renoprotective activity of benincasa cerifera fruit extract on ischemia/reperfusion-induced renal damage in rat. Iran J Kidney Dis. 2009; Apr;3(2):80-5.

Boldt J, Suttner S, Brosch C, Lehmann A, Röhm K, Mengistu A. Cardiopulmonary bypass priming using a high dose of a balanced hydroxyethyl starch versus an albumin-based priming strategy. Anesth Analg. 2009; 109(6):1752-62.

Bonventre J V. Recent Advances in the Pathophysiology of Ischemic Acute Renal Failure. J Am Soc Nephrol. 2003;14(8):2199-210.

Bonventre J V., Zuk A. Ischemic acute renal failure_ An inflammatory disease. Kidney Int. 2004;66:480-5.

Brunskill EW, Georgas K, Rumballe B, Little MH, Potter SS. Defining the molecular character of the developing and adult kidney podocyte. PLoS One. 2011;6(9):e24640.

Cao CC, Ding XiQ, Ou Z Lou, Liu CF, Li P, Wang L, et al. In vivo transfection of NF- $\kappa \mathrm{B}$ decoy oligodeoxynucleotides attenuate renal ischemia / reperfusion injury in rats. Kidney Int. 2004;65:834-45. 
Chakraborty S, Kaur S, Guha S, Batra SK. The multifaceted roles of neutrophil gelatinase associated lipocalin (NGAL) in inflammation and cancer. Biochim Biophys Acta. 2012; 1826(1):129-69.

Chen D, Siddiq A, Emdad L, Rajasekaran D, Gredler R, Shen X-N, et al. Insulin-like growth factor-binding protein-7 (IGFBP7): a promising gene therapeutic for hepatocellular carcinoma (HCC). Mol Ther. 2013; 21(4):758-66.

Chertow GM, Lazarus JM, Christiansen CL, Cook EF, Hammermeister KE, Grover F, et al. Preoperative Renal Risk Stratification. Circulation. 1997; 95:878-84.

Chiao H, Kohda Y, Mcleroy P, Craig L, Housini I, Star RA. AlfaMelanocyte-stimulating Hormone Protects Against Renal Injury after Ischemia in Mice and Rats. J Clin Invest. 1997; 99(6):1165-72.

Chiarla C, Giovannini I. Citrulline and metabolomics in acute kidney injury. J Chromatogr B. 2013; 913-914:137.

Chou SY, Porush JG, Faubert PF. Renal medullary circulation: hormonal control. Kidney Int. 1990; 37(1):1-13.

Clerico A, Galli C, Fortunato A, Ronco C. Neutrophil gelatinase-associated lipocalin (NGAL) as biomarker of acute kidney injury: a review of the laboratory characteristics and clinical evidences. Clin Chem Lab Med. 2012; 50(9):1505-17.

Conger J. Vascular abnormalities in the maintenance of acute renal failure. Circ Shock. 1983;11(3):235-44.

Conger JD, Schrier RW. Renal hemodynamics in acute renal failure. Ann Rev Physiol. 1980;42:603-14.

Crane NJ, Huffman SW, Gage FA, Levin IW, Elster EA. Evidence of a heterogeneous tissue oxygenation : renal ischemia / reperfusion injury in a large animal. J Biomed Opt. 2003;18(3):035001-7.

D’Alessandro A, Giardina B, Gevi F, Timperio AM, Zolla L. Clinical metabolomics: the next stage of clinical biochemistry. Blood Transfus. 2012 10 Suppl 2:s19-24.

Damianovich M, Ziv I, Heyman SN, Rosen S, Shina A, Kidron D, et al. ApoSense: a novel technology for functional molecular imaging of cell death in models of acute renal tubular necrosis. Eur J Nucl Med Mol Imaging. 2006; 33(3):281-91. 
Desmond CR, Maiuri T, Truant R. A multifunctional, multi-pathway intracellular localization signal in Huntingtin. Commun Integr Biol. 2013; 6(2):e23318.

Devarajan P. Cellular and molecular derangements in acute tubular necrosis. Curr Opin Pediatr. 2005;17:193-9.

Devarajan P. Update on mechanisms of ischemic acute kidney injury. $J$ Am Soc Nephrol. 2006; 17(6):1503-20.

Donnahoo KK, Meng X, Ayala A, Cain MP, Harken AH, Meldrum DR, et al. Early kidney TNF $\alpha$ expression mediates neutrophil infiltration and injury after renal ischemia-reperfusion.Rapid communication. Am J Physiol Regul Integr Comp Physiol. 1999;277(30):R922-R929.

Le Dorze M, Legrand M, Payen D, Ince C. The role of the microcirculation in acute kidney injury. Curr Opin Crit Care. 2009; 15(6):503-8.

Fakuda S, Kopple J. Uptake and release of amino acids by the normal dog kidney. Min Electr Metab. 1980;(3):237-47.

Fanos V, Fanni C, Ottonello G, Noto A, Dessì A, Mussap M. Metabolomics in adult and pediatric nephrology. Molecules. 2013; 18(5):4844-57.

Flacke S, Harty NJ, Laskey DH, Moinzadeh A, Benn J A, Villani R, et al. Targeted endovascular temporary vessel occlusion with a reverse thermosensitive polymer for near-bloodless partial nephrectomy: comparison to standard surgical clamping techniques. Cardiovasc Intervent Radiol. 2012; 35(5):1163-71.

Fonouni H, Esmaeilzadeh M, Jarahian P, Rad MT, Golriz M, Faridar A, et al. Early detection of metabolic changes using microdialysis during and after experimental kidney transplantation in a porcine model. Surg Innov. 2011;18(4):321-8.

Fonouni H, Tahmasbi Rad M, Golriz M, Faridar A, Esmaeilzadeh M, Jarahian $\mathrm{P}$, et al. Using microdialysis for early detection of vascular thrombosis after kidney transplantation in an experimental porcine model. Nephrol Dial Transplant. 2012; 27(2):541-7.

Formiga C, Mitre A, Castilho L, Buchpiguel C, Marques F, Radin A, et al. Comparison of clamping modalities in a rabbit model of normothermic renal ischemia. J Endourol. 2011; 25(11):1787-91.

Gao X, Chen W, Li R, Wang M, Chen C, Zeng R, et al. Systematic variations associated with renal disease uncovered by parallel metabolomics of urine and serum. BMC Syst Biol. 2012; 6 Suppl 1(Suppl 1):S14. 
Garibotto G. Kidney Protein Dynamics and Ammoniagenesis in Humans with Chronic Metabolic Acidosis. J Am Soc Nephrol. 2004; 15(6):1606-15.

Gobé G, Willgoss D, Hogg N, Schoch E, Endre Z. Cell survival or death in renal tubular epithelium after ischemia-reperfusion injury. Kidney Int. 1999 Oct;56(4):1299-304.

Gong Y, Zhang F, Ding F, Gu Y. Elderly patients with acute kidney injury (AKI): clinical features and risk factors for mortality. Arch Gerontol Geriatr.2012; 54(2):e47-51.

Goodsaid FM, Blank M, Dieterle F, Harlow P, Hausner E, Sistare F, et al. Novel biomarkers of acute kidney toxicity. Clin Pharmacol Ther. 2009; 86(5):490-6.

Hagberg H, Lehmann a, Sandberg M, Nyström B, Jacobson I, Hamberger a. Ischemia-induced shift of inhibitory and excitatory amino acids from intrato extracellular compartments. J Cereb Blood Flow Metab. 1985 5(3):4139.

Han K-H, Kim H-Y, Croker BP, Reungjui S, Lee S-Y, Kim J, et al. Effects of ischemia-reperfusion injury on renal ammonia metabolism and the collecting duct. Am J Physiol Renal Physiol. 2007; 293(4):F1342-54.

Han WK, Bailly V, Abichandani R, Thadhani R, Bonventre J V. Kidney Injury Molecule-1 (KIM-1): a novel biomarker for human renal proximal tubule injury. Kidney Int. 2002; 62(1):237-44.

Han WK, Wagener G, Zhu Y, Wang S, Lee HT. Urinary Biomarkers in the Early Detection of Acute Kidney Injury after Cardiac Surgery. Clin J Am Soc Nephrol. 2009; 4(5):873-82.

Hauser P, Schwarz C, Mitterbauer C, Regele HM, Mühlbacher F, Mayer G, et al. Genome-wide gene-expression patterns of donor kidney biopsies distinguish primary allograft function. Lab Invest. 2004; 84(3):353-61.

Ho JK, Liakopoulos OJ, Crowley R, Yezbick AB, Sanchez E, Shivkumar K, et al. In vivo detection of myocardial ischemia in pigs using visible light spectroscopy. Anesth Analg. 2009;108(4):1185-92.

Hobson CE, Yavas S, Segal MS, Schold JD, Tribble CG, Layon a J, et al. Acute kidney injury is associated with increased long-term mortality after cardiothoracic surgery. Circulation. 2009; 119(18):2444-53.

Hofmann W, Guder WG. A diagnostic programme for quantitative analysis of proteinuria. J Clin Chem Clin Biochem. 1989; 27(9):589-600.

Holmes E, Foxall PJ, Spraul M, Farrant RD, Nicholson JK, Lindon JC. 750 $\mathrm{MHz} 1 \mathrm{H}$ NMR spectroscopy characterisation of the complex metabolic 
pattern of urine from patients with inborn errors of metabolism: 2hydroxyglutaric aciduria and maple syrup urine disease. J Pharm Biomed Anal. 1997;15(11):1647-59.

Hoyert DL, Ph D, Xu J, Statistics V. National Vital Statistics Reports Deaths. National Vital Statistics Reports. 2012;61(6):1-51.

Hue L, Beauloye C, Marsin A., Bertrand L, Horman S, Rider M. Insulin and ischemia stimulate glycolysis by acting on the same targets through different and opposing signaling pathways. J Mol Cell Cardiol. 2002; 34(9):1091-7.

Hunter JP, Hosgood S a, Patel M, Rose R, Read K, Nicholson ML. Effects of hydrogen sulphide in an experimental model of renal ischaemiareperfusion injury. Br J Surg. 2012; 99(12):1665-71.

Ichimura T. Kidney Injury Molecule-1 (KIM-1), a Putative Epithelial Cell Adhesion Molecule Containing a Novel Immunoglobulin Domain, Is Upregulated in Renal Cells after Injury. J Biol Chem. 1998 273(7):4135-42.

Irving E a, Barone FC, Reith a D, Hadingham SJ, Parsons a a. Differential activation of MAPK/ERK and p38/SAPK in neurones and glia following focal cerebral ischaemia in the rat. Brain Res Mol Brain Res. 2000 Apr 14;77(1):65-75.

Ismailoglu I, Chen Q, Popowski M, Yang L, Gross SS, Brivanlou AH. Huntingtin protein is essential for mitochondrial metabolism, bioenergetics and structure in murine embryonic stem cells. Dev Biol. 2014; 391(2):230 40.

Jochmans I, Lerut E, van Pelt J, Monbaliu D, Pirenne J. Circulating AST, HFABP, and NGAL are early and accurate biomarkers of graft injury and dysfunction in a preclinical model of kidney transplantation. Ann Surg. 2011; 254(5):784-92.

Johannes, Boonstra, Jan Andries P. Molecular events associated with reactive oxygen species and cell cycle progression in mammalian cells. Gene. 2004;337(4):1-13.

Kalhan SC, Guo L, Edmison J, Dasarathy S, Arthur J, Hanson RW, et al. Plasma Metabolomic Profile in Non-Alcoholic Fatty Liver Disease. Metabolism. 2012; 60(3):404-13.

Kashani K, Al-Khafaji A, Ardiles T, Artigas A, Bagshaw SM, Bell M, et al. Discovery and validation of cell cycle arrest biomarkers in human acute kidney injury. Crit Care. 2013; 17(1):R25. 
Kaushal GP, Basnakian AG, Shah S V. Apoptotic pathways in ischemic acute renal failure endonucleases in renal tubular. Kidney Int. 2004;66(2):500-6.

Kegel KB, Meloni AR, Yi Y, Kim YJ, Doyle E, Cuiffo BG, et al. Huntingtin is present in the nucleus, interacts with the transcriptional corepressor C-terminal binding protein, and represses transcription. J Biol Chem. 2002; 277(9):7466-76.

Keller AK, Jorgensen TM, Olsen LH, Stolle LB. Early detection of renal ischemia by in situ microdialysis: an experimental study. J Urol. 2008; 179(1):371-5.

Keller AK, Jorgensen TM, Olsen LH, Stolle LB. Detection of local metabolic changes after progressive and stepwise reduction of renal blood flow in pigs. Transplant Proc. 2009; 41(1):44-8.

Kim Y., Woo J., Kim Y., Jung J., Kim B., Lee S. Effect of renal ischaemia on organic compound transport in rabbit kidney proximal tubule. Pharmacol Toxicol. 1995;77:121-9.

Kim YJ, Yi Y, Sapp E, Wang Y, Cuiffo B, Kegel KB, et al. Caspase 3cleaved $\mathrm{N}$-terminal fragments of wild-type and mutant huntingtin are present in normal and Huntington's disease brains, associate with membranes , and undergo calpain- dependent proteolysis. PNAS. 2001; 98(22):12784-9.

Kiroycheva M, Ahmed F, Anthony GM, Szabo C, Southan GJ, Bank N. Mitogen-activated protein kinase phosphorylation in kidneys of beta(s) sickle cell mice. J Am Soc Nephrol. 2000; 11(6):1026-32.

Kjeldsens L, Johnsen H, Sengelbv H, Borregaard N. Isolation and Primary Structure of NGAL , a Novel Protein Associated with Human Neutrophil Gelatinase. J Biol Chem. 1993; 268(14):10425-32.

Koning TJDE, Snell K, Duran M, Berger R, Surteesr R. L-Serine in disease and development. Biochem J. 2003; 661:653-61.

Korth U, Krieter K, Denz C, Jank C, Elinger K, Bertsch T, et al. Intestinal ischaemia during cardiac arrest and resuscitation: comparative analysis of extracellular metabolites by microdialysis. Resuscitation. 2003; 58(2):20917.

Kuhlmann MK, Kopple JD. Amino acid metabolism in the kidney. Semin Nephrol. 1990; 10(5):445-57.

Kumagai H, Katoh S, Hirosawa K, Kimura M, Hishida A, Ikegaya N. Renal tubulointerstitial injury in weanling rats with hyperhomocysteinemia. Kidney Int. 2002; 62:1219-28. 
Kwon O, Hong S, Ramesh G. Diminished NO generation by injured endothelium and loss of macula densa nNOS may contribute to sustained acute kidney injury after ischemia-reperfusion. Am J Physiol - Ren Physiol. 2009; 296:25-33.

Lameire NH. Pathophysiology of ischaemic acute renal failure. Best Pract Res Clin Anaesthesiol. 2004; 18(1):21-36.

Levey a S. Measurement of renal function in chronic renal disease. Kidney Int. 1990; 38(1):167-84.

Levy EM, Viscoli CM, Horwitz RI. The Effect of Acute Renal Failure on Mortality: A Cohort Analysis. JAMA. 1996; 275(19):1489-94.

Li C, Jackson RM. Reactive species mechanisms of cellular hypoxiareoxygenation injury. Am J Physiol Cell Physiol. 2002; 282(2):C227-41.

Liangos O, Perianayagam MC, Vaidya VS, Han WK, Wald R, Tighiouart H, et al. Urinary N-acetyl-beta-(D)-glucosaminidase activity and kidney injury molecule-1 level are associated with adverse outcomes in acute renal failure. J Am Soc Nephrol. 2007; 18(3):904-12.

Lieberthal W, Nigam S. acute renal failure forum. Am Physiol Soc. 1998; 275(61):623-31.

Lieberthal W, Nigam SK. Acute renal failure. II. Experimental models of acute renal failure: imperfect but indispensable. Am J Physiol Renal Physiol. 2000 Jan;278(1):F1-F12.

Lieske JC, Chawla L, Kashani K, Kellum J a., Koyner JL, Mehta RL. Biomarkers for Acute Kidney Injury: Where Are We Today? Where Should We Go? Clin Chem. 2014; 60(2):294-300.

Liu Y, Yan S, Ji C, Dai W, Hu W, Zhang W, et al. Metabolomic changes and protective effect of (L)-carnitine in rat kidney ischemia/reperfusion injury. Kidney Blood Press Res. 2012; 35(5):373-81.

Lunney JK. Advances in swine biomedical model genomics. Int J Biol Sci. 2007 Jan;3(3):179-84.

Lusczek ER, Lexcen DR, Witowski NE, Mulier KE, Beilman G. Urinary metabolic network analysis in trauma, hemorrhagic shock, and resuscitation. Metabolomics. 2012; 9(1):223-35.

Macedo E. Biomarcadores na injuria renal aguda in Biomarcadores na Nefrol.São Paulo. Roche and Sociedade Brasileira de Nefrologia. 2011. p. 21. 
Macedo E, Bouchard J, Mehta RL. Renal recovery following acute kidney injury. Curr Opin Crit Care. 2008; 14(6):660-5.

Malet-Martino M, Holzgrabe U. NMR techniques in biomedical and pharmaceutical analysis. J Pharm Biomed Anal. 2011; 55(1):1-15.

Mangano CM, Diamondstone LS, Ramsay JG, Aggarwal A, Herskowitz A, Mangano DT. Annals of Internal Medicine Renal Dysfunction after Myocardial Revascularization: Risk Factors, Adverse Outcomes, and Hospital Resource Utilization. Ann or Intern Med. 1998;128(3):194-203.

Mariscalco G, Lorusso R, Dominici C, Renzulli A, Sala A. Acute kidney injury: a relevant complication after cardiac surgery. Ann Thorac Surg; 2011; 92(4):1539-47.

Matějková Š, Scheuerle A, Wagner F, McCook O, Matallo J, Gröger M, et al. Carbamylated erythropoietin-FC fusion protein and recombinant human erythropoietin during porcine kidney ischemia/reperfusion injury. Intensive Care Med. 2013; 39(3):497-510.

Matthijsen R a, Huugen D, Hoebers NT, de Vries B, Peutz-Kootstra CJ, Aratani $\mathrm{Y}$, et al. Myeloperoxidase is critically involved in the induction of organ damage after renal ischemia reperfusion. Am J Pathol. 2007; 171(6):1743-52.

Mehta RL, Kellum J a, Shah S V, Molitoris B a, Ronco C, Warnock DG, et al. Acute Kidney Injury Network: report of an initiative to improve outcomes in acute kidney injury. Crit Care. 2007;11(2):R31.

Meldrum KK, Hile K, Meldrum DR, Crone J a, Gearhart JP, Burnett a L. Simulated ischemia induces renal tubular cell apoptosis through a nuclear factor-kappaB dependent mechanism. J Urol. 2002 Jul;168(1):248-52.

Mishra J, Dent C, Tarabishi R, Mitsnefes MM, Ma Q, Kelly C, et al. Neutrophil gelatinase-associated lipocalin (NGAL) as a biomarker for acute renal injury after cardiac surgery. Lancet. 2005; 365(9466):1231-8.

Misra S, Gordon JD, Fu AA, Glockner JF, Chade AR, Mandrekar J, et al. The porcine remnant kidney model of chronic renal insufficiency. $J$ Surg Res. 2006; 135(2):370-9.

Mori K, Lee HT, Rapoport D, Drexler IR, Foster K, Yang J, et al. Endocytic delivery of lipocalin-siderophore- iron complex rescues the kidney from ischemia-reperfusion injury. J Clin Invest. 2005;115(3):610-21.

$\mathrm{Mu}$ X WT. Response of LLC-PK1-F+ cells to metabolic acidosis. Am J Physiol. 1996;270(3 Pt 1):C920-5. 
Nakamura T, Sugaya T, Koide H. Urinary liver-type fatty acid-binding protein in septic shock: effect of polymyxin B-immobilized fiber hemoperfusion. Shock. 2009; 31(5):454-9.

Nash K, Hafeez A, Hou S. Hospital-Acquired Renal Insufficiency. Am J Kidney Dis. 2002; 39(5):930-6.

Negishi K, Noiri E, Doi K, Maeda-Mamiya R, Sugaya T, Portilla D, et al. Monitoring of urinary L-type fatty acid-binding protein predicts histological severity of acute kidney injury. Am J Pathol. 2009; 174(4):1154-9.

Nguyen MT, Devarajan P. Biomarkers for the early detection of acute kidney injury. Pediatr Nephrol. 2008; 23(12):2151-7.

Nguyen TQ, Maalouf NM, Sakhaee K, W. O. Comparison of Insulin Action on Glucose versus Potassium Uptake in Humans. Clin J Am Soc Nephrol. 2011;6(7):1533-9.

Nicholls D, Attwell D. The release and uptake of excitatory amino acids. Trends Pharmacol Sci. 1990;11:462-8.

Nicholson JK, Lindon JC, Holmes E. "Metabonomics": understanding the metabolic responses of living systems to pathophysiological stimuli via multivariate statistical analysis of biological NMR spectroscopic data. Xenobiotica. 1999 Nov;29(11):1181-9.

Nickolas TL, Barasch J, Devarajan P. Biomarkers in acute and chronic kidney disease. Curr Opin Nephrol Hypertens. 2008 Mar;17(2):127-32.

Nisula S, Kaukonen K-M, Vaara ST, Korhonen A-M, Poukkanen M, Karlsson S, et al. Incidence, risk factors and 90-day mortality of patients with acute kidney injury in Finnish intensive care units: the FINNAKI study. Intensive Care Med. 2013; 39(3):420-8.

Noto A, Cibecchini F, Fanos V, Mussap M. NGAL and metabolomics: the single biomarker to reveal the metabolome alterations in kidney injury. Biomed Res Int. 2013

Oberbauer R, Rohrmoser M, Regele H, Mühlbacher F, Mayer G. Apoptosis of tubular epithelial cells in donor kidney biopsies predicts early renal allograft function. J Am Soc Nephrol. 1999 10(9):2006-13.

Ostermann M, Chang RWS. Acute kidney injury in the intensive care unit according to RIFLE. Crit Care Med. 2007 Aug 35(8):1837-43.

Parikh CR, Coca SG, Thiessen-Philbrook H, Shlipak MG, Koyner JL, Wang $\mathrm{Z}$, et al. Postoperative biomarkers predict acute kidney injury and poor outcomes after adult cardiac surgery. J Am Soc Nephrol. 2011 Sep 22(9):1748-57. 
Parikh CR, Mishra J, Thiessen-Philbrook H, Dursun B, Ma Q, Kelly C, et al. Urinary IL-18 is an early predictive biomarker of acute kidney injury after cardiac surgery. Kidney Int. 2006; 70(1):199-203.

Pasikanti K., Ho P., Chan ECY. Gas chromatography/mass spectrometry in metabolic profiling of biological fluids. J Chromatogr B. 2008;871(2):202 11.

Piriou-guzylack L, Salmon H. Review article Membrane markers of the immune cells in swine : an update. VetRes. 2008;39-54.

Platts SH, Linden J, Duling BR. Rapid modification of the glycocalyx caused by ischemia-reperfusion is inhibited by adenosine A2A receptor activation. Am J Physiol Heart Circ Physiol. 2003; 284(6):H2360-7.

Poch E. Acute kidney injury on normally functioning kidneys and long-term mortality after coronary bypass surgery. Eur J Cardiothorac Surg. 2013; 43(3):560-1.

Ponticelli C, Graziani G. Proteinuria after kidney transplantation. Transpl Int. 2012 Sep;25(9):909-17.

Preston R, Epstein M. Ischemic renal disease: an emerging cause of chronic renal failure and end-stage renal disease. J Hypertens. 1997; 15(12):136577.

Quan-hui Y, Da-wei L, Yun L, Hong-zhong L, Wen-zhao C, Xiao-Ting W. Acute renal failure during sepsis: Potential role of cell cycle regulation. $J$ Infect. 2009;58(6):459-64.

Van Raamsdonk JM, Gibson WT, Pearson J, Murphy Z, Lu G, Leavitt BR, et al. Body weight is modulated by levels of full-length huntingtin. Hum Mol Genet. 2006; 15(9):1513-23.

Racusen L., Solez K. The morphology of acute renal failure and the tubular cell exfoliation phenomenon. Nefrologia. 1992; XII(Supl 4).

Racusen LC, Prozialeck DH, Solez K. Glomerular epithelial cell changes after ischemia or dehydration. Possible role of angiotensin II. Am J Pathol. 1984; 114(1):157-63.

Ralib AM, Pickering JW, Shaw GM, Devarajan P, Edelstein CL, Bonventre $\mathrm{J} \mathrm{V}$, et al. Test characteristics of urinary biomarkers depend on quantitation method in acute kidney injury. J Am Soc Nephrol. 2012; 23(2):322-33

Redfors B, Bragadottir G, Sellgren J, Swärd K, Ricksten S-E. Acute renal failure is NOT an "acute renal success"--a clinical study on the renal oxygen supply/demand relationship in acute kidney injury. Crit Care Med. 2010; 38(8):1695-701. 
Rewa O, Bagshaw SM. Acute kidney injury-epidemiology, outcomes and economics. Nat Rev Nephrol. 2014;10:193-207.

Riella M. Princípios de nefrologia e distúrbios hidroeletrolíticos. 3rd ed. Koogan G, editor. Insuficiência Ren. crônica Fisiopatol. da Urem. 1996. p. 456-76.

Rippe C, Rippe A, Larsson A, Asgeirsson D, Rippe B, Asgeirs- D. Nature of glomerular capillary permeability changes following acute renal ischemiareperfusion injury in rats. Am J Physiol - Ren Physiol. 2006;291:1362-8.

Rodier F, Campisi J, Bhaumik D. Two faces of p53: aging and tumor suppression. Nucleic Acids Res. 2007; 35(22):7475-84.

Rosen S, Stillman IE. Acute tubular necrosis is a syndrome of physiologic and pathologic dissociation. J Am Soc Nephrol. 2008; 19(5):871-5.

Runembert I, Couette S, Federici P, Colucci-guyon E, Babinet C, Briand P. Recovery of Na-glucose cotransport activity after renal ischemia is impaired in mice lacking vimentin. Am J Physiol Ren Physiol. 2004; 287:960-8.

Sabbagh R, Chawla A, Tisdale B, Kwan K, Chatterjee S, Kwiecien JM, et al. Renal histopathology features according to various warm ischemia times in porcine laparoscopic and open surgery model. Can Urol Assoc J. 2011; $5(1): 40-3$.

Schmidt-Ott KM, Mori K, Li JY, Kalandadze A, Cohen DJ, Devarajan P, et al. Dual action of neutrophil gelatinase-associated lipocalin. J Am Soc Nephrol. 2007; 18(2):407-13.

Schnermann J. The Juxtaglomerular Apparatus: From Anatomical Peculiarity to Physiological Relevance. J Am Soc Nephrol. 2003; 14(6):1681-94.

Schrier RW, Wang W, Poole B, Mitra A. Science in medicine Acute renal failure: definitions, diagnosis, pathogenesis, and therapy. Sci Med. 2004;114(1):5-14.

Seo D-W, Li H, Qu C-K, Oh J, Kim Y-S, Diaz T, et al. Shp-1 mediates the antiproliferative activity of tissue inhibitor of metalloproteinase-2 in human microvascular endothelial cells. J Biol Chem. 2006; 281(6):3711-21.

Serkova N, Fuller TF, Klawitter J, Freise CE, Niemann CU. H-NMR-based metabolic signatures of mild and severe ischemia/reperfusion injury in rat kidney transplants. Kidney Int. 2005; 67(3):1142-51.

Shemesh O, Golbetz H, Kriss JP, Myers BD. Limitations of creatinine as a filtration marker in glomerulopathic patients. Kidney Int. 1985; 28(5):830-8. 
Silberstein JL, Sprenkle PC, Su D, Power NE, Tarin T V, Ezell P, et al. Neutrophil gelatinase-associated lipocalin (NGAL) levels in response to unilateral renal ischaemia in a novel pilot two-kidney porcine model. BJU Int. 2013; 112(4):517-25.

Da Silveira KD, Pompermayer Bosco KS, Diniz LRL, Carmona AK, Cassali GD, Bruna-Romero O, et al. ACE2-angiotensin-(1-7)-Mas axis in renal ischaemia/reperfusion injury in rats. Clin Sci. 2010; 119(9):385-94.

Simmons MN, Schreiber MJ, Gill IS. Surgical renal ischemia: a contemporary overview. J Urol. 2008; 180(1):19-30.

Simon F, Scheuerle A, Calzia E, Bassi G, Öter S, Duy CN, et al. Erythropoietin during porcine aortic balloon occlusion-induced ischemia/reperfusion injury. Crit Care Med. 2008;36(7):2146-50.

Simon F, Scheuerle A, Gröger M, Stahl B, Wachter U, Vogt J, et al. Effects of intravenous sulfide during porcine aortic occlusion-induced kidney ischemia/reperfusion injury. Shock. 2011; 35(2):156-63.

Simsek A, Tugcu V, Tasci AI. New Biomarkers for the Quick Detection of Acute Kidney Injury. ISRN Nephorology. 2013.

Slocum JL, Heung M, Pennathur S. Marking renal injury: can we move beyond serum creatinine? Transl Res. 2012; 159(4):277-89.

Slyshenkov VS, Shevalye A a, Liopo A V, Wojtczak L. Protective role of Lmethionine against free radical damage of rat brain synaptosomes. Acta Biochim Pol. 2002 Jan;49(4):907-16.

Smeltzer SC, Bare B, Hinkle JL, Cheever KH. Brunner and Suddarth's Textbook of Medical-Surgical Nursing. 2010. p. 1312.

Smith AC, Swindle MM. Preparation of swine for the laboratory. ILAR J. 2006 Jan;47(4):358-63.

Snell K, Natsumeda Y, Weber G. The modulation of serine metabolism in hepatoma 3924A during different phases of cellular proliferation in culture. Biochem J. 1987; 245(2):609-12.

Di Sole F, Hu MC, Zhang J, Babich V, I Alexandru B, Shi Im, et al. The reduction of $\mathrm{Na} / \mathrm{H}$ exchanger-3 protein and transcript expression in acute ischemia-reperfusion injury is mediated by extractable tissue factor(s). Kidney Int. 2011;80:822-31.

Song D, Phillis W. Release of the excitotoxic amino acids, glutamate and aspartate, from the isolated ischemic/anoxic rat heart. Neurosci Lett. 1996;220:1-4. 
Spiegel DM, Wilson PD, Molitoris BA. Epithelial polarity following ischemia: a requirement for normal cell function. Am J Physiol - Ren Physiol. 1989;256:F430-F436.

Stefanidis I, Heintz B, Stocker G, Mrowka C, Sieberth H-G, Haubeck H-D. Association Between Heparan Sulfate Proteoglycan Excretion and Proteinuria After Renal Transplantation. $J$ Am Soc Nephrol. 1996;7(12):2670-6.

Striz I, Krasna E, Honsova E, Lacha J, Petrickova K, Jaresova M, et al. Interleukin 18 (IL-18) upregulation in acute rejection of kidney allograft. Imuno Lett. 2005;15(99):30-5.

Sui W, Li L, Che W, Zuo G, Chen J, Li W, et al. A proton nuclear magnetic resonance-based metabonomics study of metabolic profiling in immunoglobulin a nephropathy. Clinics. 2012; 67(4):363-73.

Sun J, Shannon M, Ando Y, Schnackenberg LK, Khan N a, Portilla D, et al. Serum metabolomic profiles from patients with acute kidney injury: a pilot study. J Chromatogr B. 2012 Apr 15;893-894:107-13.

Supavekin S, Zhang W, Kucherlapati R, Kaskel FJ, Moore LC, Devarajan P. Differential gene expression following early renal ischemia/reperfusion. Kidney Int. 2003 May;63(5):1714-24.

Susa D, Mitchell JR, Verweij M, Ven M Van De, Engel S Van Den, Bajema I, et al. Congenital DNA repair deficiency results in protection against renal ischemia reperfusion injury in mice. Aging Cell. 2009;8(2):192-200.

Sutton T a, Fisher CJ, Molitoris B a. Microvascular endothelial injury and dysfunction during ischemic acute renal failure. Kidney Int. 2002; 62(5):1539-49.

Thadhani R, Pascual M, Bonventre J V. ACUTE RENAL FAILURE. N Engl J Med. 1996; 334(22):1448-60.

Timmeren MM Van, Heuvel MC Van Den, Bailly V, Bakker SJL, Goor H Van, Stegeman CA. Tubular kidney injury molecule-1 ( KIM-1 ) in human renal. J Pathol. 2007; 212:209-17.

Tizianello a, Deferrari G, Garibotto G, Robaudo C, Acquarone N, Ghiggeri GM. Renal ammoniagenesis in an early stage of metabolic acidosis in man. J Clin Invest. 1982; 69(1):240-50.

Tsuji Y, Ariyoshi A, Sakamoto K. An experimental model for unilateral ischaemic acute renal failure in dog. Int Urol Nephrol. 1993; 25(1):83-8. 
Tyurina Y., Shvedovab A., Kawaia K, Tyurin V., Komminenib C, Quinnd P., et al. Phospholipid signaling in apoptosis: peroxidation and externalization of phosphatidylserine. Toxicology. 2000; 148(2-3):93-101.

Vaidya VS, Ramirez V, Ichimura T, Bobadilla NA, Bonventre J V, Vishal $\mathrm{S}$, et al. Urinary kidney injury molecule-1: a sensitive quantitative biomarker for early detection of kidney tubular injury. Am J Physiol - Ren Physiol. 2006;290:517-29.

Vaidya VS, Waikar SS, Ferguson MA, Collings FB, Gioules C, Bradwin G, et al. Clin Transl Sci. 2008; 1(3):200-8.

Vogt W. Review Article Oxidation of methionyl residues in proteins : tools , targets , and reversal. Free Radic Biol Med. 1995;18(1):93-105.

Waikar SS, Sabbisetti VS, Bonventre J V. Normalization of urinary biomarkers to creatinine during changes in glomerular filtration rate. Kidney Int. 2011;78(5):486-94.

Wald DS, Law M, Morris JK. Homocysteine and cardiovascular disease: evidence on causality from a meta-analysis. BMJ. 2002; 325(7374):1202.

Walker LM, Walker PD, Imam SZ, Ali SF, Mayeux PR. Evidence for peroxynitrite formation in renal ischemia-reperfusion injury: studies with the inducible nitric oxide synthase inhibitor L-N(6)-(1-Iminoethyl)lysine. J Pharmacol Exp Ther. 2000; 295(1):417-22.

Wei Q, Yin X, Wang M, Dong Z. Bid deficiency ameliorates ischemic renal failure and delays animal death in C57BL / 6 mice. Am J Physiol - Ren Physiol. 2006;290:35-42.

Weld KJ, Montiglio C, Bush AC, Dixon PS, Schwertner H a, Hensley DM, et al. Predicting irreparable renal ischemic injury using a real-time marker in the porcine model. J Urol. 2008a; 180(5):2218-25.

Weld KJ, Montiglio C, Bush AC, Harroff HH, Cespedes RD. Real-time analysis of renal interstitial metabolites during induced renal ischemia. $J$ Endourol. 2008b; 22(3):571-4.

Wettersten HI, Weiss RH. Applications of metabolomics for kidney disease research. Organogenesis. 2013;9(1):11-8.

Witzgall R, Brown D, Schwarz C, Bonventre J V. Localization of Proliferating Cell Nuclear Antigen, Vimentin , c-Fos, and Clusterin in the Postischemic Kidney. J Clin Investig. 1994;93(May):2175-88.

Xia J, Mandal R, Sinelnikov I V, Broadhurst D, Wishart DS. MetaboAnalyst 2.0--a comprehensive server for metabolomic data analysis. Nucleic Acids Res. 2012; 40(Web Server issue):W127-33. 
Xia J, Psychogios N, Young N, Wishart DS. MetaboAnalyst: a web server for metabolomic data analysis and interpretation. Nucleic Acids Res. 2009; 37(Web Server issue):W652-60.

Yamamoto T, Noiri E, Ono Y, Doi K, Negishi K, Kamijo A, et al. Renal Ltype fatty acid--binding protein in acute ischemic injury. J Am Soc Nephrol. 2007; 18(11):2894-902.

Yang B, Hosgood S a, Da Z, Harper SJF, Waller HL, Kay MD, et al. Biomarkers assessing warm ischemic injury using an isolated porcine kidney hemoreperfusion model. Exp Biol Med (Maywood). 2012; 237(12):1462-73.

Yatsu T, Arai Y, Takizawa K, Kasai-nakagawa C, Takanashi M, Uchida W, et al. Effect of YM435, a Dopamine DA 1 Receptor Agonist, in a Canine Model of Ischemic Acute Renal Failure. Gen Pharmac. 1998;31(5):803-7.

Yokoyama T, Kamijo-Ikemori A, Sugaya T, Hoshino S, Yasuda T, Kimura K. Urinary excretion of liver type fatty acid binding protein accurately reflects the degree of tubulointerstitial damage. Am J Pathol. 2009; 174(6):2096-106.

Zacharias HU, Schley G, Hochrein J, Klein MS, Köberle C, Eckardt K-U, et al. Analysis of human urine reveals metabolic changes related to the development of acute kidney injury following cardiac surgery. Metabolomics. 2012; 9(3):697-707.

Zäll S, Milocco I, Ricksten SE. Effects of adenosine on myocardial blood flow and metabolism after coronary artery bypass surgery. Anesth Analg. 1991; 73(6):689-95.

Zatz R. Bases Fisiológicas da Nefrologia. 2011. p. 299.

Zhen-Qiang F, Bing-Wei Y, Yong-Liang L, Xiang-Wei W, Shan-Hong Y, Yuan-Ning Z, et al. Localized expression of human BMP-7 by BM-MSCs enhances renal repair in an in vivo model of ischemia-reperfusion injury. Genes Cells. 2012; 17(1):53-64.

Kidney Disease: Improving Global Outcomes (KDIGO) Acute Kidney Injury Work Group (2012) KDIGO Clinical Practice Guideline for Acute Kidney Injury. Kidney Int. 2012 a; 2((Suppl 1)):1-138.

United States renal data system. 2012 b; Available from: http://www.usrds.org/ 

